\title{
DOE|PC|91053-T8 $\frac{\mathrm{N}-1}{3}$
}

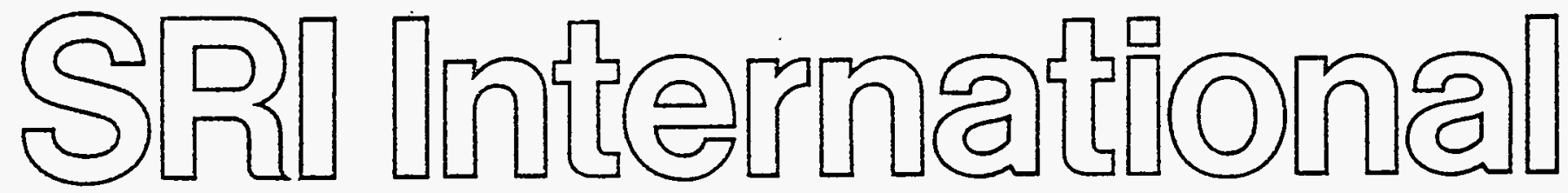

Final Report - 27 July 1994

\section{FUNDAMENTAL STUDIES OF COAL - LIQUEFACTION}

Prepared by:

David S. Ross, Director

Indira S. Jayaweera, Research Chemist

Sjoerd Hoogwater, International Fellow

Chemistry Laboratory

Final Report

SRI Report No. 2847

Prepared for:

U.S. Department of Energy

Pittsburgh Energy Technology Center

P.O. Box 10940, MS 921-165

Pittsburgh, PA 15236

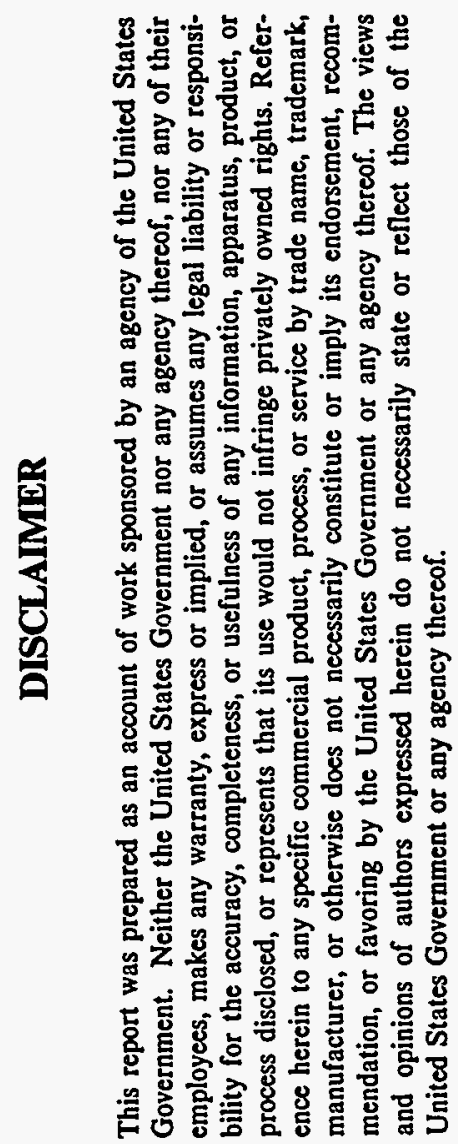

Contract No. DE-AC22-91PC91053

Approved:

David M. Golden

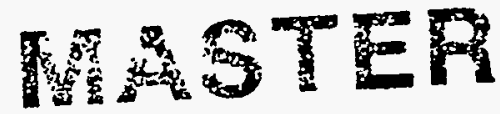

Vice President

Physical Sciences Division 


\section{DISCLAIMER}

Portions of this document may be illegible in electronic image products. Images are produced from the best available original document. 


\begin{abstract}
We have examined the pyrolysis of Argonne samples of Wyodak and Illinois No. 6 coal in argon, undecane, Tetralin, and water. The effects of the pyrolysis on individual particles of coal were monitored visually in a cell with diamond windows capable of operation to temperature and pressures in excess of $500^{\circ} \mathrm{C}$ and 3000 psi. The changes in the particles from ambient to $460^{\circ} \mathrm{C}$ were recorded in real time on video tape, and images were then taken from the tape record and analyzed.

The study showed that in argon both coals developed tars at $350^{\circ}-370^{\circ} \mathrm{C}$. The tars then quickly evaporated, leaving core particles remarkably similar in size and shape to the initial particles. These observations suggest that coal does not melt nor become fully liquid when heated. Nor does the softened coal undergo crosslinking to generate coke. Rather the simple loss of volatiles leaves behind the core residue as coke.

In undecane and Tetralin, the coals were completely unchanged to $420^{\circ} \mathrm{C}$. While the inactivity remained in undecane to $460^{\circ} \mathrm{C}$, in Tetralin the particles began to shrink rapidly, evidence of conversion by the medium. Elimination of the tar-forming stage in Tetralin is unexpected. It demonstrates that, contrary to the common view, there is no link between the bond-breaking processes yielding tar and the interation of the coal with $\mathrm{H}$-donors leading to liquefaction.

Water as a medium was surprising in its effect. Both coals began to shrink at $300^{\circ}-$ $350^{\circ} \mathrm{C}$, with the effect appearing to be more of an erosion rather than a uniform loss of substance as seen in Tetralin. The Wyodak continued to shrink to $460^{\circ} \mathrm{C}$ to about half its initial size. With the Illinois No. 6 coal, however, the process reversed at around $420^{\circ} \mathrm{C}$, and the particles appeared togrow with the evolution of a tar, continuing to $460^{\circ} \mathrm{C}$. We submit that this final observation is evidence for hydrothermal synthesis of hydrocarbons at these conditions.
\end{abstract}




\section{CONTENTS}

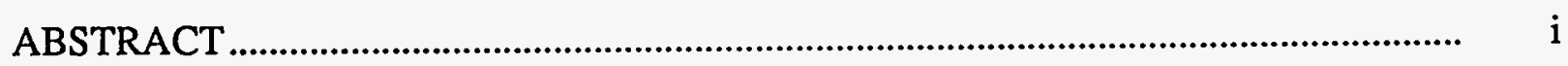

INTRODUCTION......................................................................................................

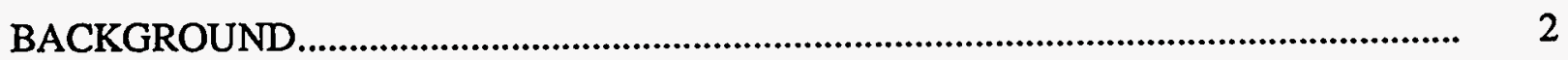

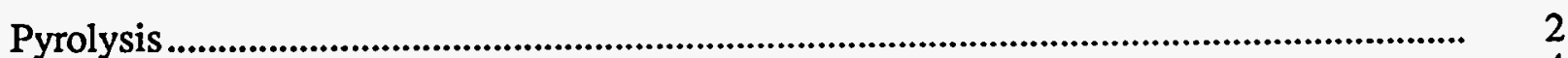

Effects of Water Pretreatment ..................................................................................................

EXPERIMENTAL PROCEDURES ................................................................................ 8

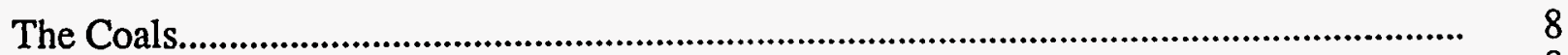

The Cell..................................................................................................................

Schematic Representation of the System ....................................................................... 8

Optics and Illumination ................................................................................................

Heating System .............................................................................................. 10

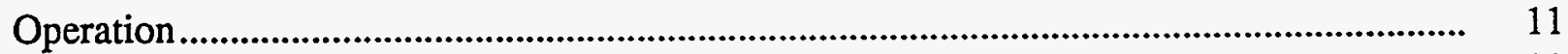

Coal Manipulation and Run Procedure.......................................................................... 11

Image Processing and Analysis ................................................................................. 12

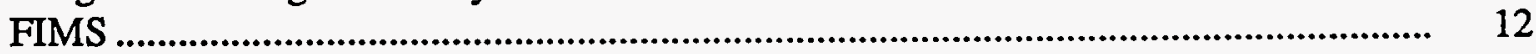

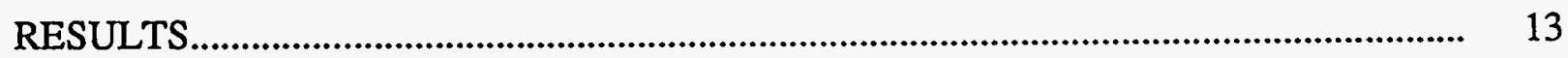

Treatment in Argon ...................................................................................................

Treatment in $n$-Undecane .....................................................................................................

Treatment in Tetralin............................................................................................................... 24

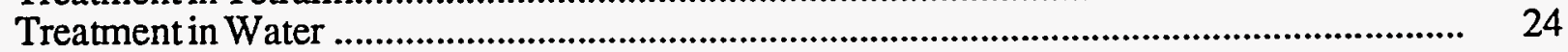

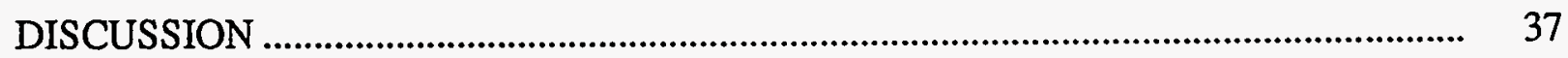

Pyrolysis in an Inert Gas ............................................................................................. 37

Pyrolysis in an Inert Organic Medium ............................................................................... 39

Pyrolysis in Tetralin ......................................................................................................... 41

Pyrolysisin Water ................................................................................................. 42

Possibe Synthesis of Organics .................................................................................. 42

The Role of Mineral Matter at the Interface ...................................................................... 44

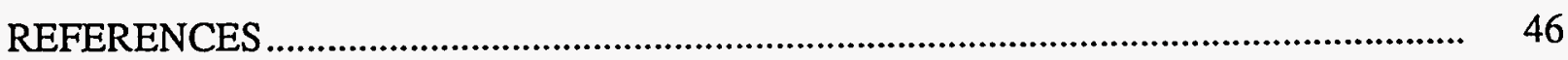

APPENDIX A-HYDROTHERMAL MEDIA, OIL SHALE, AND COAL ........................... 49

APPENDIX B-HYDROTHERMAL MEDIA, OIL SHALE, AND COAL .......................... 63 
APPENDIX C-PREPARATION OF METAL CARBONYL-LOADED COALS............... 68 APPENDIX D-PARTS, MATERIALS, AND SAFETY DATA FOR THE CELL ASSEMBLY 


\section{LIST OF FIGURES}

Figure 1. FIMS response vs temperature for Wyodak Coal. The treated coals were heated at $350^{\circ} \mathrm{C}$ for $30 \mathrm{~min}$. The temperature ramp during the FIMS analysis was $2.5^{\circ} \mathrm{C} / \mathrm{min}$.

Figure 2. Volatility and molecular weight profiles for tars recovered from 30-min and 5hr hydrothermolytic treatments of Wyodak coal.

Figure 3. The continuous flow observation cell with peripheral system, desinged for pressures up to $5000 \mathrm{psi}$ at $550^{\circ} \mathrm{C}$. Clean solvent, pressurized by P1, passes through the autoclave, containing a dispersion of coal. The mixture then flows to the heated reactor, where a camera observes the reaction. Particles settle in a disengagement zone and the pressure is relieved.

Figure 4. The illumination and lens system for the cell. ...................................................... 10

Figure 5. Heating profile for the studies described here.................................................... 11

Figure 6. The initial image of the observation area at $85.8^{\circ} \mathrm{C}$ for an experiment at 100 psi argon with Wyodak coal. Particles A, B, and C were selected for size analysis.

Figure 7. Particle A (see Figure 6 ( of Wyodak coal in argon at $85^{\circ}-460^{\circ} \mathrm{C}$... 16

Figure 8. Size profiles for particles of Wyodak and Illinois No. 6 coal in argon.

Figure 9. The initial image of the observation area at $50.2^{\circ} \mathrm{C}$ for an experiment at 100 psi argon with Illinois No. 6 coal. Particles A, B, and C were selected for size analysis.

Figure 10. Particle A (see Figure 9) of Illinois No. 6 in argon at $50^{\circ}-440^{\circ} \mathrm{C}$

Figure 11. The inital image of the observation area at $30.2^{\circ} \mathrm{C}$ for an experiment in $n$-undecane with Wyodak coal at $3000 \mathrm{psi}$. The particle selected for size analysis is boxed.

Figure 12. Particle A (see Figure 11) of Wyodak coal in $n$-undecane at $30^{\circ}-461^{\circ} \mathrm{C}$

Figure 13. The initial image of the observation area at $65.2^{\circ} \mathrm{C}$ for an experiment in $n$-undecane with Illinois No. 6 coal at 3000 psi. The particle chosen for size analysis is boxed

Figure 14. Particle A (see Figure 13) of Illinois No. 6 in $n$-undecane at $65^{\circ}-450^{\circ} \mathrm{C}$. The second $450^{\circ} \mathrm{C}$ image is 15 minutes after the first.

Figure 15. The initial image of the observation area at $32^{\circ} \mathrm{C}$ for an experiment in Tetralin with Wyodak coal at 3000 psi. Particles A, B, and C, chosen for size analysis are boxed.

Figure 16. Particles A, B, and C, (see Figure 15) of Wyodak coal at $32^{\circ}-460^{\circ} \mathrm{C}$. The holding times at $460^{\circ} \mathrm{C}$ are given in parentheses.

Figure 17. Particle A (see Figure 15) of Wyodak coal at $32^{\circ}-460^{\circ} \mathrm{C}$. The holding time at $460^{\circ} \mathrm{C}$ is given in parentheses. 
Figure 18. Size profiles for particles of Wyodak and Illinois No. 6 coal in Tetralin. The numbers within the plots are the holding times in minutes at $460^{\circ} \mathrm{C}$.

Figure 19. The initial image of the observation area at $225^{\circ} \mathrm{C}$ for an experiment in Tetralin with Illinois No. 6 coal at 3000 psi

Figure 20. Particles (see Figure 19) of Illinois No. 6 in Tetralin at $225^{\circ}-460^{\circ} \mathrm{C}$. The second $460^{\circ} \mathrm{C}$ image is 10 minutes after the first..

Figure 21. The initial image of the observation area at $33^{\circ} \mathrm{C}$ for an experiment in water with Wyodak coal at 3000 psi. Particles A, B, and C, are chosen for size analysis.

Figure 22. Particle A (see Figure 21) of Wyodak coal in water at $33^{\circ}-460^{\circ} \mathrm{C}$.

Figure 23. Size profiles for particles of Wyodak and Illinois No. 6 coal in water. The profile for Wyodak/Particle $C$ is repeated in the plot for Illinois No. 6 coal for comparison.

Figure 24. The initial image of the observation area at $40^{\circ} \mathrm{C}$ for an experiment in water with Illinois No. 6 coal at 3000 psi. Particles selected for analysis are boxed. .

Figure 25. Particles (see Figure 24) of Illinois No. 6 in water at $40^{\circ}-450^{\circ} \mathrm{C}$. The second $450^{\circ} \mathrm{C}$ image is 10 minutes after the first.

Figure 26. For Wyodak coal, FIMS profiles for 110 dalton (dihydroxybenzenes) and 94 dalton (phenols) anf profile for Particle $A$ in argon. (The phenols response is multiplied by a factor of 2 for better comparison.).

Figure 27. Comparison of the visual production of tar from this work for Wyodak coal with the production of water and tars from the work of Solomon et al. (1990a).

Figure 28. FIMS ion count profiles from the pyrolysis of samples of Wyodak coal in the inlet of the spectrometer. The undecane treatments were $350^{\circ} \mathrm{C}$.

Figure 29. FIMS profiels for $\mathrm{C}_{6} \mathrm{H}_{4}(\mathrm{OH})_{2}$ evolution for untreated Wyodak coal anf for the same coal treated for $30 \mathrm{~min}$ in undecane at $350^{\circ} \mathrm{C}$.

Figure 30. Profiles for production of water, carbon dioxide, and tar from Illinois No. 6 coal, from the TG-FTIR work of Solomon et al. (1990a). 


\section{INTRODUCTION}

SRI has studied the conversion of Wyodak and Illinois No. 6 coals supplied by the Argonne Premium Coal Sample Bank under pyrolytic and liquefaction conditions, using a high pressure, high temperature diamond observation cell. Thermal treatment of the coals was carried out in argon at pressures of $100 \mathrm{psi}$ and in Tetralin, $n$-undecane $\left(n-\mathrm{C}_{11} \mathrm{H}_{24}\right)$, and water, all at 3000-3500 psi.

The focus of this work has been the development of an understanding of the physical and chemical aspects of the transformation of the coal in the different media using visual means. We have sought to correlate our observations with earlier studies we conducted with the same media and using SRI's field ionization mass spectrometer (FIMS) (DOE Contract No. DE-AC2289PC89880; Ross et al., 1991). The data accumulated in that work, a portion of which was not reported for reasons of space and the desire to present a concise account of the findings, we now find to be very useful in discussion here.

Some of the observations discussed here are at variance with the common views of coal chemistry. For example, we found that both coals appeared to melt, in line with current thoughts on coal softening and fluidity. However, careful examination of the images showed that the phenomenon was in actuality the thermally prompted evolution of a mobile tar that enclosed each particle. The respective core particles, representing the major portion of the coal, remained unchanged throughout the heating.

This report includes discussion of the bond breaking that takes place in coal during heating. The effects of water and organic media on the coal are also discussed, with both the physical and chemical effects of their presence considered.

During the work we presented a paper titled "Hydrothermal Media, Oil Shale, and Coal" at the 204th American Chemical Society national meeting, held in Washington DC, August 2328, 1992. The paper is presented in Appendix A. David Ross was invited to present a paper at the 4th International Symposium on Hydrothermal Reactions held in Nancy, France, 31 August 3 September, 1993. The paper, titled "Hydrothermal Media, Oil Shale, and Coal," is presented in Appendix B. (The same title was used for both papers, but they are different in content and scope.) 
We were joined in this effort by Amoco Corporation, which supplied us with some coals treated with $\mathrm{Fe}(\mathrm{CO})_{5}$ and $\mathrm{Mo}(\mathrm{CO})_{6}$. We expected to be able to note the effects of that treatment directly in our visual studies and then to provide some insight into how the carbonyls affected upgrading. Unfortunately, our work with these materials showed only the rapid production of bubbles on the surfaces of the coal particles. The action was rather violent, and we were unable to obtain satisfactory images of the process. The procedures for the preparation of the coals are presented in Appendix C.

\section{BACKGROUND}

\section{PYROLYSIS}

The pyrolysis of coal has been widely studied over the past 3-4 decades, and detailed reviews have appeared citing literally hundreds of accounts. Howard's summary of pyrolysis and hydropyrolysis (1981) and the discussion of the plastic properties of coal by Habermehl et al. (1981) provide thorough and useful presentations of the topic, and more recent summaries are included in several journal accounts (Kelemen et al., 1993; Lee et al., 1991a; Solomon et al., 1990a,b; 1992; 1993a).

A number of models for the process have been advanced, the most accepted based on the views of van Krevelen that the heating brings about a pair of consecutive reaction families.

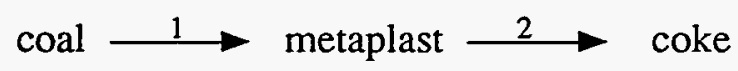

Thus as communicated by Habermehl et al. (1981), coal is first depolymerized to metaplast, a softened state variously described as plastic, and even as fully liquid (Solomon et al., 1992). The metaplast then resolidifies via subsequent, slower cracking and condensations into a new solid material.

Microscopic examination of heated exinite and vitrinite concentrates under inert gas in pioneering work by Ergun et al. (1959) indeed describe initial fusion, with the particles "forming a big globule." That statement suggests a true melting of the macerals, with consolidation into a single unit. The melt then was seen to undergo rapid devolatilization, with bubbles forming and bursting from the material. Recent work by Lee et al. (1991b) has provided SEM 
photomicrographs of char particles isolated from studies with Illinois No. 6 coal in an entrainedflow furnace, which nicely show blow holes resulting from the bursting of bubbles at the surfaces.

One of the most ambitious modeling efforts was recently been put forward by Solomon et al. (1991, 1993a,b). The model describes the formation of light gases and tars in the depolymerization step 1 and condensations of aromatic clusters in the resolidification step 2 . The step 1 gases including water, methane, and carbon dioxide develop, respectively, from the thermolysis of aryl-OH and - $\mathrm{OCH}_{3}$ groups and the decarboxylation of carboxylic acids, and the tars evolve from the thermolytic scission of bibenzyl- and benzyl-phenyl ether-like bridges in the macromolecular network.

The condensation in step 2 has been put on a quantitative basis in solvent swelling studies of recovered, heated samples, and a rank dependence is observed for the onset of crosslinking. For high rank coals the crosslinking takes place following most of the bridge breaking, while for lower rank coals the two processes apparently take place more or less at the same time. These events are then said in turn to lead to promotion of liquefaction for the higher rank coal through the dissolution of the initially formed liquid in the liquefaction medium (Solomon et al., 1991, 1992, 1993b). The lower rank coals must undergo liquefaction through reaction of the medium at the coal surfaces, presumably a slower and more limited process .

A keystone of this and similar models is the presumed existence of thermally weak links in the coal positioned as key bridges in the structure, and to our knowledge there is no direct experimental evidence demonstrating their presence. Solomon and coworkers, however, present observations providing lines of indirect support (1991, 1993b), including Arrhenius plots developed from tar release and weight loss providing $E_{a}$ values in the $190-230 \mathrm{~kJ} / \mathrm{mol}(45-55$ $\mathrm{kcal} / \mathrm{mol}$ ) range expected for labile bridge cleavage. Other support includes proton magnetic resonance thermal analysis, which shows increased proton mobility of bulk coal up to about $430^{\circ} \mathrm{C}$, reversing to return to starting values above that point, and Giesler plastometer work showing increased fluidity to around that same temperature, followed by a rapid decline at higher temperatures.

However, the $\mathrm{E}_{\mathrm{a}}$ values are based on assigned pre-exponential factors; there seem to be no unambiguous kinetic data to employ in the argument. And while the NMR and plastometer findings unquestionably demonstrate increased bulk fluidity, they are plainly not compelling toward labile bridge breaking. As presented below, the data generated in this program are 
decidedly inconsistent with key bridge homolysis and underscore the question of their significance in the thermal chemistry of coal.

\section{EFFECTS OF WATER PRETREATMENT}

The work conducted on this program was prompted by observations we made on an earlier DOE-sponsored program (Contract No. DE-AC22-89PC89880) dealing with the effects of near critical liquid water on coal (Ross et al., 1990, 1991). That program in turn was directed to trying to understand the influence of water on coal in several accounts on the enhancing effects of steam pretreatment at $300^{\circ}-350^{\circ} \mathrm{C}$ on liquid yields during coal pyrolysis (Bienkowksi et al., 1987; Brandes and Graff, 1987a,b). (Brandes and Graff cite yet other reports of the effects of steam on the reactivity of coal, 1987b.) Kahn et al. (1989) questioned the enhancing effects of the pretreatment, but noted nonetheless an extraction of oxygen-bearing fractions by the steam.

Our study showed that liquid water at $350^{\circ} \mathrm{C}$ clearly enhanced the volatiles yields for Argonne Coal Bank Wyodak coal samples. The coal was heated for $30 \mathrm{~min}$ or $5 \mathrm{hr}$ in batch stainless steel reactors with quartz liners, with enough water added that a liquid phase was present at $350^{\circ} \mathrm{C}$. Control runs included samples heated under nitrogen with no added water, and samples heated in undecane $\left(n-\mathrm{C}_{11} \mathrm{H}_{24}\right)$, which acted essentially as an inert medium.

Analysis included studies with SRI's field ionization mass spectrometer (FIMS). Product coals were heated in the sample chamber at $2.5^{\circ} \mathrm{C} / \mathrm{min}$, and the evolved materials were immediately swept into the instrument. Some of our results for the starting coal, the coal heated with water (hydrothermal), and control samples (thermal and undecane) are presented in Figure 1.

\footnotetext{
* Undecane was chosen because its critical temperature is the same as that of water, and its lack of reactivity with the coal at least in our brief treatment was demonstrated in that the treated coal showed no evidence of incorporation of the alkane.
} 


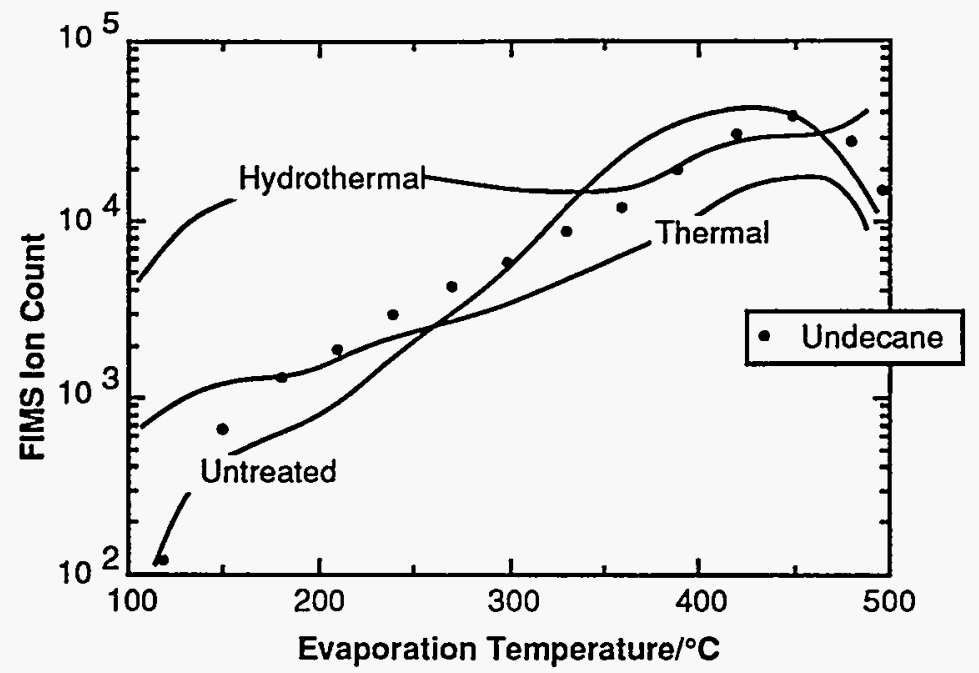

Figure 1. FIMS response vs temperature for Wyodak Coal. The treated coals were heated at $350^{\circ} \mathrm{C}$ for $30 \mathrm{~min}$. The temperature ramp during the FIMS analysis was $2.5^{\circ} \mathrm{C} / \mathrm{min}$.

The figure shows that the coal recovered from the treatment in undecane responded similarly to the thermally treated and untreated coals. The net effect of hydrothermal treatment, however, is apparent; added water clearly prompts the formation of material that is volatile at temperatures as low as $100^{\circ} \mathrm{C}$. Molecular weight data showed in addition that the material volatile above $400^{\circ} \mathrm{C}$ for the untreated samples was the product of fragmentation of structures within the bulk coal. Those for the hydrothermally treated samples, on the other hand, were volatile, high molecular weight material. The most prominent identifiable material in the volatiles were dihydroxybenzenes and their $\mathrm{C}_{1^{-}}, \mathrm{C}_{2^{-}}$, and $\mathrm{C}_{3}$-derivatives. Phenol and its derivatives were somewhat less prominent and evolved at higher temperatures.

The tar-prompting effect of water was clearly evident from the deposits of tars on the quartz liners. The tenacious material, corresponding to $7 \%-8 \%$ of the mass of the starting coal, was found solely in the case of the water-added runs; the walls of the liners from strictly thermal runs, or from runs with undecane added as medium in place of water, were clean.

The effects of prolonged hydrothermal treatment were determined by comparing tars from 30-min and 5-hr heatings. The extended treatment generated no greater quantities of tar. However, the quality changed as shown in Figure 2, which presents the volatility and molecular weight profiles as established from FIMS studies of the tars themselves. The figure shows that the tar from the extended heating is the more volatile, but at the same time is composed of higher molecular weight material. In addition, the decrease in molecular weight for the 30-min material 
above $300^{\circ} \mathrm{C}$ reflects thermal fragmentation of components not sufficiently volatile at the higher temperatures. In contrast, the monatonic increase in molecular weight with increasing temperature for the 5-hr material shows no fragmentation but rather simple distillation, consistent with the greater volatility. Clearly at these conditions, water acts first on the coal to generate the tars, and then continues its action on the tars themselves. 

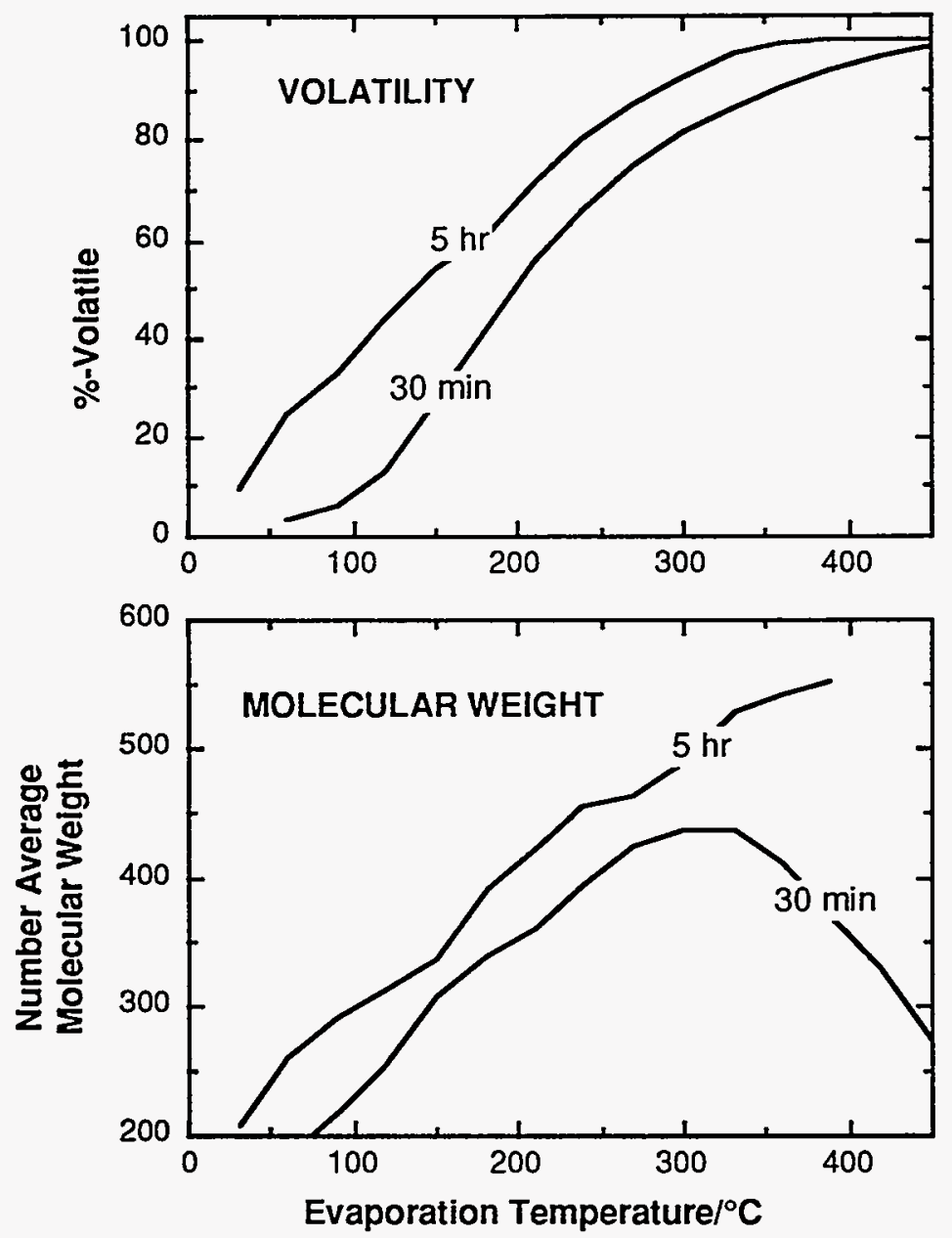

Figure 2. Volatility and molecular weight profiles for tars recovered from 30-min and 5-hr hydrothermolytic treatments of Wyodak coal. 


\section{EXPERIMENTAL PROCEDURES}

\section{THE COALS}

Analyses for the Argonne samples of Wyodak and Illinois No. 6 coals used in this study are presented in Table 1 (Vorres, 1989).

\begin{tabular}{|c|c|c|}
\hline & Wyodak & Illinois No. 6 \\
\hline \multicolumn{3}{|c|}{ Elemental analysis, wt \% (dmmt basis) } \\
\hline C & 76.04 & 80.73 \\
\hline$H$ & 5.42 & 5.20 \\
\hline$N$ & 1.13 & 1.43 \\
\hline 0 & 16.90 & 10.11 \\
\hline \multicolumn{3}{|c|}{ Mineral matter. wt \% (dry coal basis) } \\
\hline Total & 8.7 & 18.1 \\
\hline Quartz & 2.0 & 3.4 \\
\hline Pyrite & 0.1 & 5.5 \\
\hline Calcite & 0.4 & 1.9 \\
\hline Total Clay & 6.2 & 7.3 \\
\hline \multicolumn{3}{|l|}{ Sulfur } \\
\hline $\begin{array}{l}\text { Pyritic/ } \\
\text { organic }\end{array}$ & 0.40 & 1.09 \\
\hline
\end{tabular}

\section{THE CELL}

\section{Schematic Representation of the System}

For this work we have adapted the cell initially described by Rofer (1990). The cell is designed to be operated to temperatures and pressures of $500^{\circ} \mathrm{C}$ and $5000 \mathrm{psi}$. The two reactor windows are made of diamonds which allows us to operate the unit as a high 
temperature/pressure microscope. The images are captured with a video camera and recorded on a video cassette recorder (VCR). Process information such as reactor temperature and elapsed time are superimposed in alphanumeric form on the video signal.

The flow observation cell and peripheral system, shown in Figure 3, consists of three interconnected parts: flow system, heating system, and optical system. The flow system is constructed primarily from $1 / 16$-in.-ID stainless steel , 1/8-in. OD for the ambient-temperature components, and 1/4-in. OD for the cell itself. The HPLC-pump P1 is capable of flows from 0.1 to $10 \mathrm{ml} / \mathrm{min}$, at pressures up to $6000 \mathrm{psi}$.

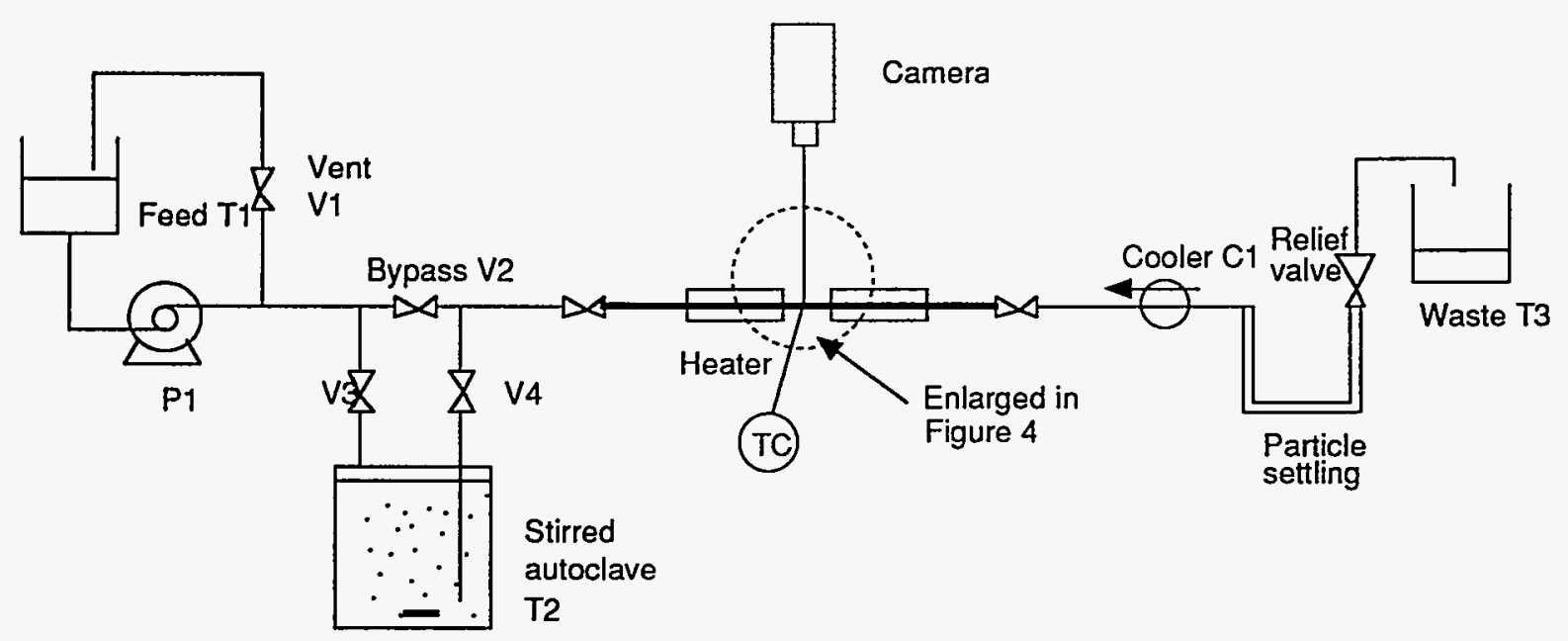

Figure 3. The continuous flow observation cell with peripheral system, designed for pressures up to $5000 \mathrm{psi}$ at $550^{\circ} \mathrm{C}$. Clean solvent, pressurized by $\mathrm{P} 1$, passes through the autoclave, containing a dispersion of coal. The mixture then flows to the heated reactor, where a camera observes the reaction. Particles settle in a disengagement zone and the pressure is relieved.

A list of parts used in the system and tables of allowable pressures and temperatures for the components are provided in Appendix D.

\section{Optics and Illumination}

The optical system is detailed in Figure 4. The heart of the system is the pair of diamond anvils tightly clamped to the stainless steel reactor tube. The diamonds are type $2 \mathrm{~A}$, "Drukker modified-brilliant" shaped, with a culet of $0.6 \mathrm{~mm}$. Gold foil gaskets provide a leaktight connection. 


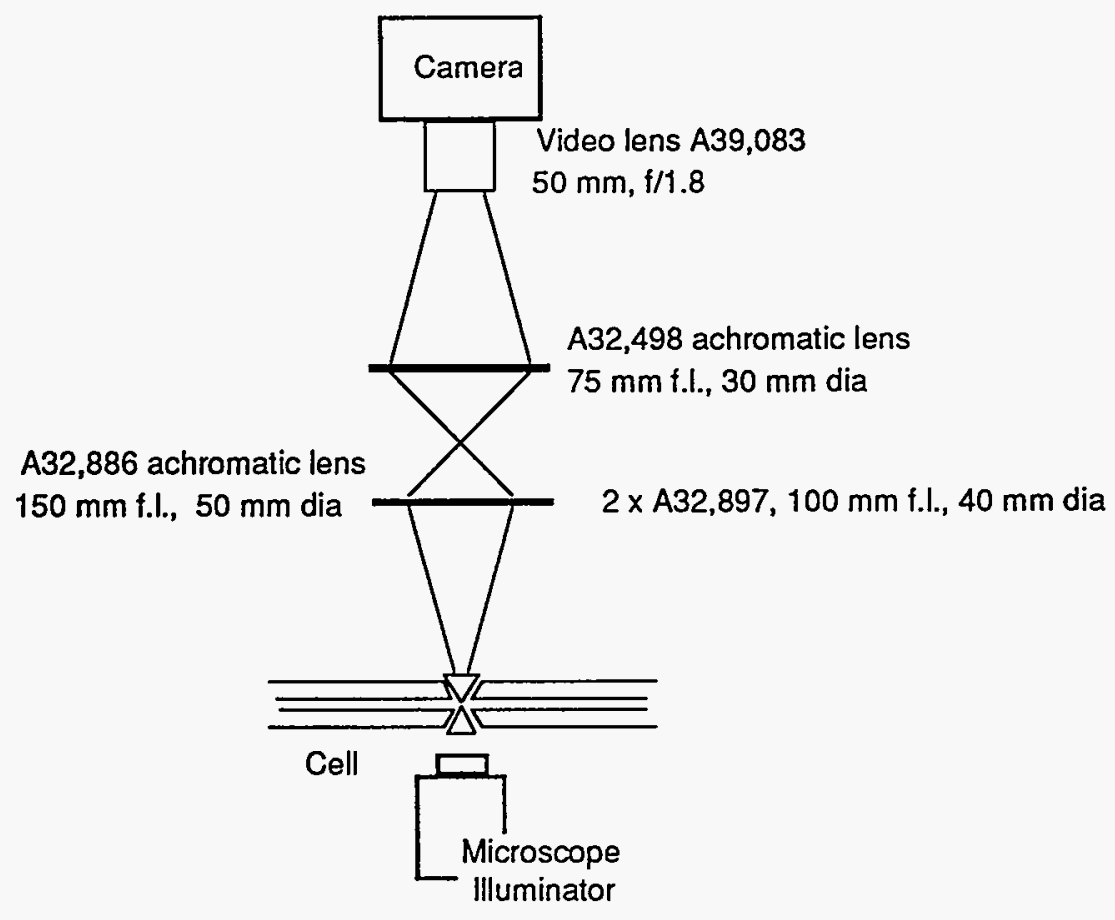

Figure 4. The illumination and lens system for the cell.

The field is back-lit by a tungsten microscope illuminator, which gives silhouette images of the particles. A lens system enlarges the image and mixes it with the images of a time and temperature display. The image is monitored by a Dage MTI CCD 72 video camera, displayed on a Dage MTI HR 1000 monitor, and recorded on video tape on a JVC HR-FC 1000 VCR.

\section{Heating System}

The reactor tube is heated by $22 \mathrm{ft}$ of mineral insulated $\mathrm{Ni} / \mathrm{Cr} / \mathrm{Fe}$ wire 9 AeroCoax, 0.063 in. $\mathrm{OD}, 1.6 \mathrm{ohm} / \mathrm{ft}$ ), wrapped around a copper bar, which has notches to accommodate the diamond windows, their clamps, and a thermowell. The temperature near the diamond windows is measured by a $\mathrm{NiCr} / \mathrm{NiAl}$ (K-type) thermocouple that provides input for the PID-controller of the electric heater. The copper bar ensures a uniform temperature of the reactor. The total resistance of the heater is $35 \mathrm{ohms}$, which results in $3.5 \mathrm{~A}$ at $120 \mathrm{~V}$, or $420 \mathrm{~W}$. The oven is insulated with mineral wool. 


\section{OPERATION}

\section{Coal Manipulation and Run Procedure}

For liquid medium runs, reactor charging is conducted from the stirred autoclave (T2 in Figure 3). Solvent from the feed tank is pressurized by pump P1. The working pressure is determined by adjusting the relief valve, while the flow is regulated by the pump. The feed passes through the autoclave, where coal particles are dispersed by vigorous magnetic stirring. The dispersion is then moved into the reactor.

For argon experiments, coal samples are loaded manually on the lower diamond window under an inert atmosphere. Moisture from the sample is removed by heating under argon at $107^{\circ} \mathrm{C}$ for at least $1 \mathrm{hr}$.

The system is cleaned after each run by alternate flushing with air and hot pyridine at $100^{\circ} \mathrm{C}$ to remove remaining coal particles and tar. In this operation the autoclave is bypassed. In some cases it has been necessary to disassemble the reactor, and in that case the tar deposited on the windows is easily removed by careful wiping with a Q-tip or soft cloth.

As shown in Figure 5, during a run the cell is heated at $25^{\circ} \mathrm{C} / \mathrm{min}$ to $250^{\circ} \mathrm{C}$, and the rate is then reduced to $10^{\circ} \mathrm{C} / \mathrm{min}$. The temperature is then held at $460^{\circ} \mathrm{C}$.

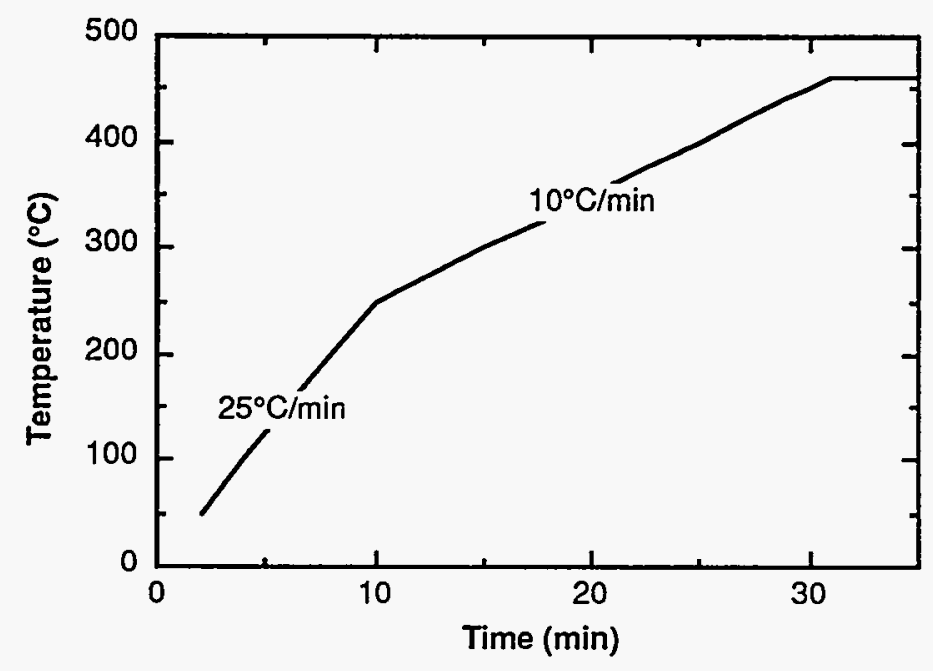

Figure 5. Heating profile for the studies described here. 


\section{Image Processing and Analysis}

The collected video images of the process of the cell were transferred to a disc using an image processing computer employing a video spigot card. For each run we acquired 10 to 20 digitized gray scale images. The resolution of the captured images was 72 DPI and average image size is $320 \times 240$ pixels with each pixel $1.29 \mathrm{~mm}$.

Further processing of these captured images was carried out using Adobe Photoshop 2.5 on a Macintosh ICCi. Photoshop allows the operator to select images of individual particles and assemble them on a new canvas. Their quality can then be improved using a number of image enhancement options. Particle areas were determined using Color Image: Image Processing and Analysis (by Wayne Rasband, National Institutes of Health, Research Service Branch, NIMH).

\section{FIMS}

For the FIMS studies, 1-2 mg of sample were placed in a small furnace fixed to the inlet of the instrument. After evaluation, the samples were heated at $2.5^{\circ} \mathrm{C} / \mathrm{min}$ from ambient to $500^{\circ} \mathrm{C}$. Spectra were recorded at nominally $30^{\circ}$ intervals. 


\section{RESULTS}

Images from studies in argon, water, tetralin, and undecane have been selected from the video tapes generated during the study and reproduced here. There was little loss of image quality in the transfer from tape to computer. However, the limitations in the printing process used for this report, have degraded the quality of the images here. To assist in the evaluation of the report a video tape containing portions of the runs described here accompanies the version of this report sent to the project monitor.

\section{TREATMENT IN ARGON}

Illinois No. 6 and Wyodak coals were studied with argon as medium in experiments where 10-20 particles were within the visual field. The experiments were conducted at $100 \mathrm{psi}$. The changes observed in the particles were similar for both coals, except that the events described here took place at somewhat higher temperatures for the Illinois coal.

The first evidence of change was a very abrupt, almost explosive swelling of a small fraction of the particles. These particles appeared to soften substantially, losing their irregular edges. Their behavior appeared similar to the melting of pure, crystaline organic compounds on a microscope hot stage, collapsing into a fluid droplet over just a degree or two.

The major fraction of the particles acted more slowly, not melting but rather releasing tar over a range of temperatures. For both coals remnants of the cores of the starting particles remained within the fluids, seen often as vague shadows.

Near $360^{\circ} \mathrm{C}$ for Wyodak and $400^{\circ} \mathrm{C}$ for Illinois No. 6 coal, the process then appeared to reverse itself very quickly. The fluid phase rapidly vanished, presumably evaporating, exposing the core particles. Remarkably, the remaining particles displayed the same size and shape as the starting particles, and remained unchanged with still increasing temperature.

This behavior is shown in the following series of figures for both coals. Figure 6 shows the initial image of the observation area at $85.8^{\circ} \mathrm{C}$ for an experiment at $100 \mathrm{psi}$ argon with Wyodak coal. Three particles were selected for size analysis, and the changes in the boxed one, Particle A, are shown in Figure 7. There were no observable size changes to $250^{\circ} \mathrm{C}$, at which point there appeared to be a small change in shape. At about $330^{\circ} \mathrm{C}$ the action accelerated, with 
tar evolving at a rapid rate, and at $350^{\circ} \mathrm{C}$ the particle appeared to be almost spherical. At that point the tar began to evaporate rapidly, and at $358^{\circ}$ only the core remained. The similarity of its shape to the starting particle is apparent in Figure 7.

The size change profiles for the three Wyodak particles are shown in Figure 8. Particle C behaved like $\mathrm{A}$, while Particle $\mathrm{B}$ showed virtually no change and likely was primarily mineral matter. The abrupt evaporation of the tar is apparent in the profiles.

The profiles for three Illinois No. 6 coal particles are also shown in Figure 8, and the corresponding images are presented in Figures 9 and 10. With the heating rate in the active region for both coals is $10 \%$ min, the events seen here clearly take place over short periods of time. From Figure 10 it is apparent that the particle appears almost spherical at around $400^{\circ} \mathrm{C}$, and rapid evaporation of the fluid takes place at higher temperatures. As for the Wyodak coal, the final particle has essentially the same size and shape as the starting particle.

\section{TREATMENT IN $\boldsymbol{n}$-UNDECANE}

The experiments in undecane were conducted with the pressure relief valve set at $3000 \mathrm{psi}$, and the effects were in considerable contrast to those in argon. Figure 11 shows the initial image of Wyodak coal at $30.2^{\circ} \mathrm{C}$, and Figure 12 shows the temperature dependence of the particle in the boxed area of the Figure 11. Figures 13 and 14 show the respective results for the Illinois coal. Outside of the Brownian motion seen for the very small particles in the field, there was no visual activity to $460^{\circ} \mathrm{C}$. Figure 14 shows the almost negligible effect of holding the sample at $460^{\circ} \mathrm{C}$ for $15 \mathrm{~min}$. 


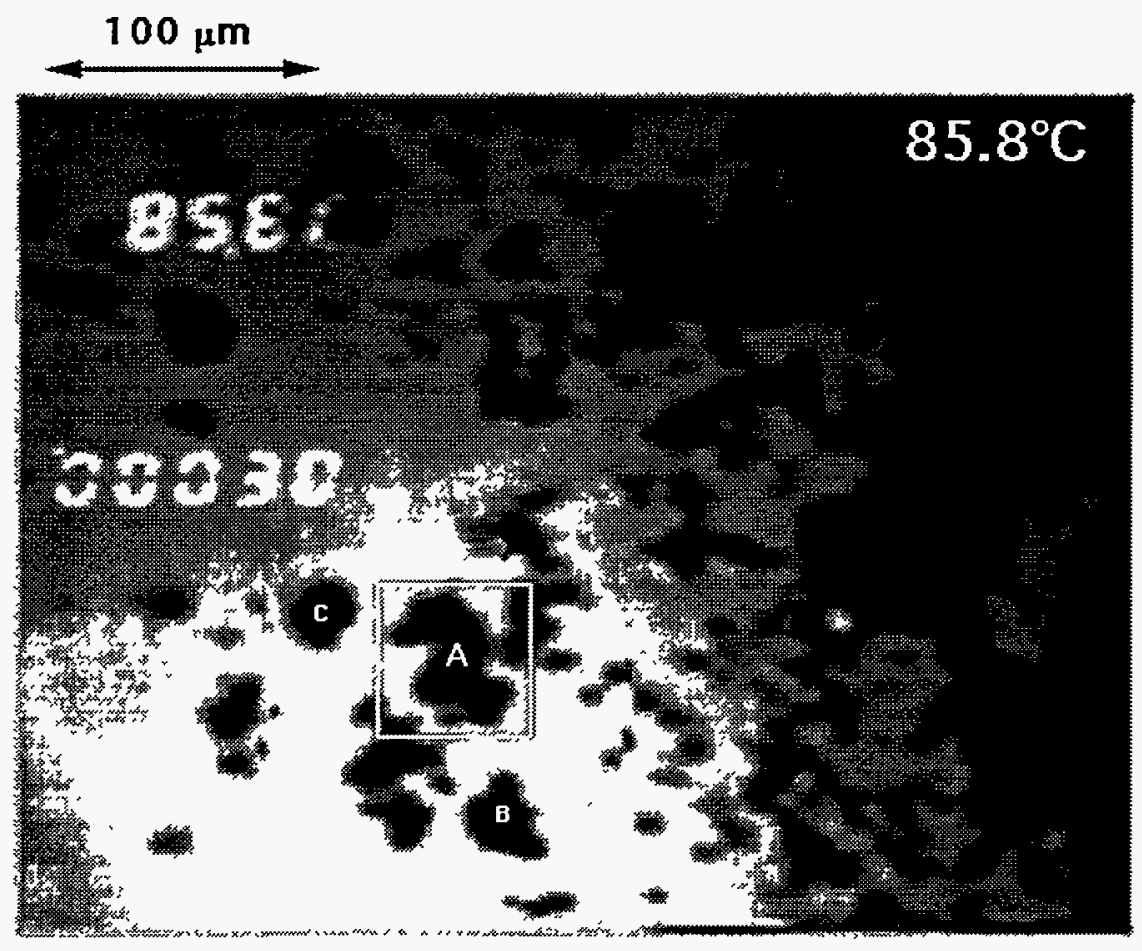

Figure 6. The initial image of the observation area at $85.8^{\circ} \mathrm{C}$ for an experiment at $100 \mathrm{psi}$ argon with Wyodak coal. Particles A, B, and C were selected for size analysis. 

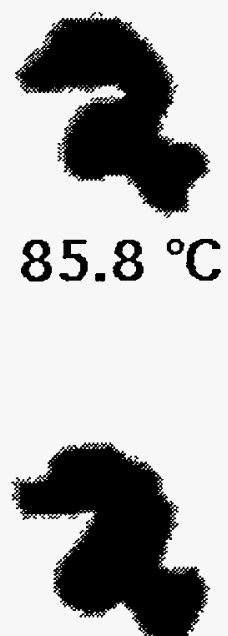

$305.2{ }^{\circ} \mathrm{C}$

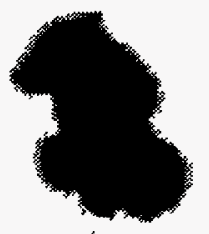

$336.4{ }^{\circ} \mathrm{C}$

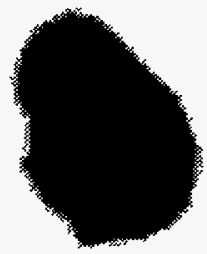

$352.8^{\circ} \mathrm{C}$

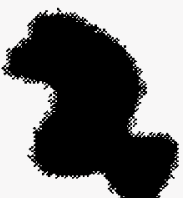

$400.0^{\circ} \mathrm{C}$

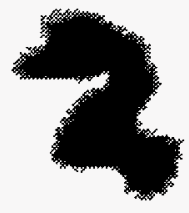

$153.4{ }^{\circ} \mathrm{C}$

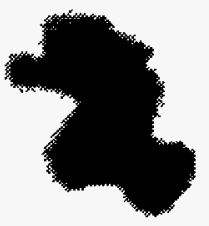

$320.4{ }^{\circ} \mathrm{C}$

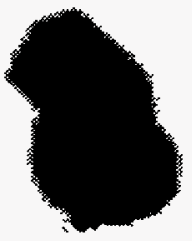

$340.0^{\circ} \mathrm{C}$

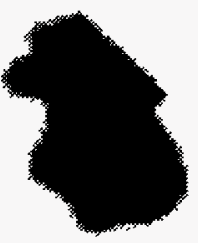

$356.0^{\circ} \mathrm{C} \quad 358.4^{\circ} \mathrm{C}$

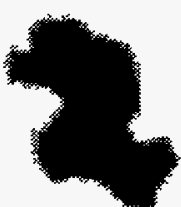

$450.2^{\circ} \mathrm{C}$

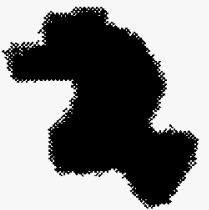

$250.2{ }^{\circ} \mathrm{C}$

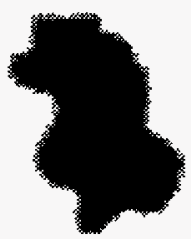

$331.8^{\circ} \mathrm{C}$

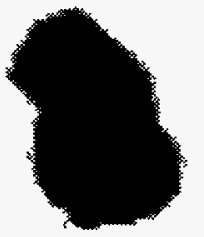

$346.2{ }^{\circ} \mathrm{C}$
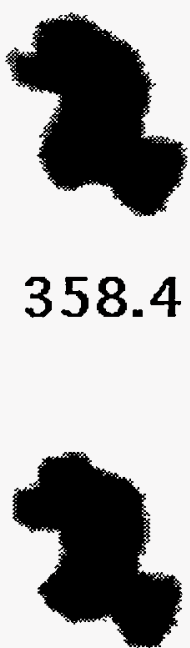

$460.0^{\circ} \mathrm{C}$

Figure 7. Particle A (see Figure 6) of Wyodak coal in argon at $85^{\circ}-460^{\circ} \mathrm{C}$.

16 

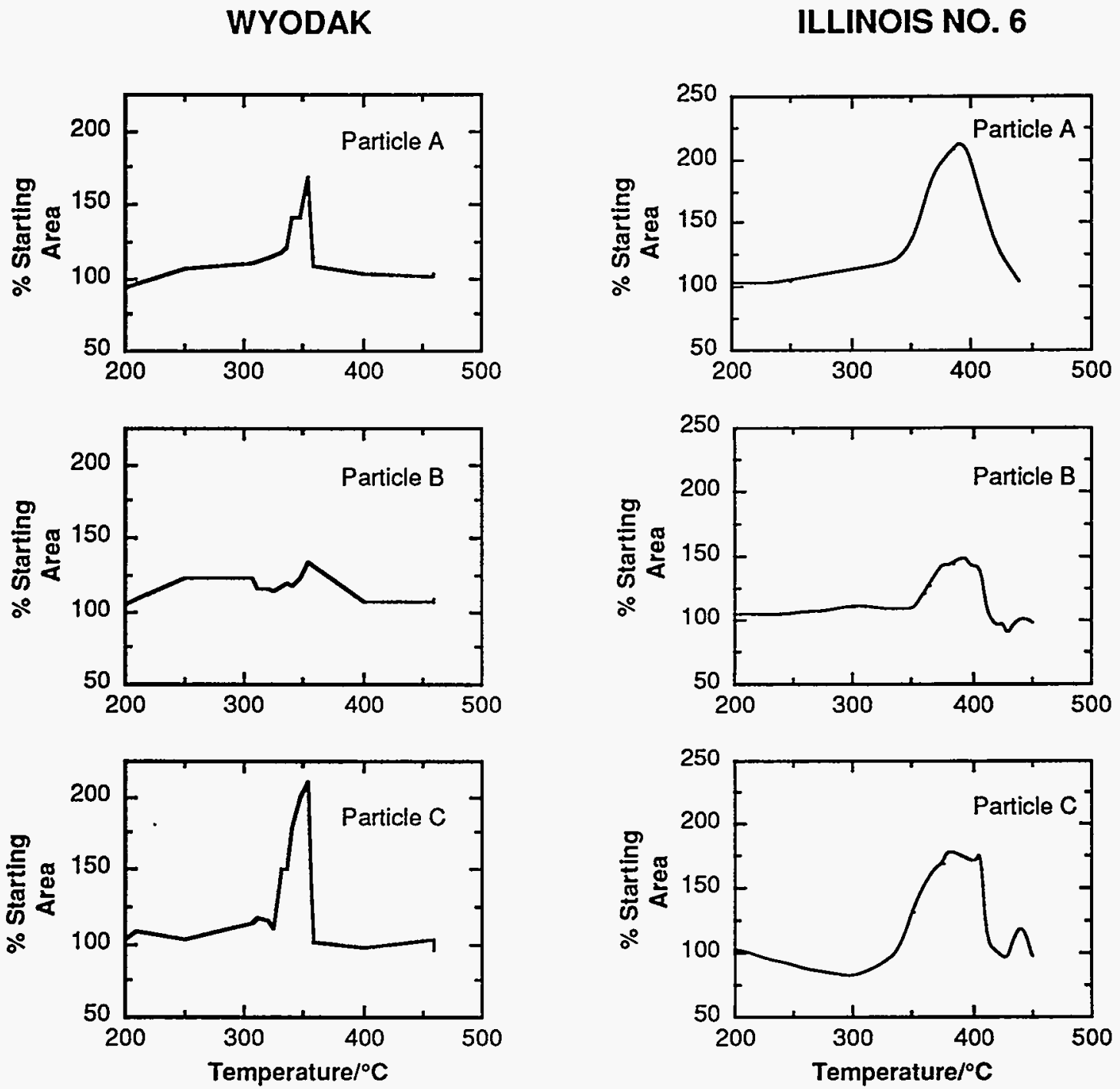

Figure 8. Size profiles for particles of Wyodak and Illinois No. 6 coal in argon. 


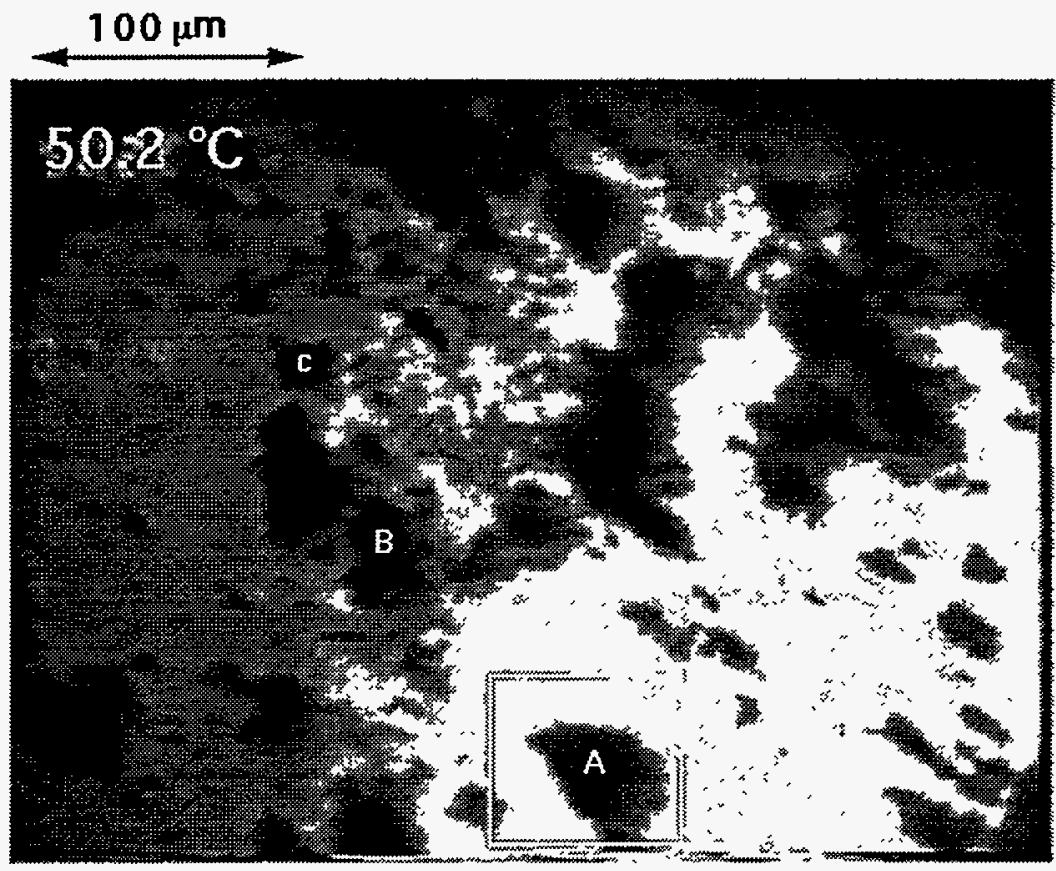

Figure 9. The initial image of the observation area at $50.2^{\circ} \mathrm{C}$ for an experiment at $100 \mathrm{psi}$ argon with Illinois No. 6 coal. Particles A, B, and C were selected for size analysis. 


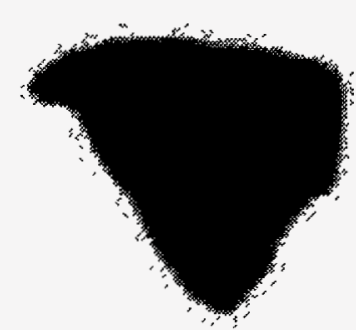

$50^{\circ} \mathrm{C}$

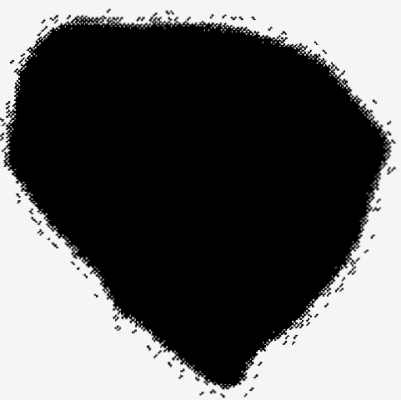

$365^{\circ} \mathrm{C}$

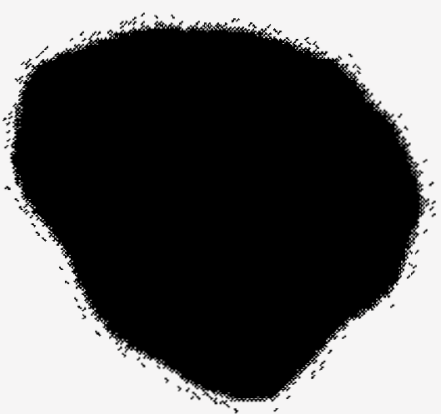

$400^{\circ} \mathrm{C}$

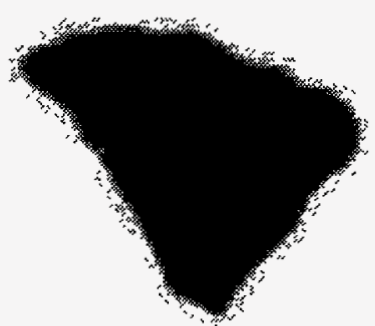

$250^{\circ} \mathrm{C}$

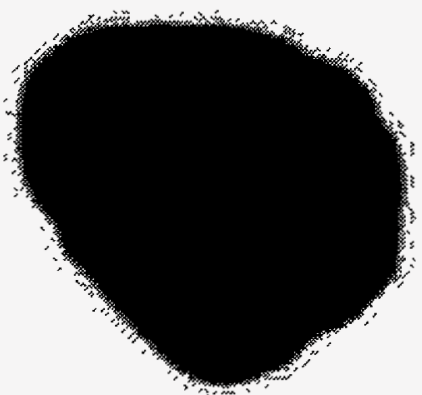

$386^{\circ} \mathrm{C}$

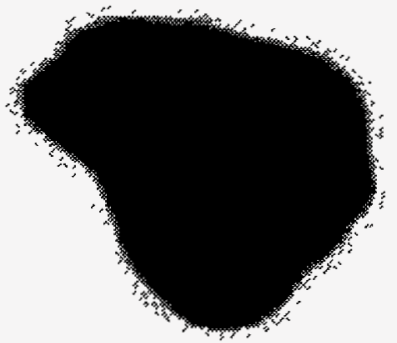

$413^{\circ} \mathrm{C}$

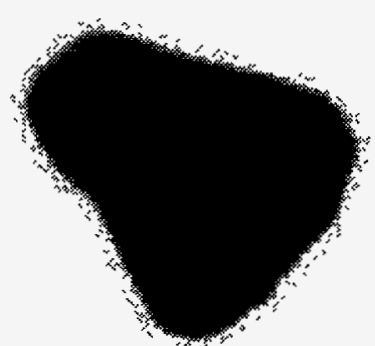

$350^{\circ} \mathrm{C}$

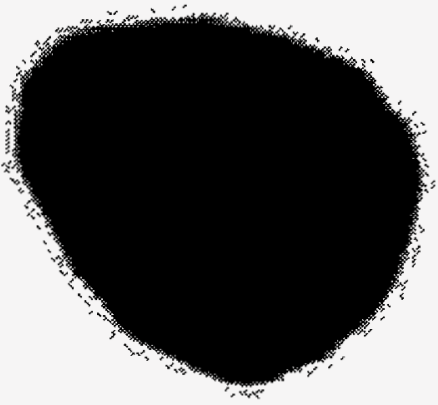

$395^{\circ} \mathrm{C}$

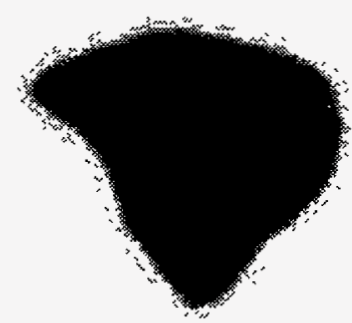

$440^{\circ} \mathrm{C}$

Figure 10. Particle A (see Figure 9) of lllinois No.6 in argon at $50^{\circ}-440^{\circ} \mathrm{C}$. 


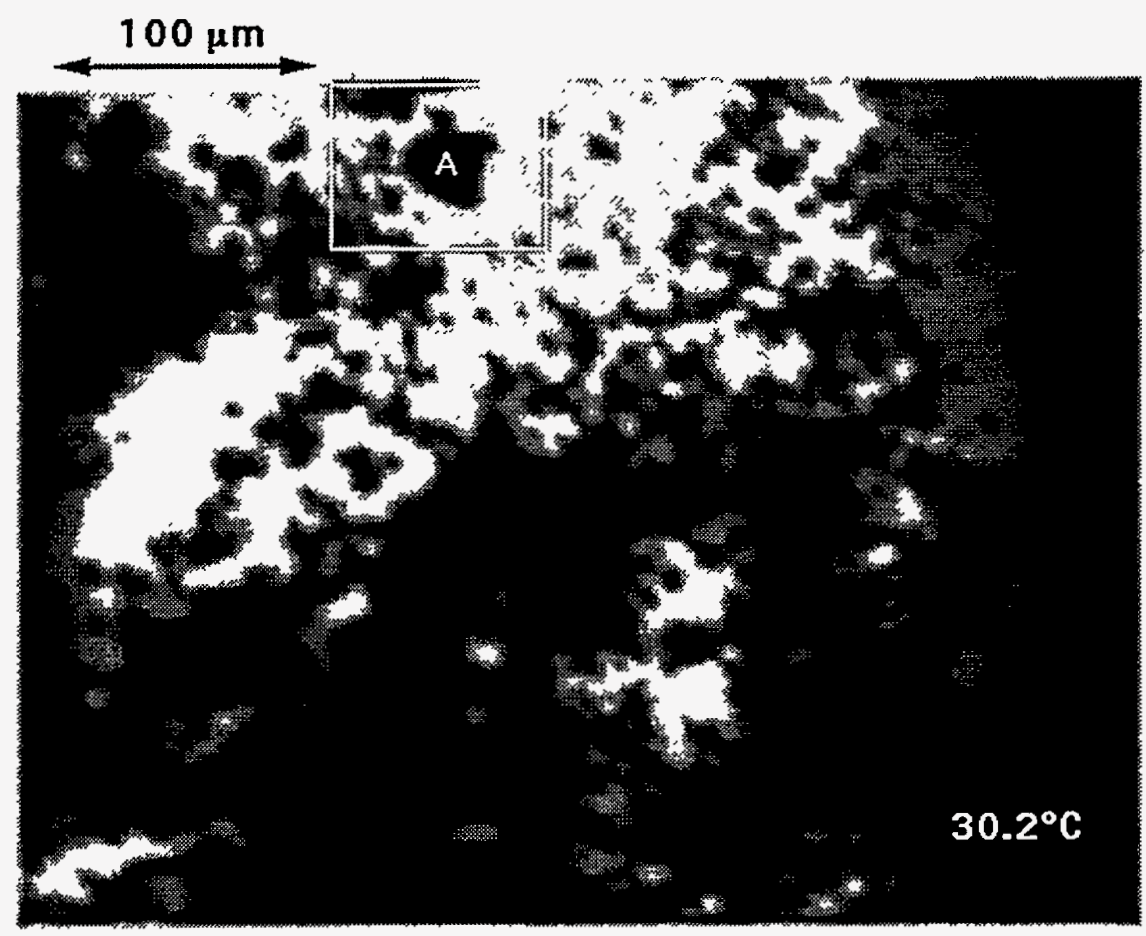

Figure 11. The initial image of the observation area at $30.2^{\circ} \mathrm{C}$ for an experiment in $n$-undecane with Wyodak coal at 3000 psi. The particle selected for size analysis is boxed. 

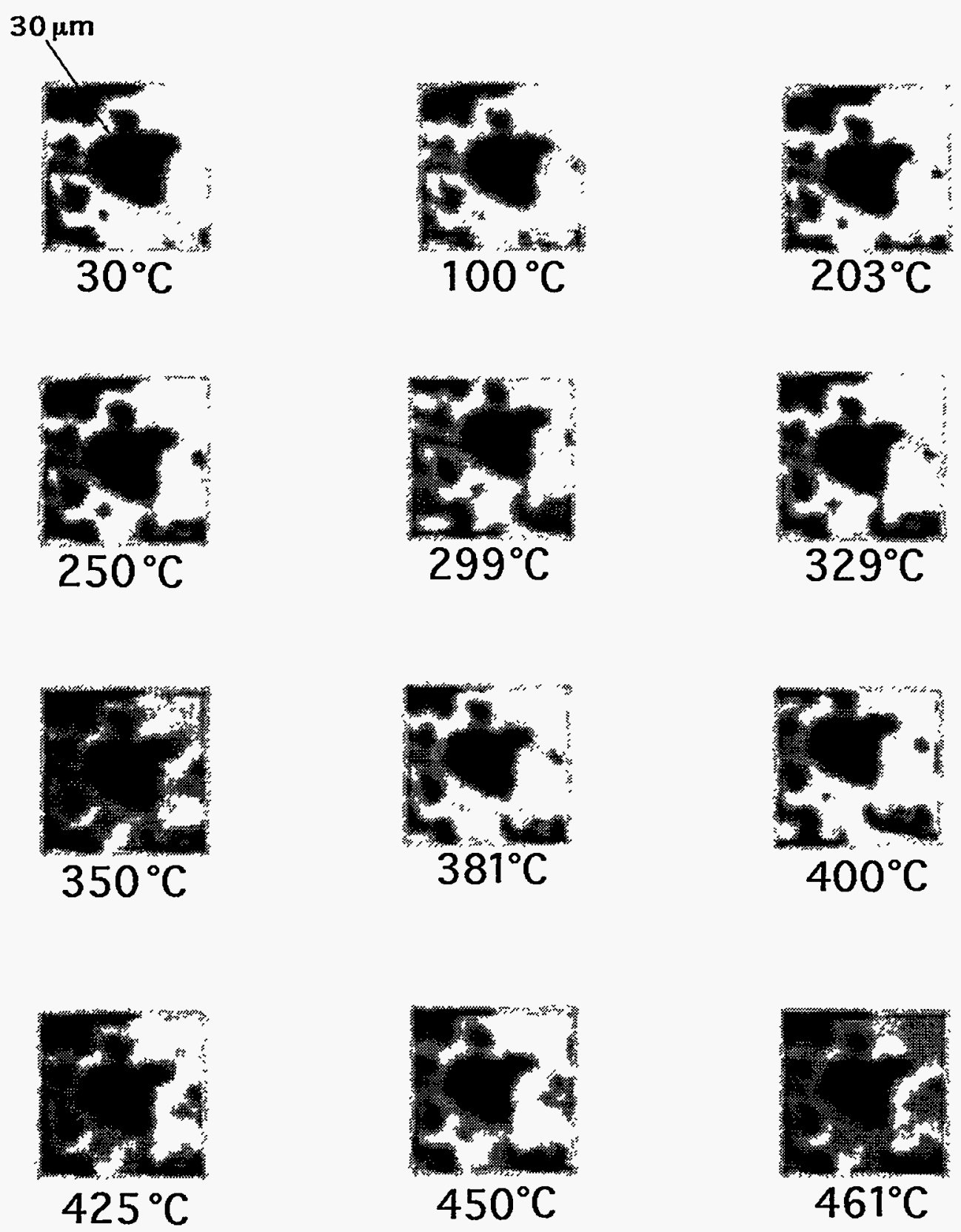

Figure 12. Particle A (see Figure 11) of Wyodak coal in $n$-undecane at $30^{\circ}-461^{\circ} \mathrm{C}$. 


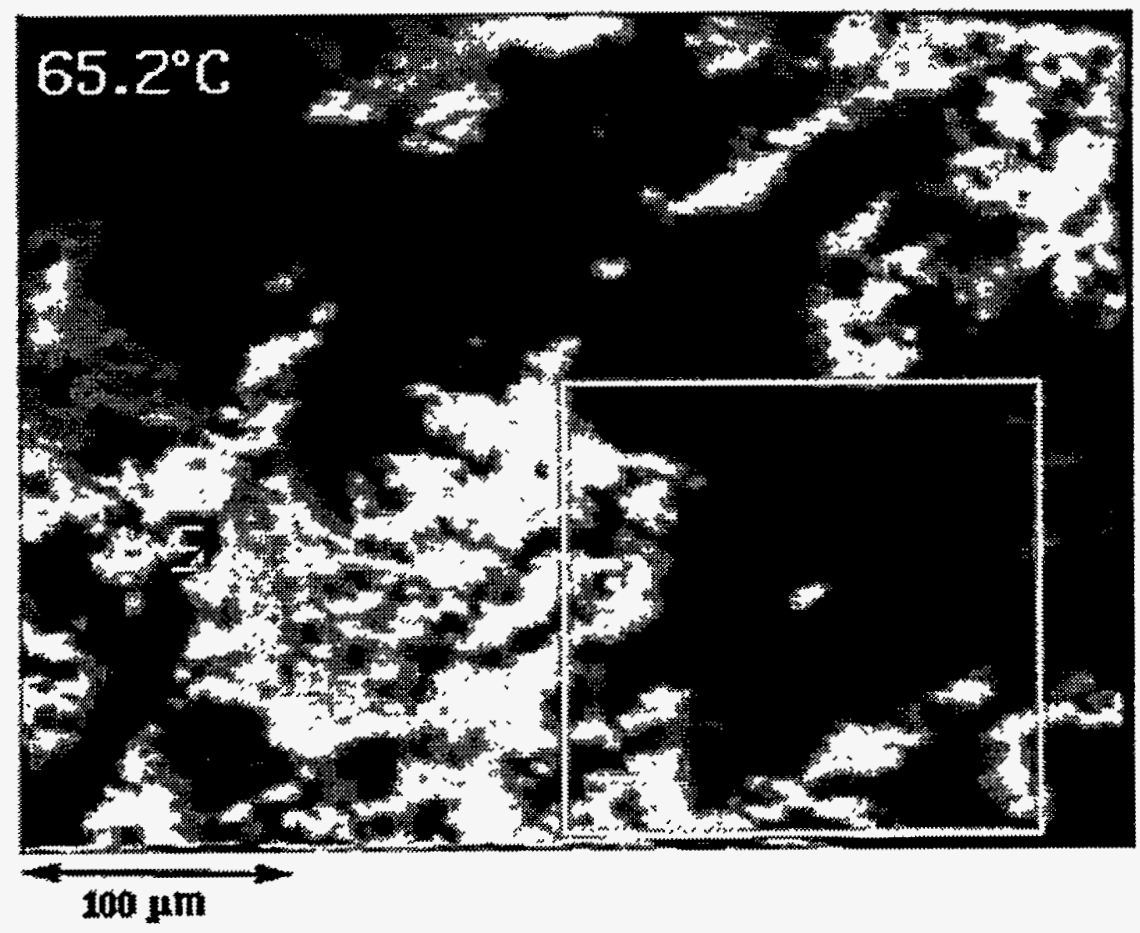

Figure 13. The initial image of the observation area at $65.2^{\circ} \mathrm{C}$ for an experiment in n-undecane with Illinois No.6 coal at 3000 psi. The particle chosen for size analysis is boxed. 


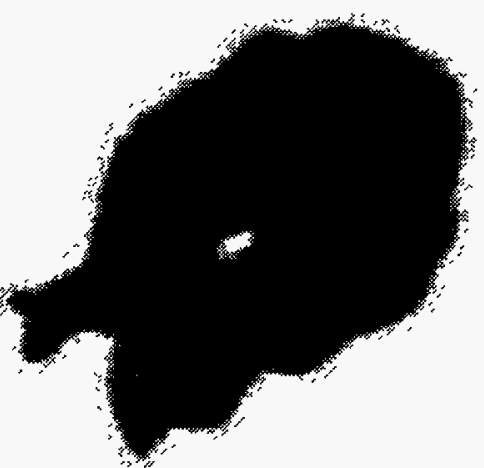

$65^{\circ} \mathrm{C}$

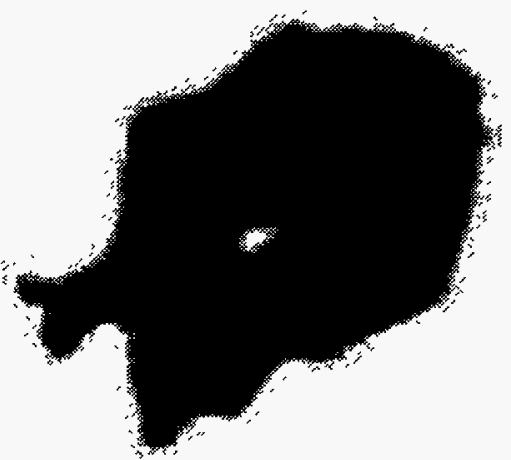

$350^{\circ} \mathrm{C}$

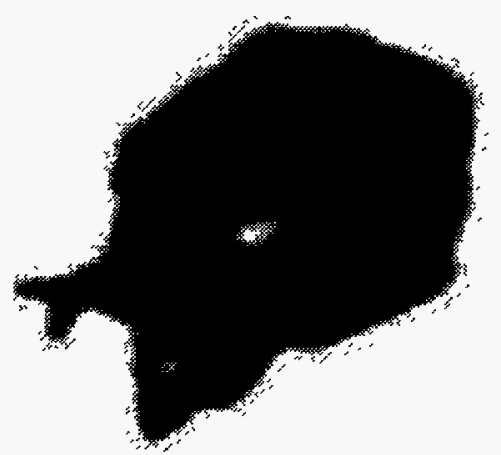

$450^{\circ} \mathrm{C}$

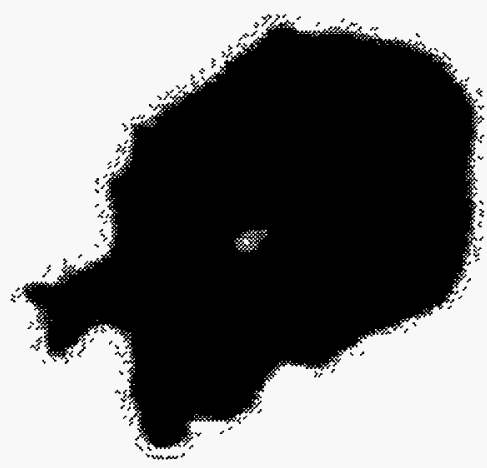

$253^{\circ} \mathrm{C}$

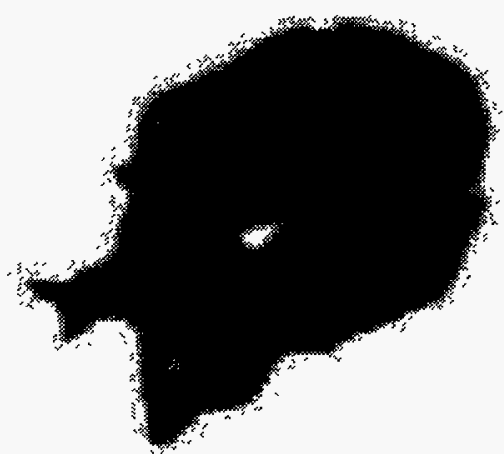

$400^{\circ} \mathrm{C}$

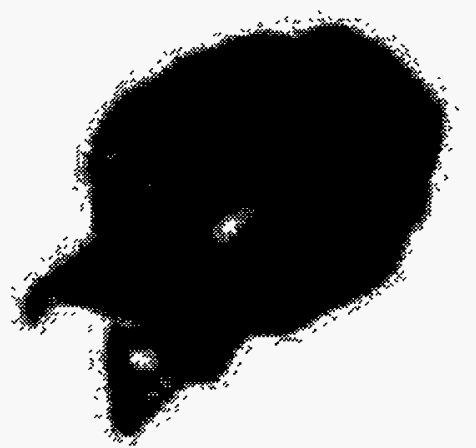

$450^{\circ} \mathrm{C}(15 \mathrm{~min})$

Figure 14. Particle A (see Figure 13) of Illinois No.6 in $n$-undecane at $65^{\circ}-450^{\circ} \mathrm{C}$. The second $450^{\circ} \mathrm{C}$ image is 15 minutes after the first. 


\section{TREATMENT IN TETRALIN}

The experiments in Tetralin were conducted with the pressure relief valve set at $3000 \mathrm{psi}$ as in the studies in undecane. The findings were surprisingly similar to those in undecane up to $420^{\circ} \mathrm{C}$, with no movement or change in morphology. However, as is seen below, at that point changes in the particles take place rapidly. Heating was continued to $460^{\circ} \mathrm{C}$, at which point the temperature was held constant.

For Wyodak coal Figure 15 shows the starting condition and the boxed area chosen for analysis, and Figures 16 and 17 show, respectively, the changes in the boxed region and in particle $\mathrm{A}$. The size changes in particles $\mathrm{A}, \mathrm{B}$, and $\mathrm{C}$ are presented graphically in Figure 18 . Between $420^{\circ}-460^{\circ} \mathrm{C}$ all three particles shrank at a rate of about $10 \%-15 \% / m i n$. During the holding period, the rate dropped to $1 \%-2 \% / \mathrm{min}$. Overall the particles were reduced in size by about $50 \%$ over the entire period of heating.

Two large particles of Illinois No. 6 coal were studied in Tetralin, as shown in Figure 19. Figure 20 shows the change in sizes, and the size profiles are included in Figure 18. The results for particle B are similar to those for Wyodak coal; however, particle A behaved very differently. That particle became reactive at around $300^{\circ} \mathrm{C}$, shrinking at a rate of about $5 \% / \mathrm{min}$. The rate increased with increasing temperature, with the particle ultimately reduced to about $30 \%$ of its initial size.

\section{TREATMENT IN WATER}

The results in undecane showed that the thermal treatment of coal in an inert liquid medium showed virtually no change in particle morphology to temperatures of at least $460^{\circ} \mathrm{C}$, and a similar result might be expected for water. We found, however, that water was highly reactive with both coals, prompting morphological changes at surprisingly low temperatures. 


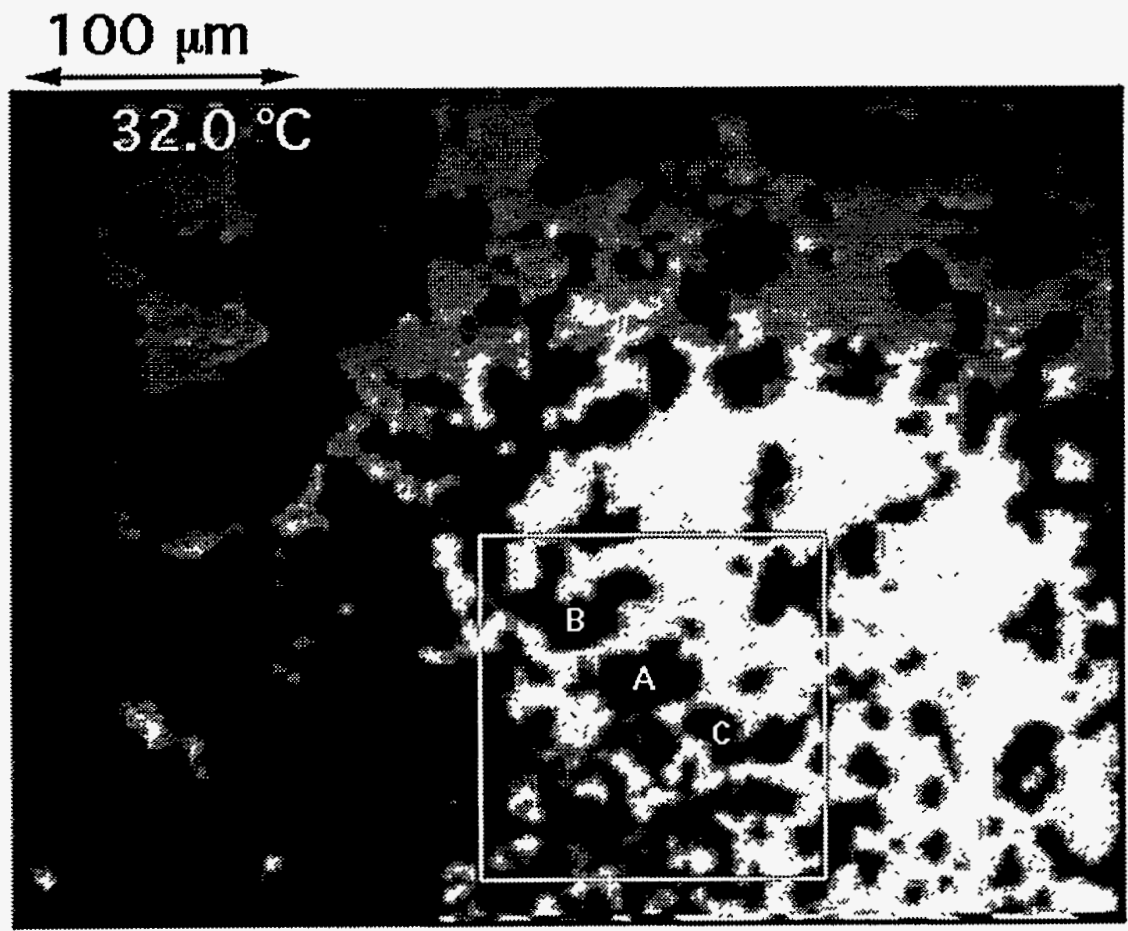

Figure 15. The initial image of the observation area at $32^{\circ} \mathrm{C}$ for an experiment in Tetralin with Wyodak coal at 3000 psi. Particles, A, B, and C, chosen for size analysis, are boxed. 

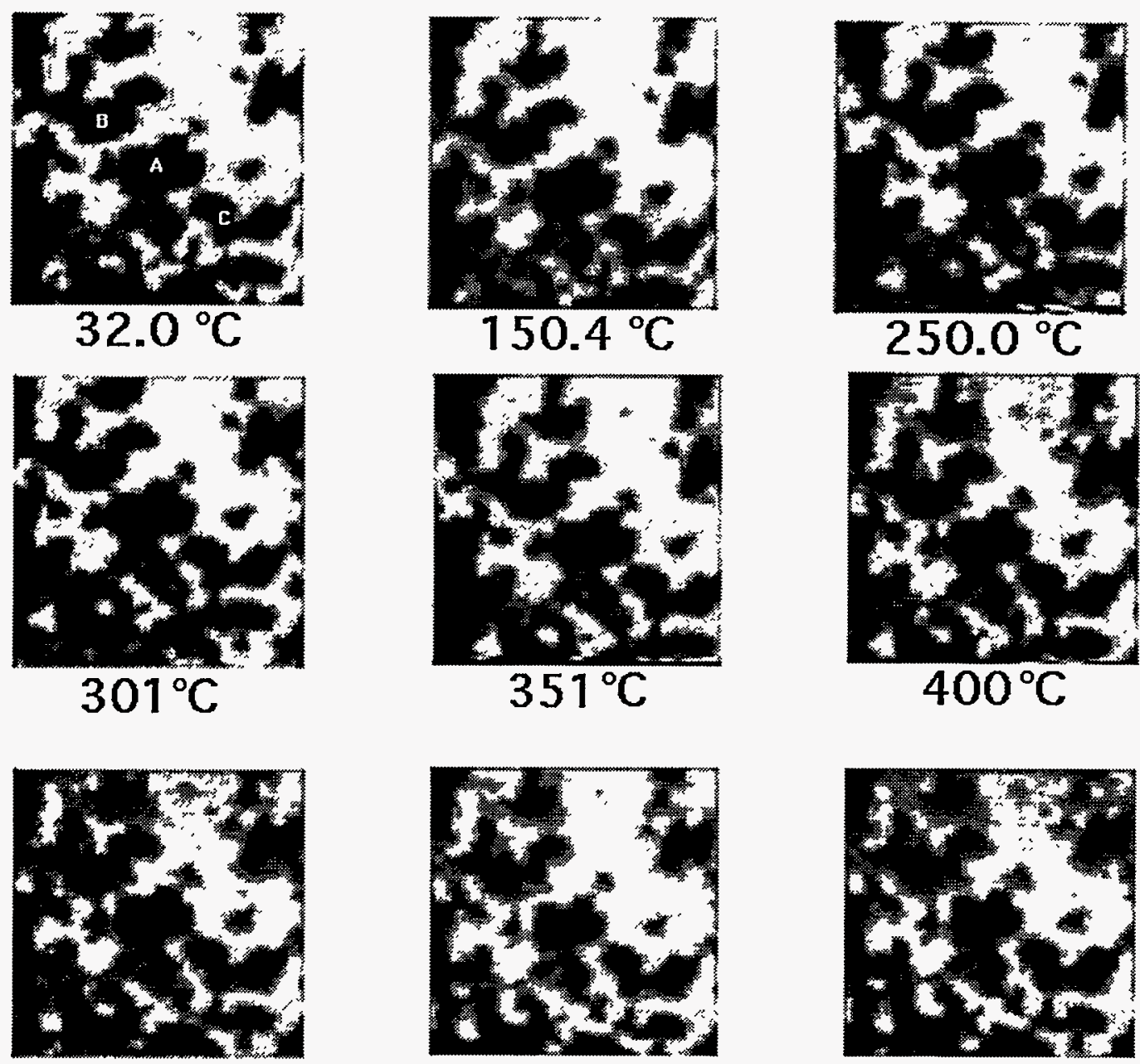

$451^{\circ} \mathrm{C}$
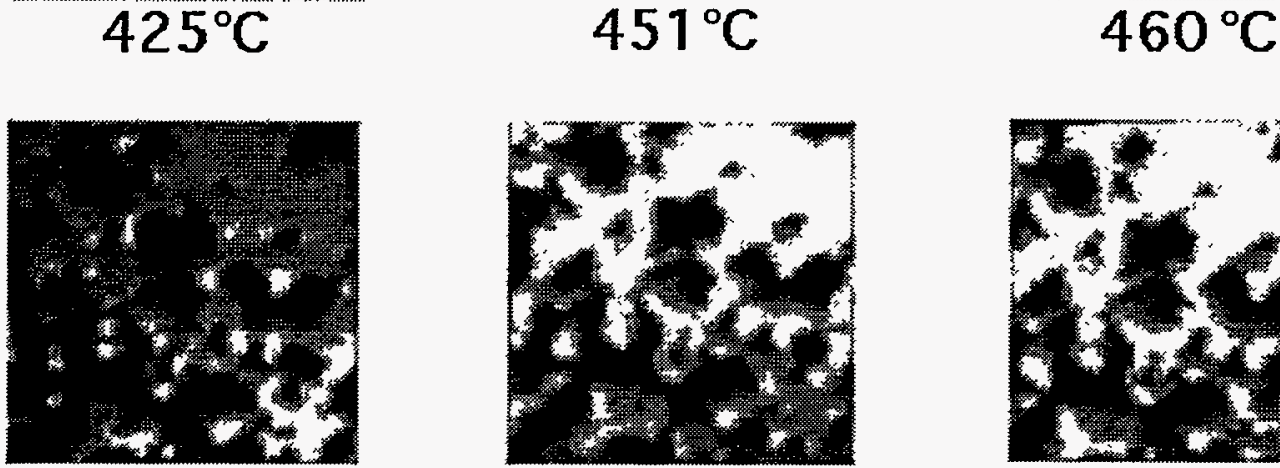

$460^{\circ} \mathrm{C}$

(5 $\mathrm{min}$ )

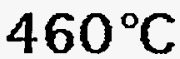

(20 $\mathrm{min})$

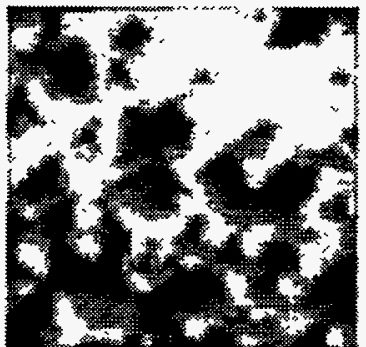

$460^{\circ} \mathrm{C}$

(30 $\mathrm{min})$

Figure 16. Particles $A, B$, and $C$, (see Figure 15) of Wyodak coal at $32^{\circ}$ to $460^{\circ} \mathrm{C}$. The holding times at $460^{\circ} \mathrm{C}$ are given in parentheses. 

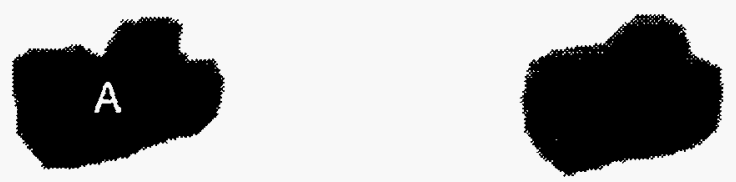

$32^{\circ} \mathrm{C}$

$150^{\circ} \mathrm{C}$
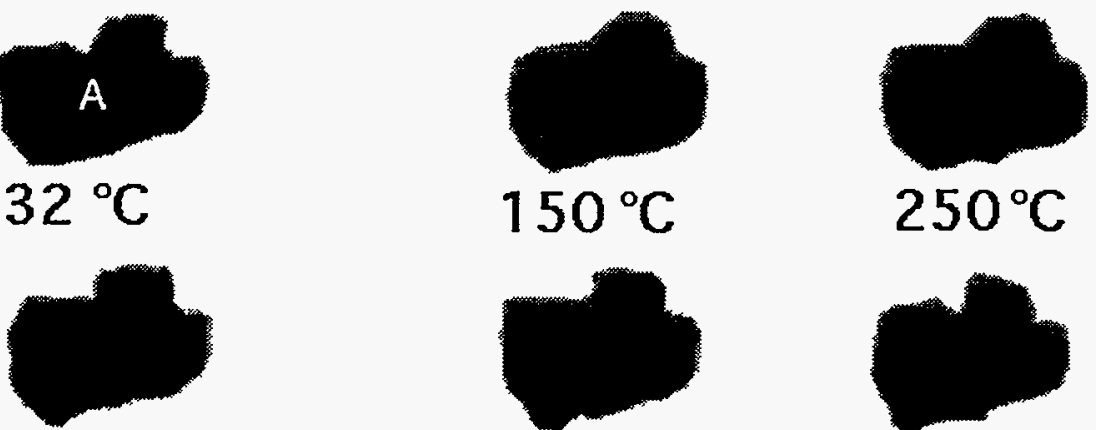

$301{ }^{\circ} \mathrm{C}$

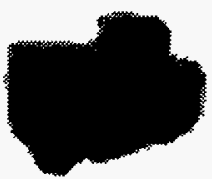

$250^{\circ} \mathrm{C}$

$351^{\circ} \mathrm{C}$

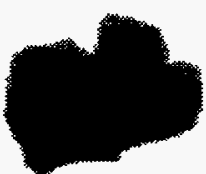

$400^{\circ} \mathrm{C}$
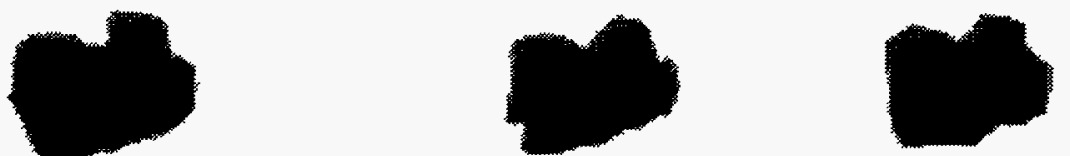

$425^{\circ} \mathrm{C}$

$452^{\circ} \mathrm{C}$

$460^{\circ} \mathrm{C}$
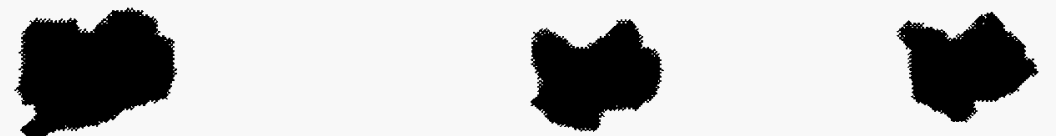

$460^{\circ} \mathrm{C}$

(5 min)

$460^{\circ} \mathrm{C}$ (20 min)

Figure 17. Particle A (see Figure 15) of Wyodak coal at $32^{\circ}-460^{\circ} \mathrm{C}$. The holding time at $460^{\circ} \mathrm{C}$ is given in parentheses. 
WYODAK
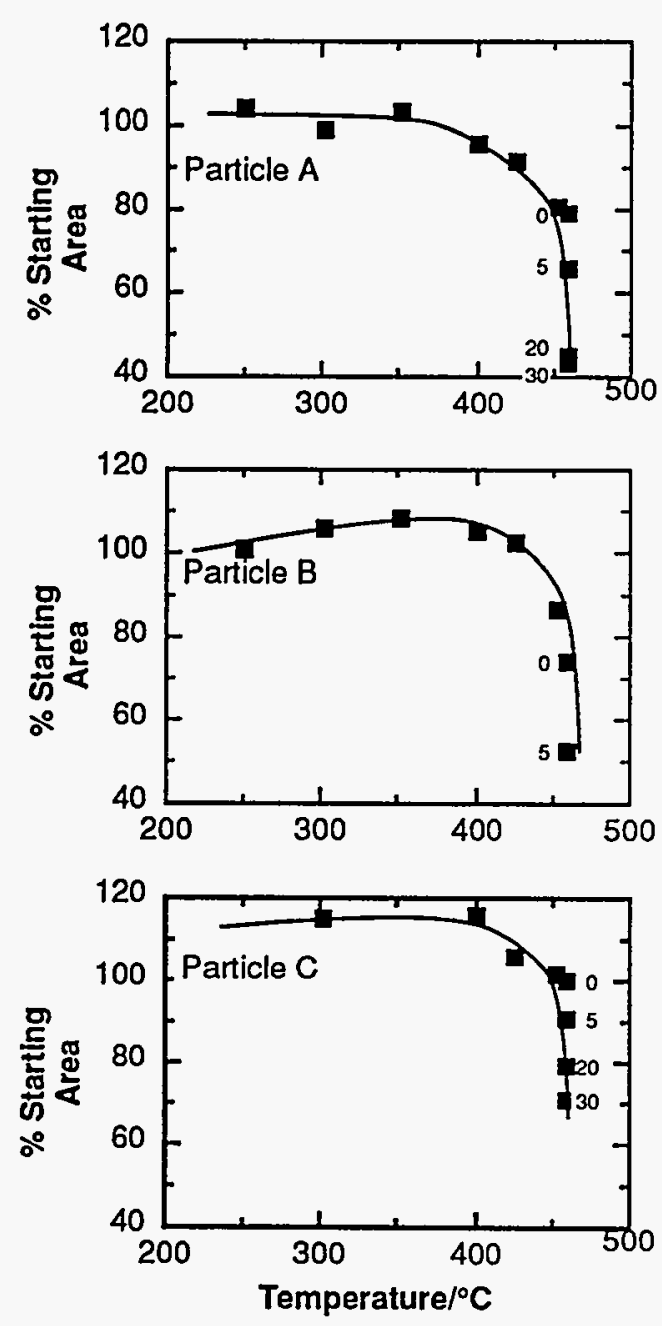

ILLINOIS NO. 6
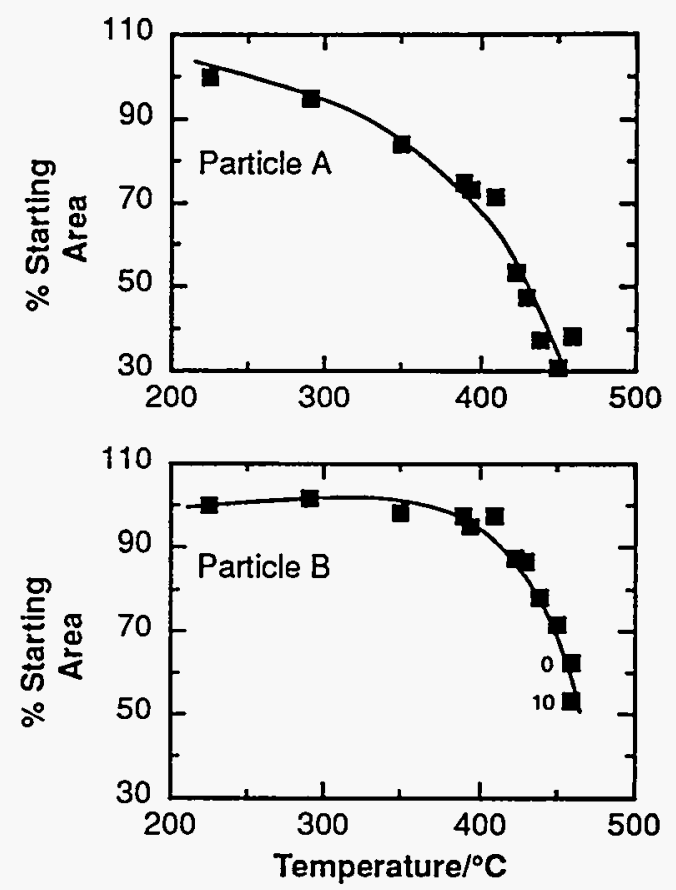

Figure 18. Size profiles for particles of Wyodak and Illinois No. 6 coal in Tetralin. The numbers within the plots are the holding times in minutes at $460^{\circ} \mathrm{C}$.

The findings for Wyodak coal are shown in Figure 21, which presents the starting condition and shows the three monitored particles, and Figure 22, which shows the changes in Particle A. The size profiles are included in Figure 23, which shows all three particles beginning to grow smaller at around $250^{\circ} \mathrm{C}$. The particles lose $20 \%-30 \%$ of their size up to about $350^{\circ} \mathrm{C}$, at which point there is curiously a brief reversal in the process. The shrinking then continues at higher temperatures at a very rapid rate.

The distinct effect of water seen in Figure 22 is very different from the more uniform shrinking seen in Tetralin in Figure 17, in which case the particle develops rounded edges and 
declines uniformly in size. In contrast the phenomenon in water appears as an erosion-like process, with some regions of the particle appearing more vulnerable to the process than others. Clearly this difference reflects a mode of reaction different from that with tetralin.

The images for the Illinois coal are shown in Figure 24, with changes in the boxed region assembled in Figure 25. The profile for Illinois coal in Figure 23 includes a duplicate of that for particle $\mathrm{C}$ in the Wyodak work, and the comparison shows that the effects of water on Illinois coal are initiated at higher temperatures.

The most significant difference, however, is the decided turnabout in behavior at around $450^{\circ} \mathrm{C}$. Unlike the case for Wyodak coal, the particle continues to increase in size and, while held at $450^{\circ}$, swells to proportions somewhat greater than those of the starting material. This activity is expressly seen in Figure 25, where the particle loses about 30\% of its cross sectional area in what clearly appears as an erosion-like process, then swelling dramatically with the production of a tar. The contrasts to the behavior in Figure 10 in argon and to the effects of Tetralin in Figure 20 are striking and reflect a major hydrothermolytic effect in bituminous coals. 


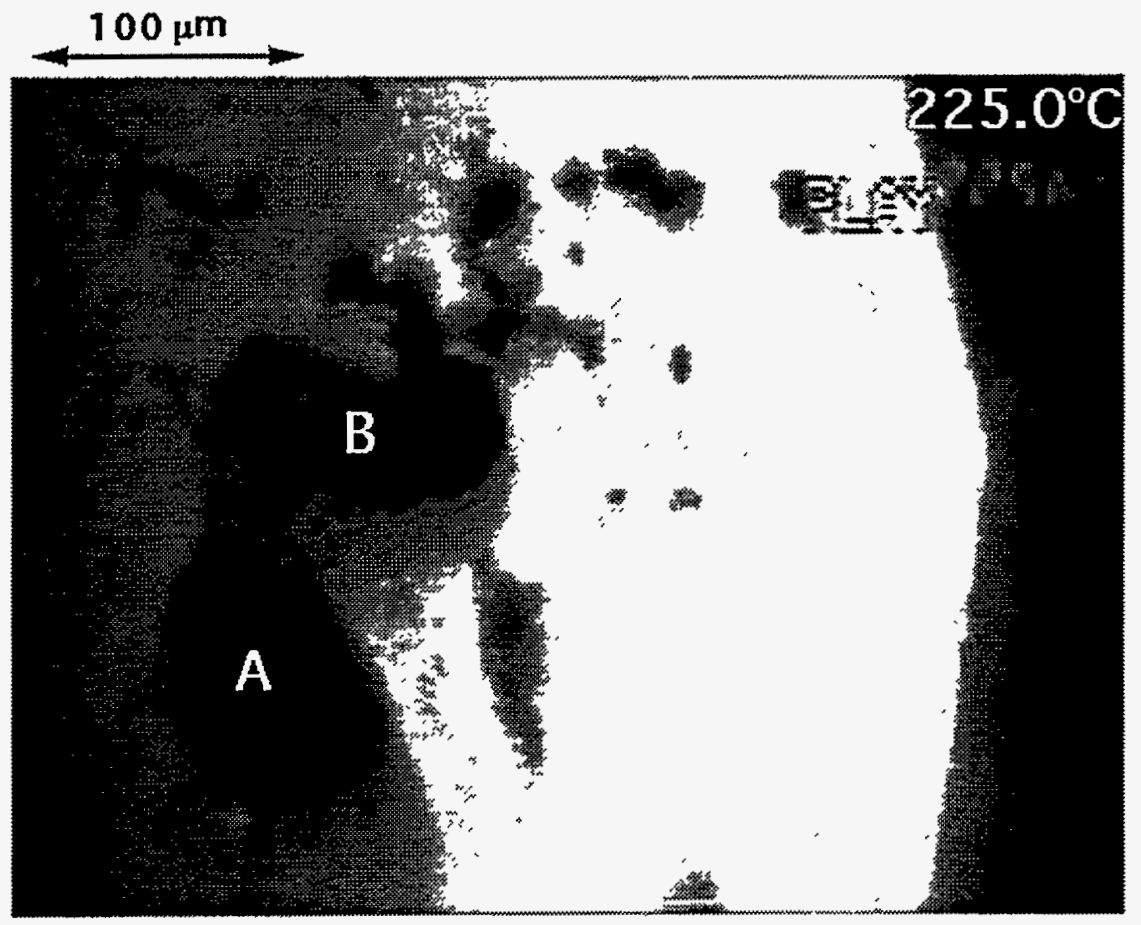

Figure 19. The initial image of the observation area at $225^{\circ} \mathrm{C}$ for an experiment in Tetralin with Illinois No. 6 coal at 3000 psi. 

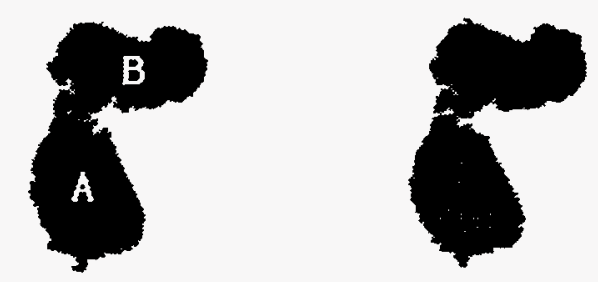

$225^{\circ} \mathrm{C}$
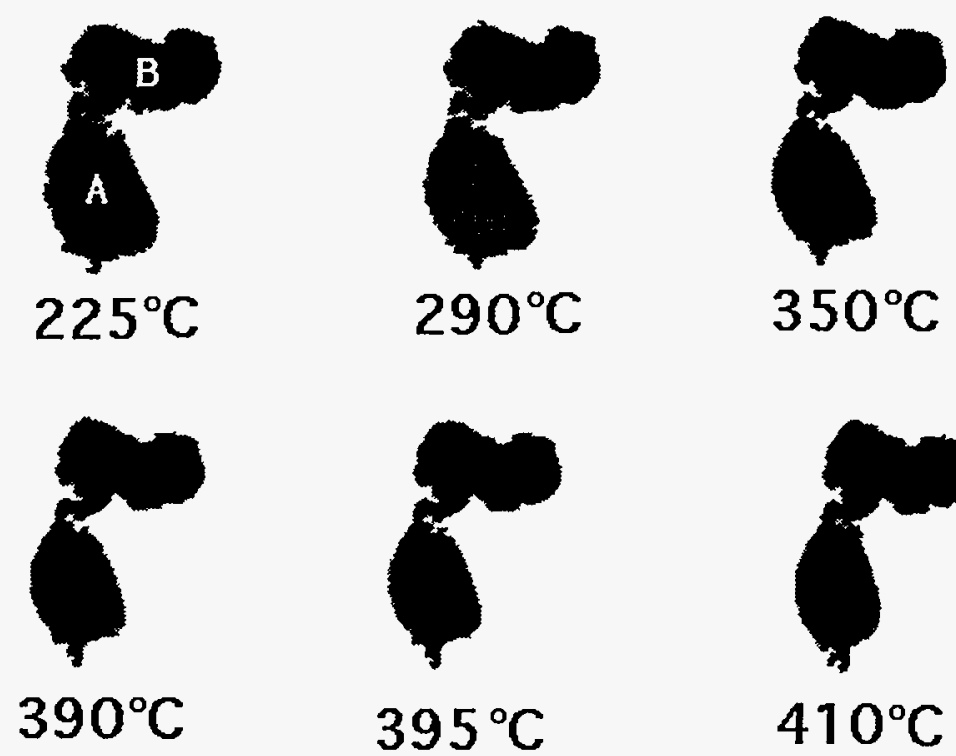

$395^{\circ} \mathrm{C}$
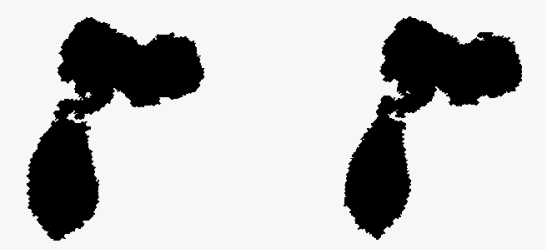

$424^{\circ} \mathrm{C}$

$430^{\circ} \mathrm{C}$
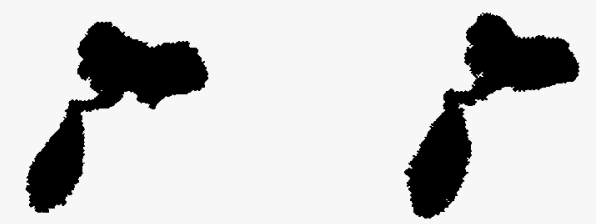

$450^{\circ} \mathrm{C}$
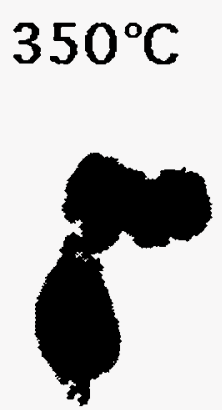

$410^{\circ} \mathrm{C}$

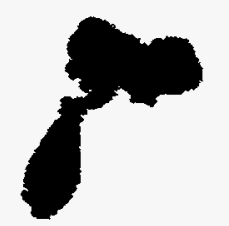

$440^{\circ} \mathrm{C}$

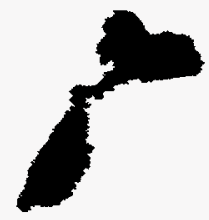

$460^{\circ} \mathrm{C}$ (10 min)

Figure 20. Particles (see Figure 19) of Illinois No. 6 in Tetralin at $225^{\circ}-460^{\circ} \mathrm{C}$. The second $460^{\circ} \mathrm{C}$ image is 10 minutes after the first. 


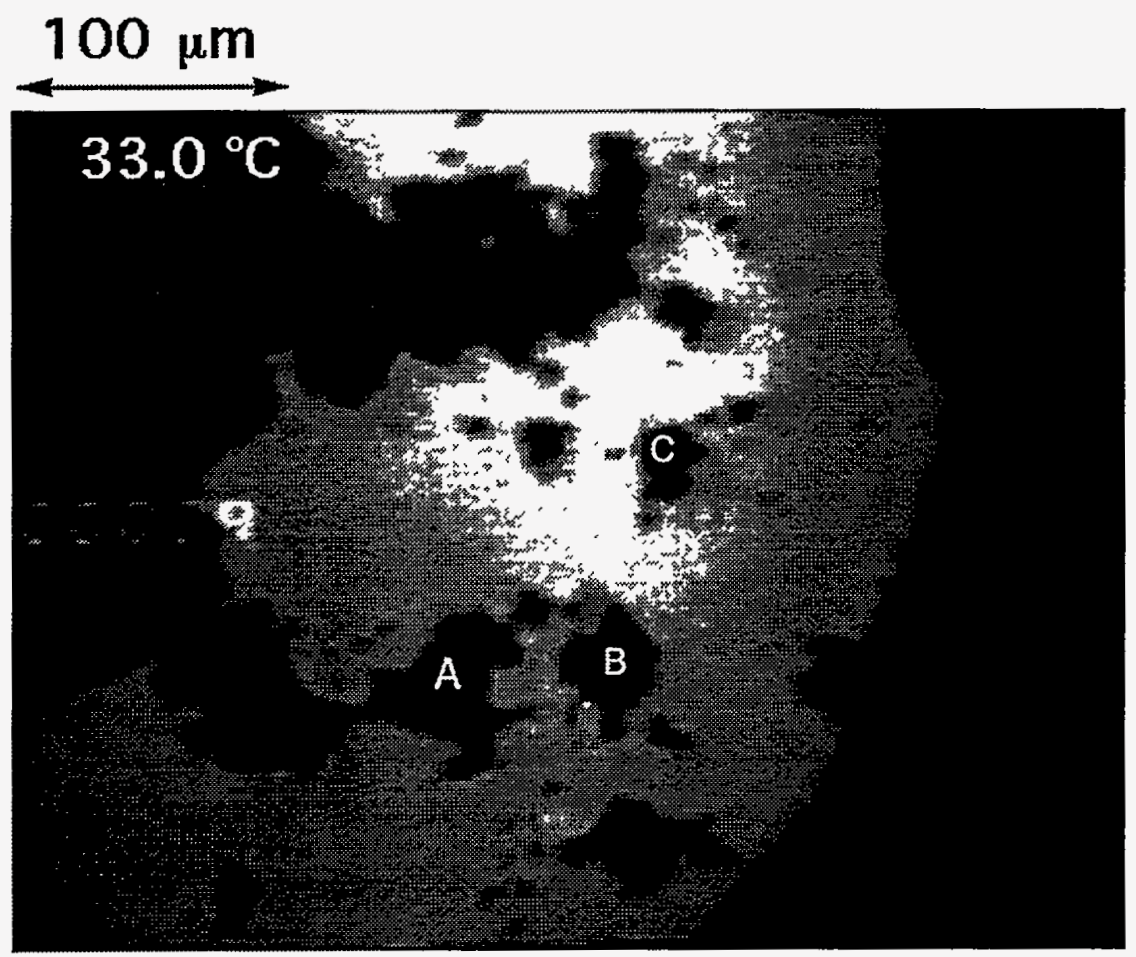

Figure 21. The initial image of the observation area at $33^{\circ} \mathrm{C}$ for an experiment in water with Wyodak coal at 3000 psi. Particles, A, B, and C are chosen for size analysis. 


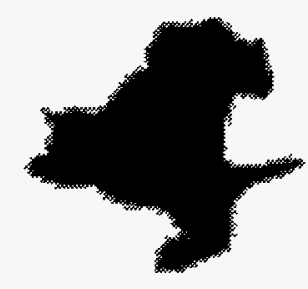

$33^{\circ} \mathrm{C}$

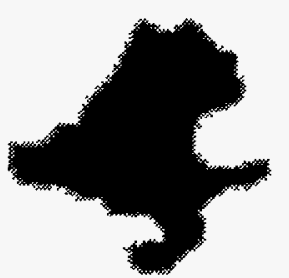

$300^{\circ} \mathrm{C}$

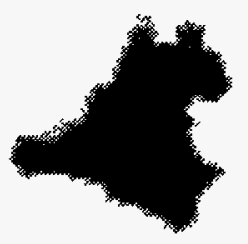

$373^{\circ} \mathrm{C}$

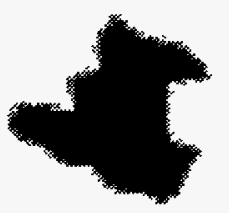

$440^{\circ} \mathrm{C}$

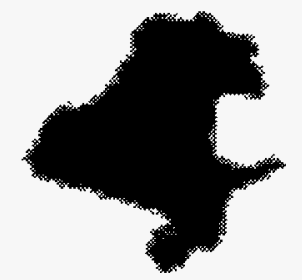

$100^{\circ} \mathrm{C}$

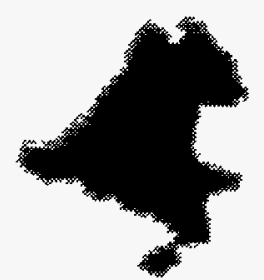

$330^{\circ} \mathrm{C}$

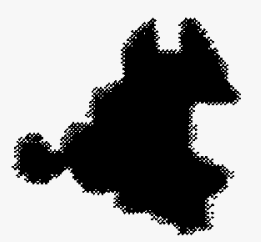

$400^{\circ} \mathrm{C}$

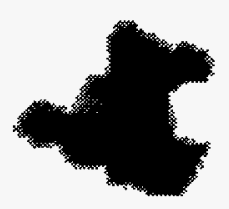

$450^{\circ} \mathrm{C}$

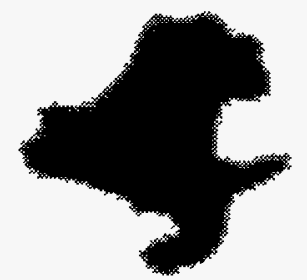

$208^{\circ} \mathrm{C}$

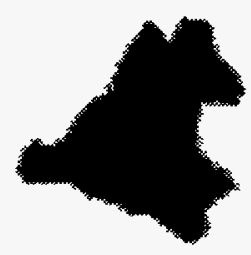

$352^{\circ} \mathrm{C}$

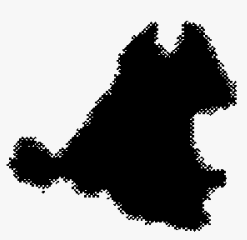

$420^{\circ} \mathrm{C}$

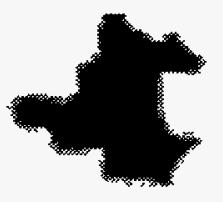

$460^{\circ} \mathrm{C}$

Figure 22. Particle A (see Figure 21) of Wyodak coal in water at $33^{\circ}-460^{\circ} \mathrm{C}$. 


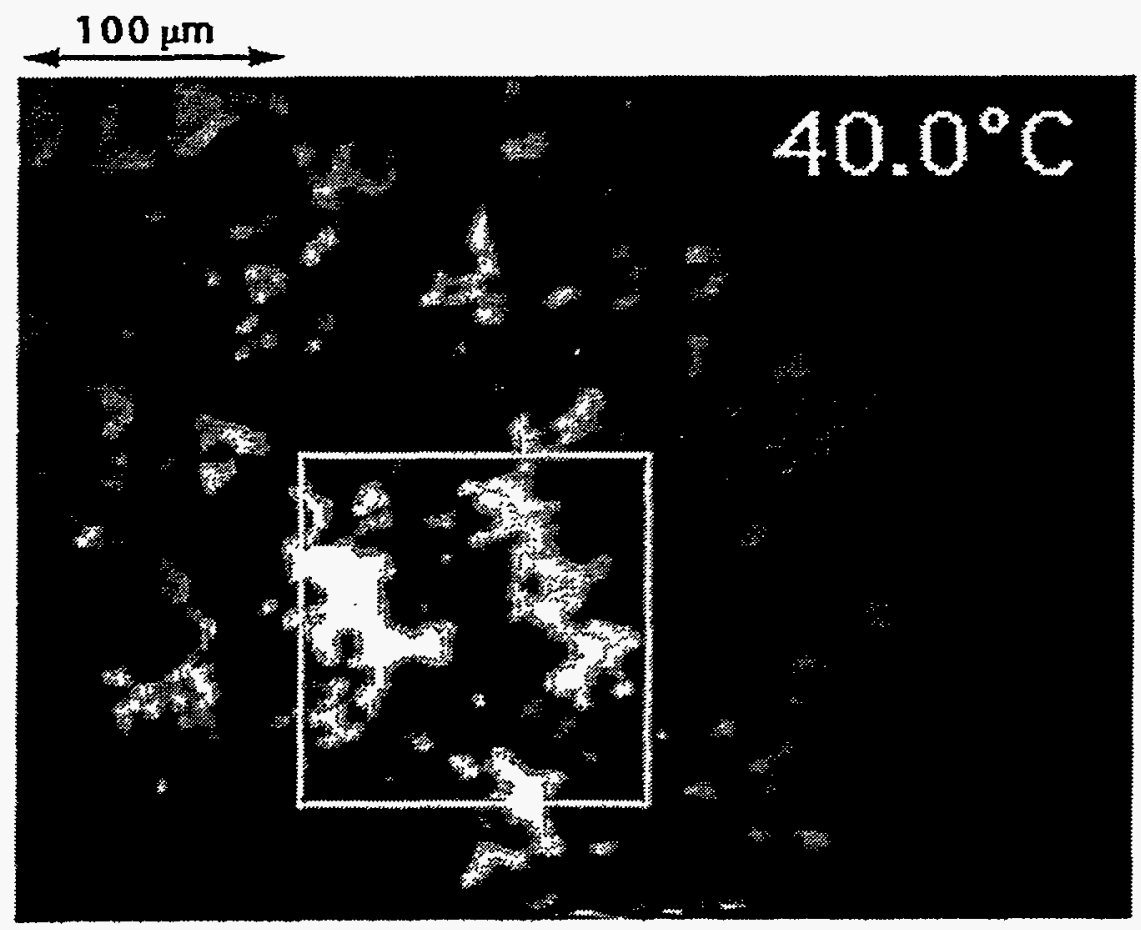

Figure 24. The initial image of the observation area at $40^{\circ} \mathrm{C}$ for an experiment in water with llinois No. 6 coal at 3000 psi. Particles selected for analysis are boxed. 


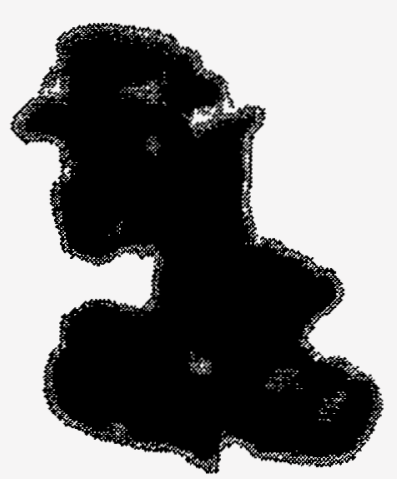

\section{$40^{\circ} \mathrm{C}$}

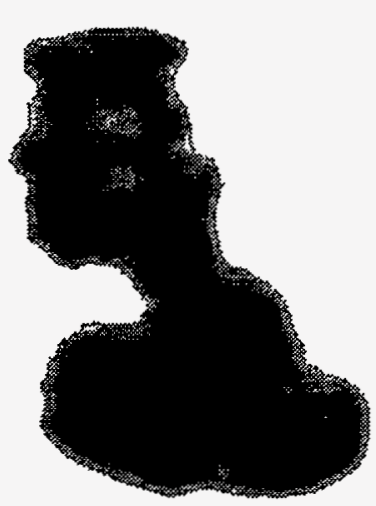

$382^{\circ} \mathrm{C}$
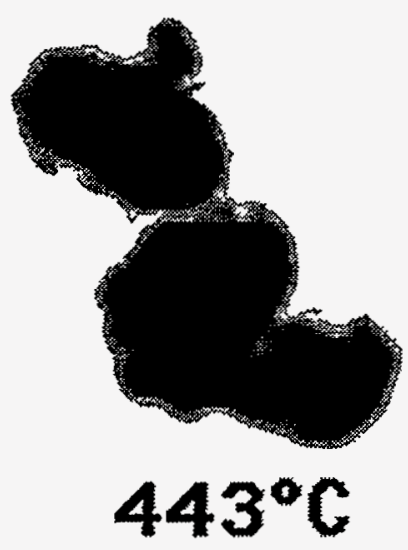

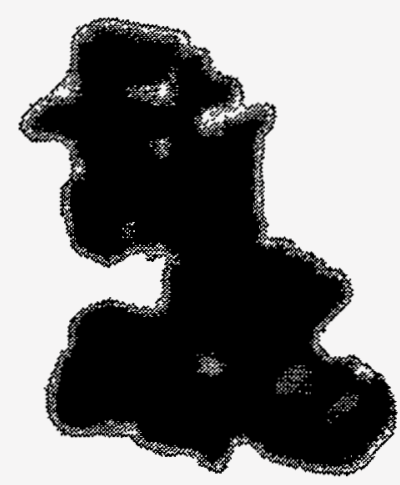

$250^{\circ} \mathrm{C}$

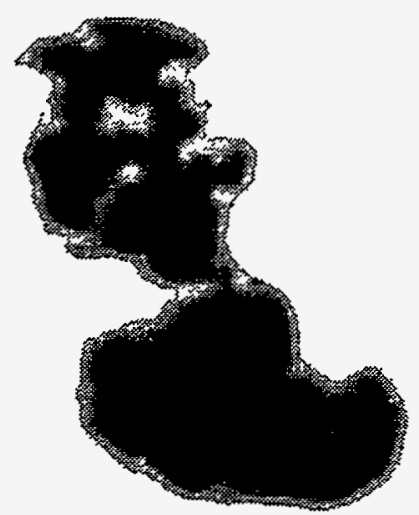

\section{$406^{\circ} \mathrm{C}$}

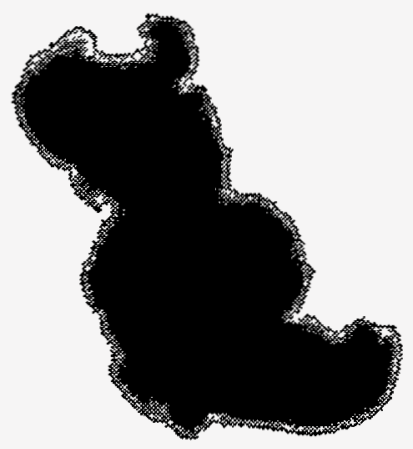

$450^{\circ} \mathrm{C}$

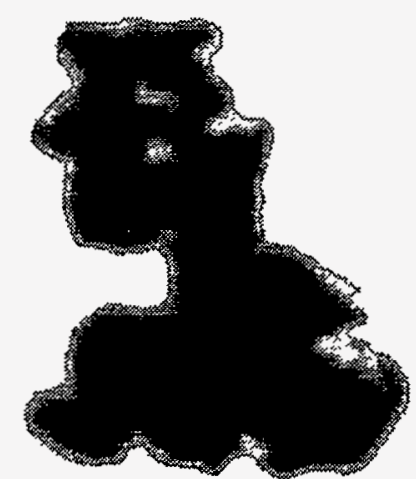

$355^{\circ} \mathrm{C}$

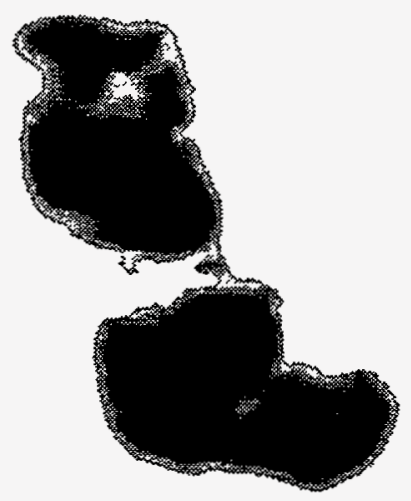

$435^{\circ} \mathrm{C}$

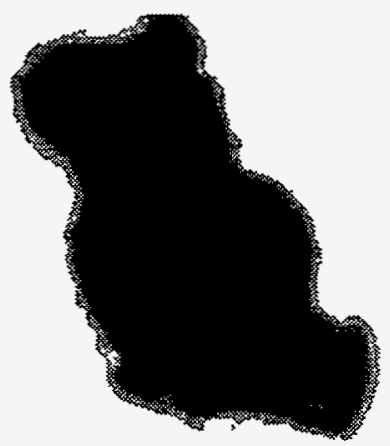

$450^{\circ} \mathrm{C}$

Figure 25. Particles (see Figure24) of Illinois No. 6 in water at $40^{\circ}-450^{\circ} \mathrm{C}$. The second $450^{\circ} \mathrm{C}$ image is 10 minutes after the first. 


\section{DISCUSSION}

A family of observations of the changes in coal with several media has been developed over the course of our program, with some differences but also some surprising similarities in the results for Illinois No. 6 and Wyodak coals. In summary we find that:

- The primary event in the heating of coal in argon is the production of tars, starting at around $300^{\circ} \mathrm{C}$. The process appears to be simple, rapid melting for some particles and a slower evolution for the major portions of the coal. That process is followed by an abrupt evaporation of the tars at $350^{\circ}-375^{\circ} \mathrm{C}$, leaving core particles with sizes and shapes similar to the starting particles.

- With undecane as medium, the coals are fully inactive visually to $460^{\circ} \mathrm{C}$.

- In tetralin, the coals are similarly inactive to around $420^{\circ} \mathrm{C}$. There, the coals abruptly begin to shrink, the particles rapidly losing about half of their cross sections as the heating continues to $460^{\circ} \mathrm{C}$.

- With water as the medium, the coals begin to shrink at about $250^{\circ}-300^{\circ} \mathrm{C}$, or at the same point they began to produce tar in argon. In these cases there is a difference in the coals, with the Wyodak coal shrinking to about half its size by $460^{\circ} \mathrm{C}$, and the Illinois No. 6 coal shrinking to about $70 \%$ of its starting size at $440^{\circ} \mathrm{C}$. In the latter case, the process suddenly reverses itself and the coal particles are seen to grow as if a tar were produced.

\section{PYROLYSIS IN AN INERT GAS}

To bring some understanding to these observations, it is useful to consider our earlier FIMS-based work (DOE Contract No. DE-AC22-89PC89880; Ross et al., 1991). The most prominent fragments seen in the pyrolysis of both coals are phenol ( 94 dalton) and the dihydroxybenzenes (110 dalton) and their methyl-substituted derivatives. The production of these fragments in the FIMS work with Wyodak coal is shown in Figure 26 along with the profile for the visual observation of tar in argon shown earlier. The correspondence between the profiles is clear and leaves little doubt that there is a connection between the two events. The same correspondence is seen for Illinois No. 6. It would appear, therefore, that the thermal production of tar is the result specifically of the thermolysis of the phenolics in the coal. 


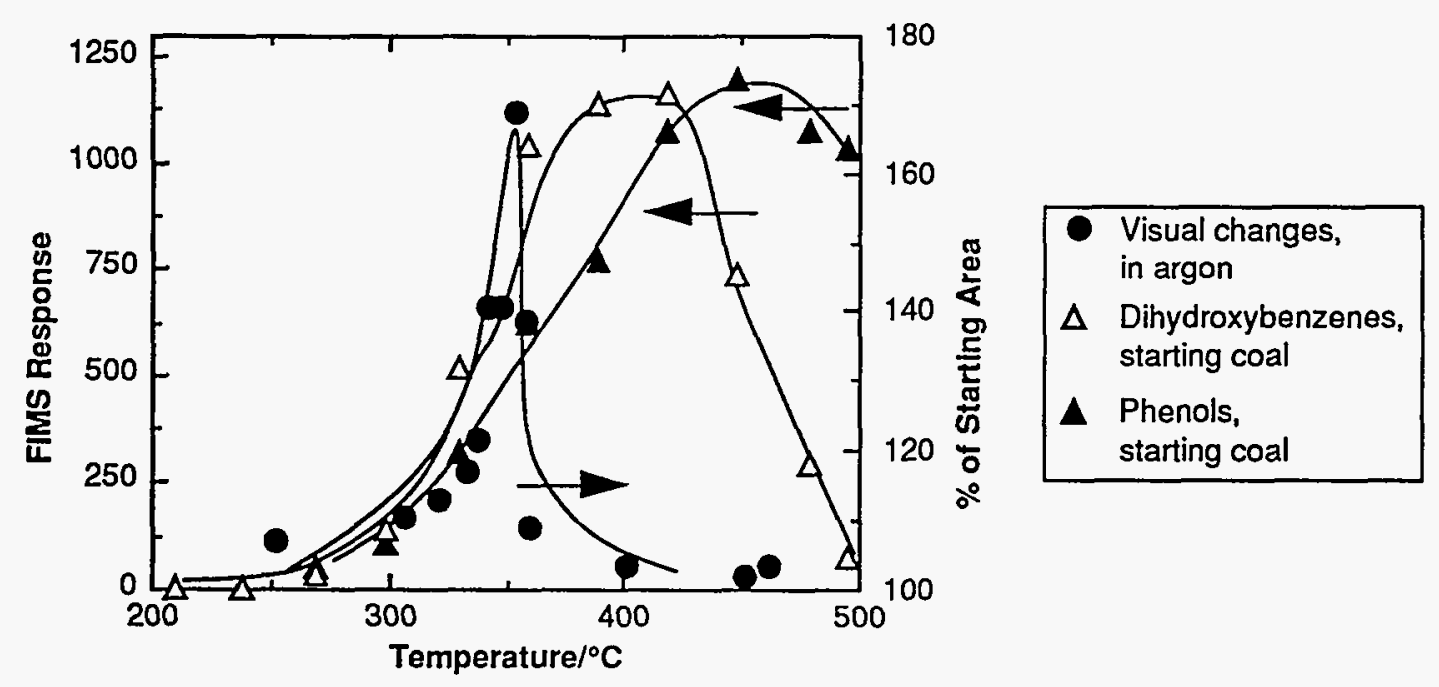

Figure 26. For Wyodak coal, FIMS profiles for 110 dalton (dihydroxybenzenes) and 94 dalton (phenols) and profile for Particle $A$ in argon. (The phenols response is multiplied by a factor of 2 for better comparison.)

This conclusion is not without some confusion, however, based on a comparison of our data with those of Solomon et al. (1990a), who conducted studies of coal pyrolysis using Fourier transform infrared spectroscopy. In that study a selection of Argonne coals including Wyodak were heated at $30^{\circ} \mathrm{C} / \mathrm{min}$ to $900^{\circ} \mathrm{C}$. The analyses provided records of production of a variety of products, including water and tars, and those data along with ours for tars appearance are presented in Figure 27.* The figure shows a satisfactory correspondence between the visual appearance of tars in our work and the production of water in the earlier study. (Large quantities of loosely bound water were released below $200^{\circ} \mathrm{C}$; shown here is the water produced just through pyrolytic processes.) Their tars production, on the other hand, occurred at temperatures around $50^{\circ} \mathrm{C}$ higher. A similar discrepancy occurs in comparison of our Illinois No. 6 data with those of Solomon et al. We have no explanation for the differences and leave the issue open for further consideration.

Our data, however, allow us to consider the common view that thermally promoted crosslinking follows tar evolution and is responsible for the increased viscosity and decreased fluidity that occurs with continued heating (Solomon et al., 1992). Our results are not consistent with that position. Rather they show that heated coal is not fully liquid, but rather a suspension of solid "core" particles in a melt. We see no evidence of charring or a thickening of the melt,

\footnotetext{
* Solomon et al. provided separate plots of temperature vs time and volatiles production vs time. For the discussion here we have converted their data to volatiles production vs time.
} 
which processes would reflect condensation reactions. Rather the melt simply evaporates, leaving the core particles behind.

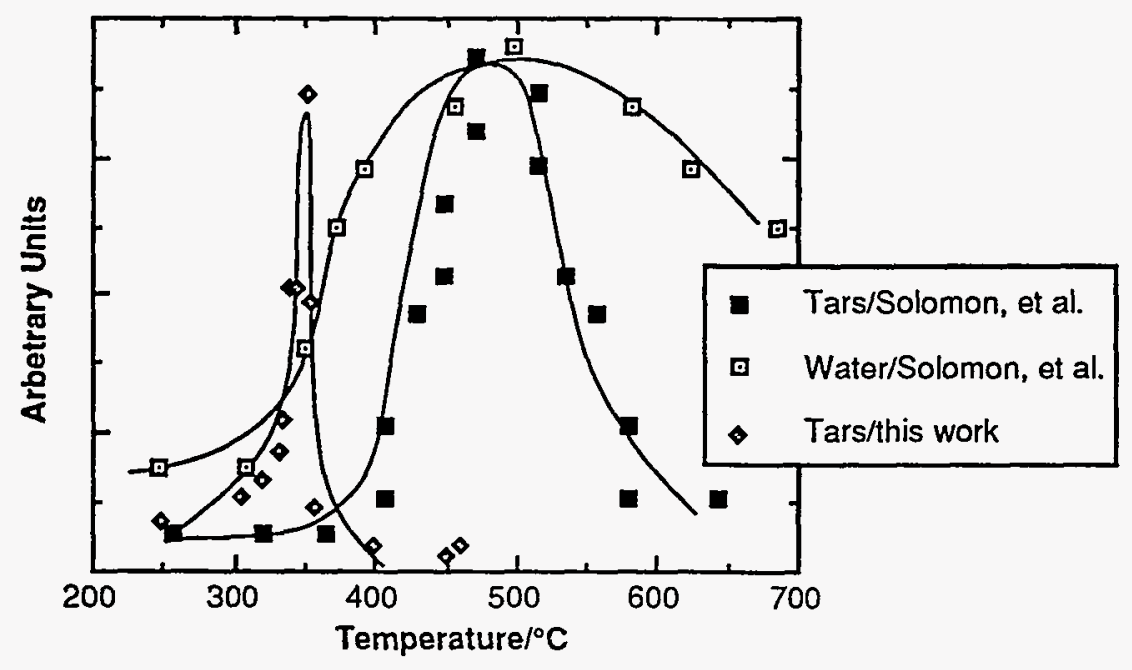

Figure 27. Comparison of the visual production of tar from this work for Wyodak coal, and the production of water and tars from the work of Solomon et al. (1990a).

The formation of coke, in other words, appears in our study to be simply the result of loss of the fluid tar phase. Cracking and condensation would be expected in extended heating in a confined system where evaporation would not take place; such processes would most likely take place at the particle surfaces tar interface. However, in the case of the pyrolysis of coal in an inert gas, we find the retention of the particle morphology throughout the process along with the "clean" evaporation of the tar supportive of a model for coal pyrolysis with little significant crosslinking chemistry.

\section{PYROLYSIS IN AN INERT ORGANIC MEDIUM}

Our observations in undecane can also be viewed in terms of our earlier FIMS data in Figure 28. The figure shows the developing volatility of the coal with increasing temperature for untreated Wyodak coal and for samples of the coal heated in undecane for both $30 \mathrm{~min}$ and $5 \mathrm{hr}$. The profiles for the untreated and briefly treated material are similar, while the coal from the extended treatment in undecane contains virtually no volatile material. Thus it appears that an organic medium traps the volatiles in the coal during extended heating. They undergo condensation and other polymerization reactions and ultimately become irreversibly incorporated 
into the bulk coal matrix. A similar scenario has been employed to explain the marked reduction in volatiles yields with increased applied pressure during coal pyrolysis (Solomon et al., 1993a).

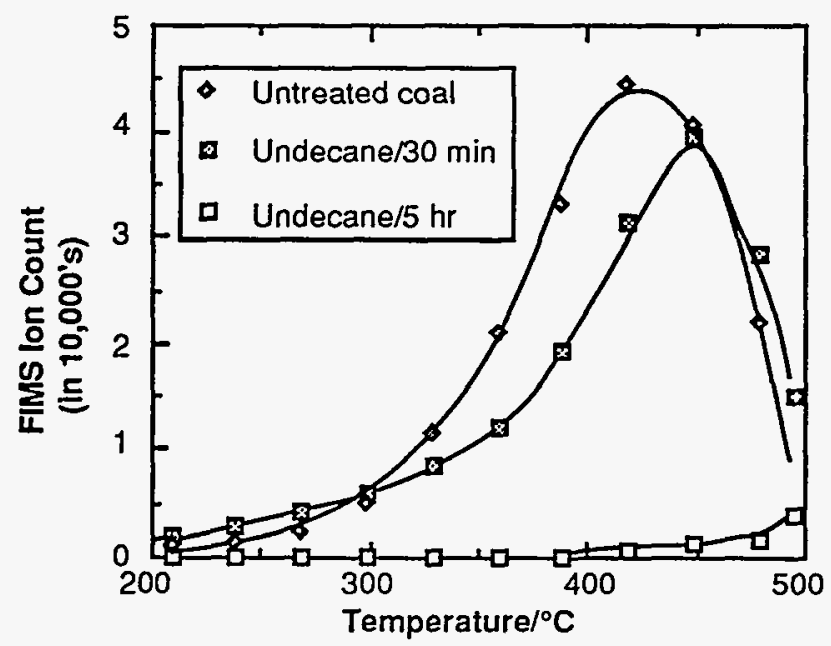

Figure 28. FIMS ion count profiles from the pyrolysis of samples of Wyodak coal in the inlet of the spectrometer. The undecane treatments were at $350^{\circ} \mathrm{C}$.

The tendency for thermal condensation of the dihydroxybenzenes, which as discussed above are the early and most prominent family of fragments from thermal and hydrothermal treatment, is apparent from FIMS data, which track the evolution of $(\mathrm{HO})_{2} \mathrm{C}_{6} \mathrm{H}_{4}$ (110 dalton). Figure 29 presents the profiles for $(\mathrm{HO})_{2} \mathrm{C}_{6} \mathrm{H}_{4}$ evolution for the untreated coal and the $30 \mathrm{~min}$ treated coal and shows that, despite the relatively unchanged volatiles quantity as just discussed, the brief heating severely reduces the $\left(\mathrm{HO}_{2} \mathrm{C}_{6} \mathrm{H}_{4}\right.$ quantities in those volatiles. The mono-, di-, and trimethyl- $(\mathrm{HO})_{2} \mathrm{C}_{6} \mathrm{H}_{4}$ and phenol derivatives show the same response. This decline thus appears to be the leading edge of the overall erosion in volatiles that takes place over longer heating periods in the presence of an organic medium. 


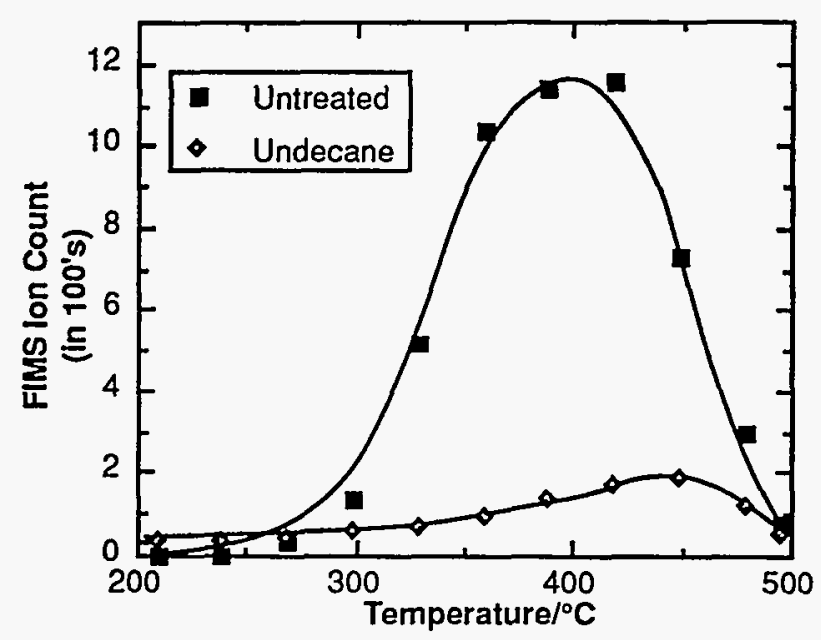

Figure 29. FIMS profiles for $\mathrm{C}_{6} \mathrm{H}_{4}(\mathrm{OH})_{2}$ evolution for untreated Wyodak coal, and for the same coal treated for $30 \mathrm{~min}$ in undecane at $350^{\circ} \mathrm{C}$.

These conclusions are supported in an account by Stein et al. (1989), who showed that at $400^{\circ} \mathrm{C}$ dihydroxybenzenes undergo rapid acid catalyzed condensations, the sites for which in coal would be at the mineral surfaces. For catechol they found that water was formed from $15 \%$ $20 \%$ of the consumed catechol, while the larger fraction underwent condensation to essentially "polycatechol," a nonvolatile residue.

\section{PYROLYSIS IN TETRALIN}

The similarity in the behavior of coal in undecane and tetralin up to $430^{\circ} \mathrm{C}$ in the present study suggests that organic media in general, presumably through lipophobic interactions between the hydrocarbon medium and the coal, tend to close or clog the pores through which the tars pass. We can conclude that the condensation reactions just discussed take place even in the presence of a conventional $\mathrm{H}$-donor medium.

It is emphasized that the dihydroxybenzene-linked tar evolution and the abrupt shrinking in tetralin, both demonstrated by both coals, are separated by $50^{\circ}-100^{\circ} \mathrm{C}$. There thus appears to be no direct link between the thermolysis leading to tar formation and liquefaction in a donor medium. This position is not in line with the common view that the liquefaction of coal is dependent upon the homolytic scission of weak links in the coal. That position is carried further by Solomon et al. (1992), who state that during liquefaction highly fluid coals "dissolve quickly in the process solvent so that further chemistry occurs by liquid-liquid interactions. ..." In fact we see no evidence of such a process for Illinois No. 6 coal, as inspection of Figure 20 shows. 
The coal appears to be fully intact throughout the heating period, little changed up to $420^{\circ} \mathrm{C}$, at which point the particles simply begin to shrink.

The question then emerging is how does tetralin convert coal, and it is of interest to consider the chemistry of tetralin rather than that of coal. Tetralin is thermally unstable, and as described by Poutsma (1987) it both isomerizes to methylindane and dehydrogenates to naphthalene in the liquid phase. Both reactions are very slow, with half lives at $450^{\circ} \mathrm{C}$ of tens of hours, but as Poutsma points out, the formation of naphthalene is autocatalytic, and as shown by de Vlieger et al. (1984), coal promotes the decomposition of tetralin. Thus the decomposition chemistry of tetralin, not well developed to our knowledge, could be key to our understanding liquefaction in H-donors.

A simple chain process can be proposed involving the hydronaphthyl radical $(\mathrm{IH} \cdot)$, which is formed by $\mathrm{H}$-abstraction from tetralin by some initiating radical and subsequent, rapid $\mathrm{H}_{2}$ loss.

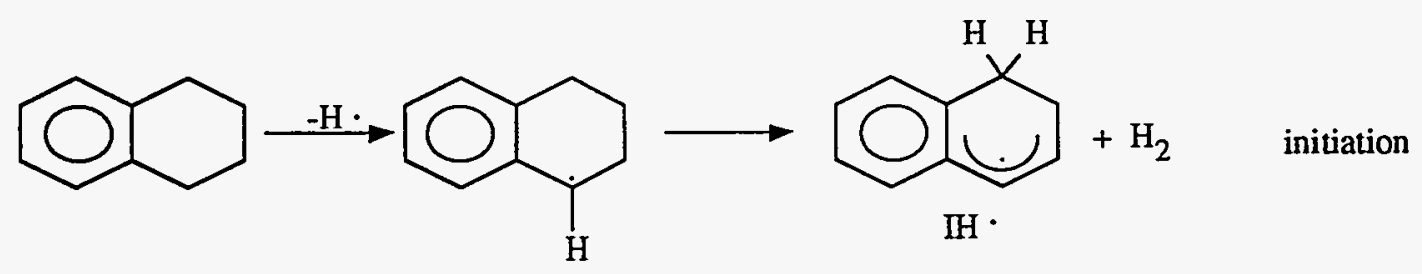

IH. should act as a good chain carrier in a process such as

$$
\begin{array}{cc}
\mathrm{IH} \cdot+\text { coal-coal } \rightarrow>\text { naphthalene }+ \text { coal-H }+ \text { coal } & \text { Propagation } \\
\text { coal }+ \text { tetralin } \rightarrow>\text { coal-H }+\mathrm{IH} \cdot+\mathrm{H}_{2} & \text { Propagation } \\
& \\
2 \mathrm{IH} \cdot-\rightarrow \rightarrow->\mathrm{H}_{2}+\text { binaphthyls } & \text { Termination } \\
\mathrm{IH} \cdot+\text { coal }-\rightarrow>\text { coal-IH } & \text { Termination }
\end{array}
$$

The $\mathrm{H}_{2}$ produced in each cycle can also play a role in the process, but it is probably minor. This sequence remains to be tested in additional work.

\section{PYROLYSIS IN WATER}

\section{Possible Synthesis of Organics}

Some of our results with water can be satisfactorily explained, recognizing that liquid water under hydrothermal conditions is both a highly diffusive medium and a very good solvent for organic compounds. (Naphthalene and liquid water are miscible in all proportions at $300^{\circ} \mathrm{C}$, 
for example; see accounts cited in Ross, 1984). Thus at around $300^{\circ} \mathrm{C}$ water will thoroughly penetrate the coal, and the thermally evolved tars, so readily apparent with argon as the medium, dissolve in the aqueous phase and are not visible.

However, our data suggest that the activity seen in water represents more than simple thermal evolution of tar. The particles remaining after heating in argon were similar in size to the respective starting particles, whereas in the case of water there was a net decrease in size for the Wyodak particles, and for Illinois No. 6 the particles shrank before growing again. These changes are undoubtedly related to the observations discussed above of enhanced liquid yields during coal pyrolysis following treatment by steam (Bienkowksi et al., 1987; Brandes and Graff, 1987a,b).

The Illinois No. 6 observations in particular are of interest (Figure 25). They suggest production of tar-like material at temperatures above about $435^{\circ} \mathrm{C}$. This activity might be simply explained through the decreasing density of water, which reduces its solvent capacity, forcing the dissolved tars out of solution. In that case, however, the tars would be deposited over the entire field of view, whereas the figure shows activity only around the particle.

It is tempting to suggest that the growth in particle cross section is evidence for hydrothermal synthesis of organic fluid from the bulk coal residue. We have proposed such a process to explain the production of petroleum hydrocarbons under hydrous pyrolysis conditions. Our rationale described in Appendix B, involves disproportion (internal oxidation and reduction) of kerogen in very hot water and in the presence of mineral components that promote electron transfer. As stated in the abstract of the paper in the Appendix, our "model views naturally occurring mineral buffers of oxygen fugacity in hydrothermal systems as sites where the redox can occur, and predicts that $\mathrm{CO}_{2}$ should accompany alkane generation. The process is very highly favored thermochemically, and is supported by recent experimental results described in the literature." Appendix B describes support for this model from hydrous pyrolysis work with Woodford shale, which showed production of both expelled oil and $\mathrm{CO}_{2}$ with water present, but virtually neither in control experiments with no water (Lewan, 1992).

There are in addition data from Solomon et al. (1990a) that support this suggestion for the case of coal. Their TG-FTIR work presented data for the evolution of water, $\mathrm{CO}_{2}$, and tars from Illinois No. 6 coal. Figure 30 shows that the three products are generated nominally simultaneously, in line with the view that tars and $\mathrm{CO}_{2}$ have a common origin tied to chemistry with water. Admittedly, the generation is over a rather broad temperature, and the data cannot be viewed as compelling. However, the accumulated data discussed in Appendices A and B provide 
intriguing support for a process involving the literal synthesis of alkanes. We view these data together with the final images in Figure 25 as suggestive of a hydrocarbon synthesis model in higher thermal environments, strongly tied in turn to action at the mineral-organic interface.

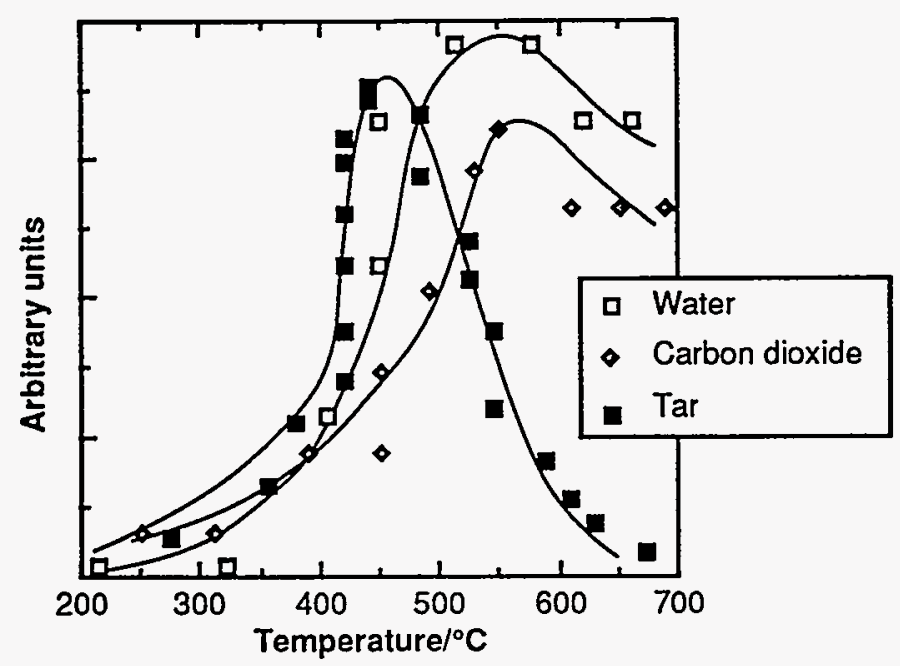

Figure 30. Profiles for production of water, carbon dioxide, and tar from lilinois No. 6 coal, from the TG-FTIR work of Solomon et al. (1990a).

\section{The Role of Mineral Matter at the Interface}

It is of interest to consider the choice of naturally occurring oxygen buffers operating in coal while under hydrothermal conditions. A convenient list by Barnes (1987) contains several candidates, and one suited to coal involves a pyrite/magnetite-pyrrhotite equilibrium.

$$
\begin{array}{ccc}
\text { Pyrite } & \text { Magnetite } & \text { Pyrrhotite } \\
{[1.5 /(0.5-x)] \mathrm{FeS}_{2}} & +\mathrm{Fe}_{3} \mathrm{O}_{4} \rightleftharpoons[3 /(0.5-\mathrm{x})] \mathrm{Fe}_{1-\mathrm{x}} \mathrm{S}+2 \mathrm{O}_{2}
\end{array}
$$

The process, stated as reversible at $>400^{\circ} \mathrm{C}$, can be viewed in the left-to-right direction as the oxidation of oxygen in magnetite by pyrite, which is reduced to pyrrhotite. The reverse reaction is of course the reduction of $\mathrm{O}_{2}$ back to its state in magnetite and the regeneration of pyrite.

Such a process can be recast as shown in eq's 2 and 3 to promote the net disproportionation shown in eq 4. 


$$
\begin{aligned}
& \text { 2) } \longrightarrow\left[1.5 /(0.5-\mathrm{x}) \mathrm{FeS}_{2}+\mathrm{Fe}_{3} \mathrm{O}_{4} \rightarrow 4 \mathrm{H}_{2} \mathrm{O}+[3 /(0.5-\mathrm{x})] \mathrm{Fe}_{1-\mathrm{x}} \mathrm{s}+2\right) \bigcirc \bigcirc \\
& {[3 /(0.5-x)] \mathrm{Fe}_{1-\mathrm{x}} \mathrm{S}+4 \mathrm{H}_{2} \mathrm{O}+4 \text { coal- } \mathrm{CH}_{2} \bigcirc \bigcirc \mathrm{coal}} \\
& \downarrow \\
& 4 \text { coal- } \mathrm{CH}_{3}+\mathrm{H} \bigcirc-\mathrm{coal}^{\prime}+[1.5 /(0.5-\mathrm{x})] \mathrm{FeS}_{2}+\mathrm{Fe}_{3} \mathrm{O}_{4}
\end{aligned}
$$

The global reactions, eqs 2 and 3, illustrate the principle of the cycling of the net oxidation state of the assemblage, and their accessibility, both thermochemically and kinetically, is still to be established. The former is calculable using software designed to provide thermochemistry for high temperature aqueous systems (Johnson, et al., 1992), and we are prepared to conduct such calculations should interest develop. Indeed we submit that calculations of the thermochemistry for similar processes using the full range of minerals present in coals would be a profitable exercise.

The mineral phases in eqs 2 and 3 promote the shuttling of hydrogen, with water as the carrier. The oxidation is eq 2 is in line with the known oxidation of coal by pyrite, producing pyrrhotite (Cleyle et al., 1984; Bommannavar et al., 1982). The reduction in eq 3 is less easily tied to recognized processes, although it is attractive to consider radical cation- or radical anionbased chemistry leading to the hydrogenolysis taking place on the mineral surfaces. This area of study, with focus on processes in the organic-mineral interfacial region in coal, could be a rewarding exercise. 


\section{REFERENCES}

Barnes, H. L., 1987. "Appendix -- Buffers for $\mathrm{pH}$ and Redox Control of Hydrothermal Systems," in Hydrothermal Experimental Techniques, G. Ulmer and H. L. Barnes, Eds., (John Wiley and Sons, New York), p.p. 505-514.

Bienkowksi, P. R., Narayan, R., Greenkorn, R. A., and Chao, K-C., 1987. "Enhanced Coal Liquefaction with Steam Pretreatment," Ind. Eng. Chem. Res., 26, 202-205.

Bommannavar, A. and Montano, P., 1982. "Mossbauer Study of the Thermal Decomposition of $\mathrm{FeS}_{2}$ in Coal," Fuel, 61, 523-528.

Brandes, S. D., and Graff, R. A., 1987a. "Investigation of the Nature of Steam Mediated Coal," Am. Chem. Soc. Div. of Fuel Chemistry Preprints, 32_(3), 385-393.

Brandes, S. D., and Graff, R. A., 1987b. "Modification of Coal by Subcritical Steam: Pyrolysis and Extraction Yields," Energy and Fuels, 1, 84-88.

Cleyle, P., Caley, W., Stewart, I., and Whiteway, S., 1984. "Decomposition of Pyrite and Trapping of Sulfur in a Coal Matrix during Pyrolysis of Coal," Fuel, 63, 1579-1582.

de Vlieger, J. J., Keiboom, A., and van Bekkum, H., 1984. "Behavior of Tetralin in Coal Liquefaction," Fuel, 63, 334-340.

Ergun, S., O'Donnel, H., and Parks, B., 1959. "Microscopic Studies of Rate of Thermal Decomposition of Petrographic Components of Coal," Fuel, 38, 205-210.

Habermehl, D., Orywal, F., and Beyer, H-D., 1981. "Plastic Properties of Coal" in Chemistry of Coal Utilization, Second Supplementary Volume, M. A. Elliott, Ed. (J. Wiley and Sons, New York).

Howard, J., 1981. "Fundamentals of Coal Pyrolysis and Hydropyrolysis" in Chemistry of Coal Utilization, Second Supplementary Volume, M. A. Elliott, Ed. (J. Wiley and Sons, New York).

Johnson, J., Oelkers, E., and Helgeson, H., 1992. "SUPCRT92: A Software Package for Calculating the Standard Molal Thermodynamic Properties of Minerals, Gases, Aqueous Species, and Reactions from 1 to $5000 \mathrm{Bar}$ and 0 to $1000^{\circ} \mathrm{C}$," Computers and Geosciences, 18, 899-947.

Kahn, M. R., Chen, W-Y., and Suuberg, E., 1989. "Influence of Steam Pretreatment on Coal Composition and Devolatization," Energy and Fuels, $\underline{3}$, 223-230.

Kelemen, S., Vaughn, S., Gorbaty, M., and Kwiatek, P., 1993. "Transformation Kinetics of Organic Sulfur Forms in Argonne Premium Coals during Pyrolysis," Fuel, 72 $\mathbf{2}$ 645-653. 
Lee, C., Scaroni, A., and Jenkins, R., 1991a. "Effect of Pressure on the Devolitization and Swelling Behavior of a Softening Coal during Rapid Heating," Fuel, 70, 957-965.

Lee, C., Jenkins. R., and Schobert, H., 1991b. "Mechanisms and Kinetics of Rapid, Elevated Pressure Pyrolysis of Illinois No. 6 Bituminous Coal," Energy and Fuels, 5, 547-555.

Lewan, M. D. (1992). "Water as a Source of Hydrogen and Oxygen in Petroleum Formation by Hydrous Pyrolysis," American Chemical Society Division of Fuel Chemistry Preprints, 37 (4), 1643-1649.

Poutsma, M. L., 1987. "A Review of Thermolysis Studies of Model Compounds Relevant to Processing of Coal," Report No. ORNL/TM-10637, Oak Ridge National Laboratory, p.p. 133-136.

Rofer, C. K., 1990. "Supercritical Fluid Oxidation of Hazardous Wastes," Progress Report for Nov. 16 - Dec. 15, 1990, to J. Wander, Tyndall AFB (Contract No. not available).

Ross, D. S., 1984. "Coal Conversion in CO-Water Systems" in Coal Science, Vol. 3, M. Gorbaty, J. Larsen, and I. Wender, eds., Academic Press, Inc., Orlando, p.p. 301338.

Ross, D., Loo, B., Tse, D., and Hirschon, A., 1990. "The Effects of Hydrothermal Treatment on Wyodak Coal," American Chemical Society Division of Fuel Chemistry Preprints, 35 (2), 352-363.

Ross, D., Loo, B., Tse, D., and Hirschon, A., 1991. "Hydrothermal Treatment and the Oxygen Functionalities in Wyodak Coal", Fuel, 70, 289-295.

Solomon, P., Serio, M., Carangelo, R., and Bassilakis, R., Gravel, D., Baillargeon, M., Baudais, F., and Vail, G., 1990a. "Analysis of the Argonne Premium Coal Samples by Thermogravimetric Fourier Transform Infrared Spectroscopy," Energy and Fuels, 4, 319333.

Solomon, P., Serio, M., Despande, G., and Kroo, E., 1990b. "Cross-Linking Reactions during Coal Conversion," Energy and Fuels, 4 (1), $42-54$.

Solomon, P., Hamblen, D., Serio, M., Yu, Z., and Charpenay, S., 1991. "Can Coal Science be Predictive?" (Storch Award Presentation), Prepr. Paper-Am. Chem. Soc., Div. Fuel Chem., 36(1), 267-300.

Solomon, P. Best, Yu, Z., and Charpenay, S., 1992. "An Empirical Model for Coal Fluidity Based on a Macromolecular Network Pyrolysis Model," Energy and Fuels, 6, 143-154.

Solomon, P., Fletcher, T., and Pugmire, R., 1993a. "Progress in Coal Pyrolysis," Fuel, 72 (5), 587-597.

Solomon, P., Hamblen, D., Serio, M., Yu, Z., and Charpenay, S., 1993b. "A Characterization Method and Model for Predicting Coal Conversion Behavior," Fuel, 72, 469-488.

Stein, S. E., Wang, F., and Senthilnathan, V. P., 1989. In Proceedings of the 1989 International Conference of Coal Science (International Energy Agency), pp. 165-168. 
Vorres, K. S., 1989. "Users Handbook for the Argonne Premium Coals Sample Program," Office of Basic Energy Sciences, US DOE Contract No. W-31-109-ENG-38. 


\section{APPENDIX A \\ HYDROTHERMAL MEDIA, OIL SHALE, AND COAL* \\ David S. Ross \\ SRI International \\ Menlo Park, CA 94025 USA}

Keywords: hydrous pyrolysis, Wyodak, hydrothermal

\section{INTRODUCTION}

Hydrous pyrolysis has proved to be useful tool for the study of accelerated petroleum generation in source rocks. The technique uses liquid water as a medium at thermolytic conditions in the $290^{\circ}-360^{\circ} \mathrm{C}$ range (Lewan et al., 1979; 1981). Dry pyrolysis provides olefins in the pyrolysate, but with the addition of water the olefin yield is reduced and $\mathrm{n}$-alkanes resembling those in petroleum emerge. Hoering (1984) extended the work using $\mathrm{D}_{2} \mathrm{O}$, developing the results discussed below. The claim that hydrous pyrolysis mimics the natural process has been questioned recently (Monthioux et al., 1985; Tannenbaum and Kaplan, 1985; Comet et al., 1986). Nonetheless there is little question that the chemistry operating at hydropyrolysis conditions generates alkanes and other hydrocarbons from the immature source material.

The lack of understanding of the chemistry at hydrothermal conditions is underscored by several observations. For example, highly condensed polynuclear aromatic hydrocarbons (PAHs) including pyrene, benzpyrenes, and coronene are found in hydrothermal vent petroleums (Simoneit, 1985; 1988). These compounds are commonly observed as products of hydrocarbon pyrolysis above $550^{\circ} \mathrm{C}$, and coronene itself is not generated in pyrolyses at temperatures below $650^{\circ} \mathrm{C}$ (Commins, 1969). However, it is difficult to explain their presence in the vent zones where temperatures are considerably lower.

Another curious point is the unusually high rate of epimerization of biological markers in hydrous pryolysis. Although cationic centers generated on highly acidic clay surfaces could be responsible (Alexander et al., 1984), the acidity of the clay sites is substantially reduced in an

\footnotetext{
* Presented at the 204th American Chemical Society national meeting, held in Washington, DC, Aug. 2328, 1992.
} 
aqueous environment (Tannenbaum and Kaplan, 1985), and the high acidities required for epimerization at the rates observed cannot be present. The activity of acid clay sites can be questioned further because of the presence of normal alkanes, whereas acid-promoted cationic chemistry should produce highly branched alkanes. Calcium carbonate has also been suggested as significant to the isomerization (Eglinton et al., 1986), but the mechanistic aspects of that process are not apparent.

The role of water in the maturation process has not been clearly defined. It has been suggested that water transfers hydrogen to organic free radicals in the reaction mixture (Monthioux et al., 1985; Hoering, 1984; Comet et al., 1986).

$$
\mathrm{R} \cdot+\mathrm{H}_{2} \mathrm{O} \rightarrow \mathrm{HO} \cdot+\mathrm{R}-\mathrm{H}
$$

However, this reaction is endothermic by $25-30 \mathrm{kcal} / \mathrm{mol}$ and should not be significant at hydrous pyrolysis temperatures.

In the discussion here we seek to develop some understanding of the chemical processes in hydrous pyrolysis by first modeling the results of Hoering in $\mathrm{D}_{2} \mathrm{O}$. Some of that work has been recently reviewed (Ross, 1992), and the results are summarized here. We then seek to extend this view to the chemistry of coal, discussing our findings in studies of Argonne samples of Wyodak coal in hydrothermal media (Ross et al., 1990a,b). We begin with a summary of the nature of the medium at hydrous pyrolysis conditions.

\section{RESULTS AND DISCUSSION}

\section{The Nature of the Hydrothermal Medium}

Under common conditions, water is a highly polar, fluid medium accommodating ionic salts and having a modest capacity for dissolving some gases and polar organic compounds. However, liquid water near its critical point $\left(374^{\circ} \mathrm{C} / 220 \mathrm{~atm}\right)$ becomes a very different medium. The shifts in the key physical properties of liquid water up to its critical temperature are presented in Figure 1, with the shaded portion representing the region where hydrous pyrolysis is commonly conducted. The figure shows that, while the density of the medium stays in the liquid-like region ( $>0.3 \mathrm{~g} / \mathrm{mL}$ ) over most of the subcritical regime, the viscosity falls early to very low, almost gas-like, values. The net result is an interesting region where the medium has a liquid-like solvent capacity combined with a very high gas-like diffusivity. The mobilities of 
both neutral and charged solutes are much higher than they are in normal liquids, overcoming what could be mass transfer limitations at more conventional conditions.

The dielectric constant falls to levels like that of organic solvents, dramatically affecting the solubilities of organic materials. Thus naphthalene, virtually insoluble in water at ambient conditions, it is miscible in all proportions in liquid water at temperatures as low as $300^{\circ} \mathrm{C}$ (Jockers and Schneider, 1978). Fully homogeneous combinations of ionic salts and nonpolar organics, which might not be feasible at common conditions, can easily be established at these conditions (Alwani and Schneider, 1969).

\section{Hydrous Pyrolysis with $\mathrm{D}_{2} \mathrm{O}$-- The Results of Hoering}

Hoering's data (1984) on the D-content in the n-alkanes from the treatment of preextracted Messel shale with $\mathrm{D}_{2} \mathrm{O}$ at $330^{\circ} \mathrm{C} / 3$ days have been used to model the process (Ross, 1992). The profiles for the heptadecane recovered from the treatment are shown in Figure 2, which also shows the results of control experiments in which heptadecane was purposely added to the treatment mixture and for heptadecane recovered from work in which heptadecene was initially added. In the latter, $60 \%$ of the added olefin was recovered as alkane, a remarkable result reflecting a considerable reducing potential in the reaction mixture, and requiring an explanation.

The added alkane does not undergo much exchange, and the fact that the kerogengenerated alkane is very highly exchanged rules out preexisting alkane as the source. The olefingenerated alkane contains considerable deuterium, but the distribution pattern is very different from that for the kerogen-derived material.

A process reconciling these facts is shown as Scheme I. The scheme features the view that water is significant to the reduction of olefins generated pyrolytically from the kerogen. The general arrangement was confirmed in modeling work done employing an integration routine based on the Gear algorithm (Moore and Pearson, 1981) and operated on a VAX 11/750 computer. The fit, shown in Figure 3, was generated for a reaction rates alignment in which reduction $\gg$ pyrolysis and exchange $\approx 2 \mathrm{x}$ pyrolysis. It is emphasized that for the fit, it is necessary that reduction requires water, but produces protio alkane. The alkane then exchanges with the medium, presumably likely on the mineral surface. 


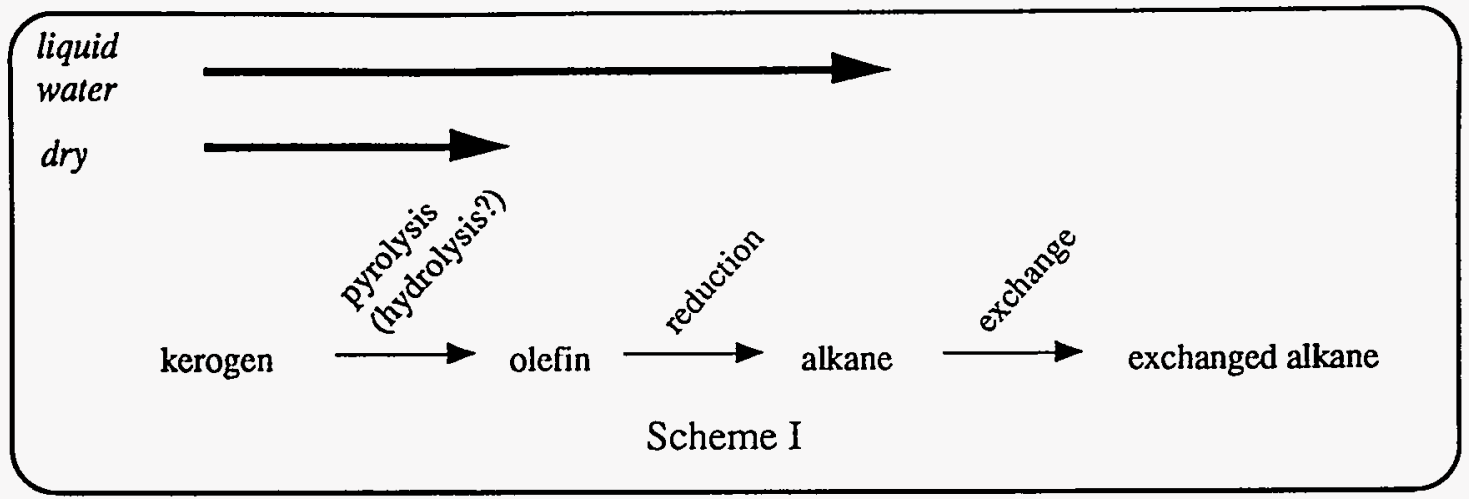

A key question concerns the reduction step; there are no obvious reducing species introduced into the reaction. A clue to that chemistry may lie in the results of Amin (1975), who studied the pyrolysis of glucose in water at its critical point. Data from the study in Table I show that the pyrolysis yields char, an oil, and gases including $\mathrm{CO}, \mathrm{CO}_{2}, \mathrm{H}_{2}$, and $\mathrm{CH}_{4}$. Significantly, however, as the density of the medium is increased from a gas-like value to one more liquid-like, the quantity of gas and oil increase substantially with a corresponding decrease in the char yield. Factors associated with the increased density appear to promote reduction of the starting glucose and formation of simple gases.

Table I. Products from the Pyrolysis of Glucose in Water $\left(374^{\circ} \mathrm{C} / 30 \mathrm{~min}\right)$ Fraction of Starting C (\%)

\begin{tabular}{ccccc} 
& & & Solid & Gas \\
\cline { 3 - 5 } Pressure (atm) & Density $(\mathrm{g} / \mathrm{mL})$ & Oil & 68.9 & 3.4 \\
152 & 0.07 & 27.8 & 8.5 & 9.5 \\
\hline
\end{tabular}

Hoogwater (1991) reports similar findings in the pyrolysis a series of haloorganic compounds in supercritical water at liquid densities. The results for trichloroethane are shown in Figure 4. These experiments, conducted in sealed quartz tubes and therefore eliminating metal wall-promoted reactions, yielded surprisingly large quantities of $\mathrm{CO}, \mathrm{CO}_{2}, \mathrm{H}_{2}$, and a collection of hydrocarbons including alkanes and benzene. 
These data suggest that liquid water in the near critical region or supercritical water at liquid densities promotes gasification reactions. Such conversions are essentially the waterpromoted disproportionation of carbon, i.e.,
modestly oxidized organics
$\rightarrow$ highly reduced products
+ highly oxidized products
e.g. olefins, phenols
alkanes, $\mathrm{H}_{2}$
PAHs, $\mathrm{CO}, \mathrm{CO}_{2}$

They could be the basis of alkane production in petroleum genesis. We are unaware of studies confirming such chemistry and submit that this area is an important one for development.

\section{Hydrous Pyrolysis of Wyodak Coal}

Our earlier accounts of this work described the effects of the treatment of Argonne samples of Wyodak coal with liquid water (hydrothermal) and with no medium (under $\mathrm{N}_{2} /$ thermal) at $250^{\circ}-350^{\circ} \mathrm{C}$ for periods of $30 \mathrm{~min}$ and $5 \mathrm{hr}$ (Ross et al., 1990a). Much of the data were developed using thermal gravimetric analysis (TGA) and SRI's field ionization mass spectrometer (FIMS), both operating from ambient to $500^{\circ} \mathrm{C}$ at $2.5^{\circ} \mathrm{C} / \mathrm{min}$. A later report included additional results from studies in which water was replaced by n-undecane, a hydrocarbon with a critical temperature $\left(363^{\circ} \mathrm{C}\right.$, estimated by the method of Lydersen, 1955) near that of water $\left(374^{\circ} \mathrm{C}\right)$, and expected to be chemically unreactive over at least the 30-min heating period (Ross et al., 1990b).

A tar representing 5\%-7\% of the starting coal was consistently deposited on the quartz insert walls solely at the hydrothermal conditions. There was no evidence of tar in the thermal and undecane runs. In all cases the coal lost oxygen, with O-losses falling in the order:

hydrothermal $(5 \mathrm{hr})>[$ hydrothermal $(30 \mathrm{~min}) \approx \operatorname{thermal}(30 \mathrm{~min}) \approx$ thermal $(5 \mathrm{hr})]>$ undecane $(30 \mathrm{~min})$

Some properties of the recovered coal and the tars are presented in Table II.

Our earlier accounts discussed these data; however two features are of specific interest here. The first is that the hydrothermally promoted tars are at the same time more volatile and of a greater molecular weight than the FIMS-volatile products from the recovered coals. They are also considerably richer in hydrogen. They are thus substantially less polar, and it is tempting to view these results as parallel to those for hydrocarbon production in the hydrous pyrolysis of petroleum source rock and due to water-promoted reduction chemistry. 
These data suggest that liquid water in the near critical region or supercritical water at liquid densities promotes gasification reactions. Such conversions are essentially the waterpromoted disproportionation of carbon, i.e.,

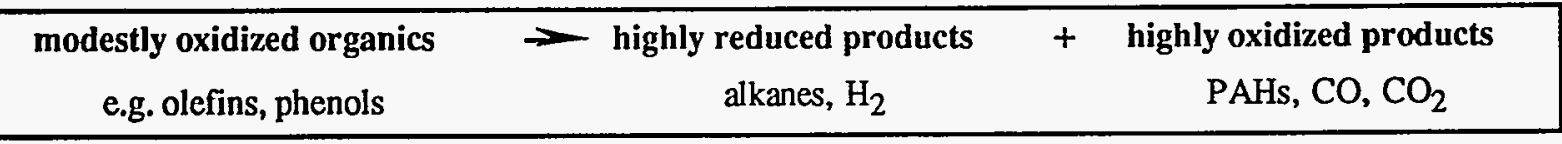

They could be the basis of alkane production in petroleum genesis. We are unaware of studies confirming such chemistry and submit that this area is an important one for development.

\section{Hydrous Pyrolysis of Wyodak Coal}

Our earlier accounts of this work described the effects of the treatment of Argonne samples of Wyodak coal with liquid water (hydrothermal) and with no medium (under $\mathrm{N}_{2}$ /thermal) at $250^{\circ}-350^{\circ} \mathrm{C}$ for periods of $30 \mathrm{~min}$ and $5 \mathrm{hr}$ (Ross et al., 1990a). Much of the data were developed using thermal gravimetric analysis (TGA) and SRI's field ionization mass spectrometer (FIMS), both operating from ambient to $500^{\circ} \mathrm{C}$ at $2.5^{\circ} \mathrm{C} / \mathrm{min}$. A later report included additional results from studies in which water was replaced by $n$-undecane, a hydrocarbon with a critical temperature $\left(363^{\circ} \mathrm{C}\right.$, estimated by the method of Lydersen, 1955) near that of water $\left(374^{\circ} \mathrm{C}\right)$, and expected to be chemically unreactive over at least the 30 -min heating period (Ross et al., 1990b).

A tar representing 5\%-7\% of the starting coal was consistently deposited on the quartz insert walls solely at the hydrothermal conditions. There was no evidence of tar in the thermal and undecane runs. In all cases the coal lost oxygen, with O-losses falling in the order:

hydrothermal $(5 \mathrm{hr})>[$ hydrothermal $(30 \mathrm{~min}) \approx$ thermal $(30 \mathrm{~min}) \approx$ thermal $(5 \mathrm{hr})]>$ undecane $(30 \mathrm{~min})$

Some properties of the recovered coal and the tars are presented in Table II.

Our earlier accounts discussed these data; however two features are of specific interest here. The first is that the hydrothermally promoted tars are at the same time more volatile and of a greater molecular weight than the FIMS-volatile products from the recovered coals. They are also considerably richer in hydrogen. They are thus substantially less polar, and it is tempting to view these results as parallel to those for hydrocarbon production in the hydrous pyrolysis of petroleum source rock and due to water-promoted reduction chemistry. 
Table II Some Properties of the Recovered Coals and Tars

Treatment

Period Starting Coal Hydrothermal Thermal Undecane

$\mathrm{H} / \mathrm{C}$

$\begin{array}{ccccc} & 0.90 & & & \\ 30 \mathrm{~min} & -- & 0.82 & 0.83 & 0.81 \\ 5 \mathrm{hr} & -- & 0.72 & 0.76 & 0.75 \\ & & 1.13(\operatorname{tar}) & & \end{array}$

$\mathrm{O} / \mathrm{C}^{\mathrm{a}}$

0.24

$5 \mathrm{hr}$

0.16

0.15

0.18

0.12

0.16

0.18 (tar)

$T_{1 / 2}\left({ }^{\circ} \mathrm{C}\right)^{b}$

$\begin{array}{ccccc}-- & 395-400 & - & -- & - \\ 30 \mathrm{~min} & -- & 340-350 & 377-395 & 405 \\ & & 200 \text { (tar) } & & \\ 5 \mathrm{hr} & -- & 410 & 425 & 465 \\ & & 140 \text { (tar) }\end{array}$

$\bar{M}_{w} c$

\begin{tabular}{ccccc}
-- & $403-411$ & -- & -- & -- \\
$30 \mathrm{~min}$ & -- & $410-421$ & $329-380$ & 373 \\
& & $393(\operatorname{tar})$ & & \\
$5 \mathrm{hr}$ & -- & 332 & 308 & 201 \\
& & $432(\operatorname{tar})$ & & \\
\hline
\end{tabular}

a. Oxygen determined by direct $O$-analysis.

b. The temperature at which one-half of the FIMS volatiles has passed into the instrument.

c. Weight average molecular weight. 
The second feature is the volatility changes shown in Figure 5, which displays the total FIMS ion count versus evaporation temperature for samples for both 30-min and 5$\mathrm{hr}$ treatments. The profile for the untreated coal is also presented for comparison. (FIMS mass analysis begins at $\mathrm{m} / \mathrm{e} 48$, and so the profiles are independent of the evolution of water and carbon dioxide; they reflect solely organic volatiles.) For the 30 -min treatment, the undecane result is little different from that for the untreated coals. The thermally pretreated sample shows the presence of volatiles beginning to emerge at around $100^{\circ} \mathrm{C}$; however, these materials must be the thermolytically volatiles generated during the pretreatment. They are deposited on the coal and then evaporated into the instrument during the FIMS heating.

The aqueous pretreatment, however, clearly has produced new material. The ordinate in the figure is logarithmic and thus the absolute quantities of product are significantly greater than for the thermal case. This new material would seem to be the portion of the tar that condensed on the coal rather than on the insert walls.

For the 5-hr treatment little of the tar remains on the coal, and the hydrothermal and thermal results are similar. Note from Table II that the tar has become considerably more volatile with little change in the molecular weight. We found in addition by FIMS that the arenol content of the 30-min tar was less than 30\% that of the treated coals. The arenols in the 5-hr tar were reduced yet further by another factor of $3 .^{*}$ Continued hydrothermal treatment appears to provide extended reduction and to convert phenols to less polar material.

Remarkably, the undecane treatment has drastically reduced the volatility of the coal, essentially converting it to a char. The shaded portion of the figure reflects the loss in volatile material, those fractions becoming irreversibly reincorporated into the coal matrix.

\section{CONCLUSIONS}

The effects of water on the thermolysis of coal suggest a process similar to that in Scheme I for petroleum source rock (Scheme II). As in I, water promotes reduction of the initial pyrolytic products, and tar is the result. The scheme shows that extended hydrothermal treatment substantially increases the volatility of the tar.

\footnotetext{
${ }^{*}$ The arenol content is the sum of the FIMS signals for phenol, dihydroxybenzene, and their respective $\mathrm{C}_{1^{-},}, \mathrm{C}_{2-}$, and $\mathrm{C}_{3}$ - derivatives.
} 
In the absence of added water, there is a pyrolytic release of material, including olefins and large quantities of phenolic material. These fragments will migrate to other regions of the coal and will probably concentrate at the mineral sites due to acid/base interactions. At this point the recent results of Stein et al. (1989) can apply. Their work showed that at $400^{\circ} \mathrm{C}$ dihydroxybenzenes are very reactive and undergo acid catalyzed dehydroxylation and condensation. For coal, with distributions of clay and silica particles throughout the organic phase in sizes down perhaps to the nanometer level (Allen and VanderSande, 1984), we can expect significant degrees of such retrogressive chemistry.

For undecane, the process is even more retrogressive. Neither water nor alkanes are good coal swelling media at ambient temperatures, the former because it is too polar, and the latter

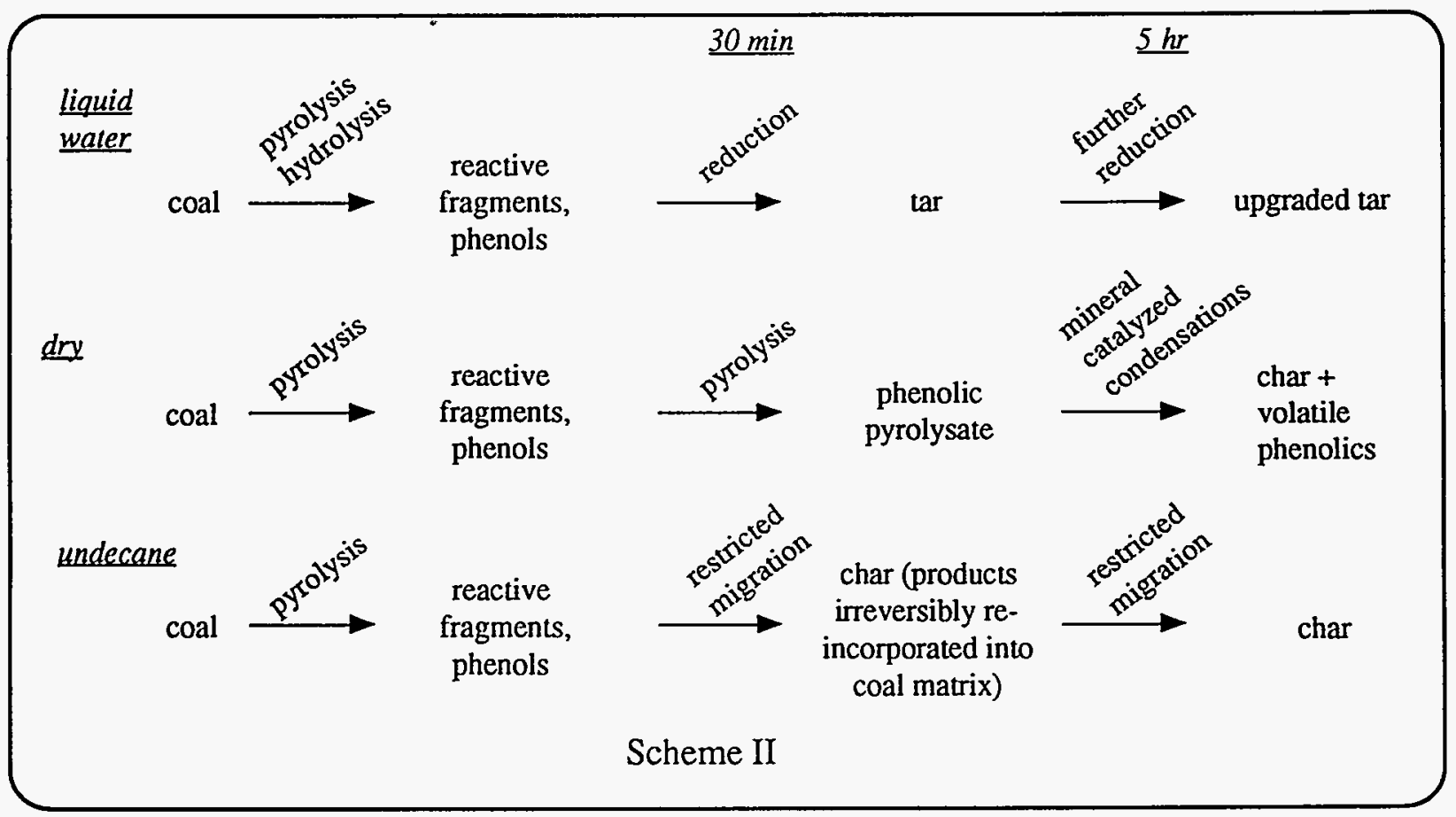

because it is not polar enough. However, water becomes increasingly more coal-accommodating in the hydrothermal region because its dielectric constant decreases to values like those for polar organic liquids (Jockers and Schneider, 1978). Undecane, in contrast, likely becomes an even poorer solvent or in effect an antisolvent. In that medium coal should thus not swell but possibly collapse, a negative solvent action discussed for polymers by Magda et al. (1988). Such a 
tendency for the coal would trap otherwise volatile fractions, resulting ultimately in their irreversible reincorporation into the coal matrix and the formation of char. As a consequence, the arenols will increasingly react within the cage.

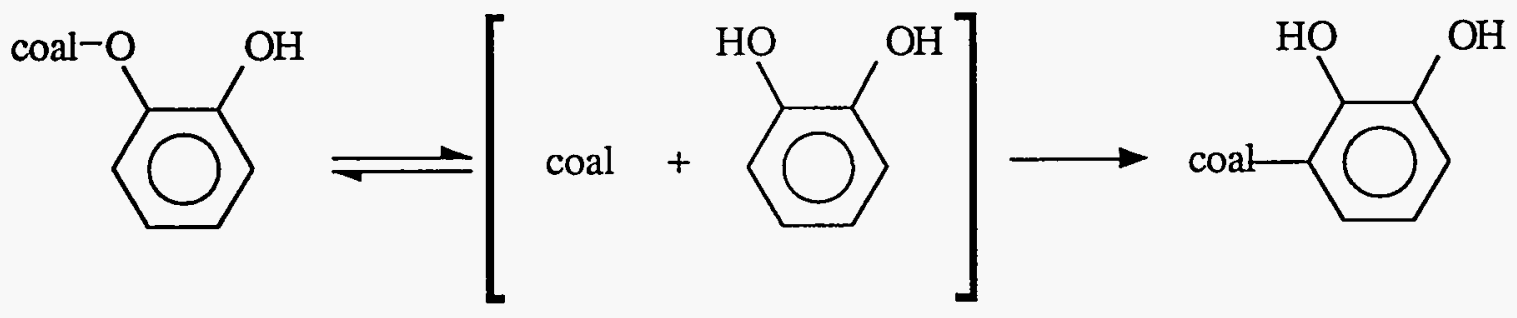

The essential component of this process is the replacement of labile, aryl ether links by stable, $\mathrm{C}$-aryl bonds. That activity ultimately leads to the accumulation of structures that will tend to condense with further heating and proceed to char. Such alkane-promoted condensation chemistry is clearly an undesirable component in conversion generally. Its regressive action, however, could be most seriously encountered in coprocessing, and additional studies in this area could prove profitable.

\section{ACKNOWLEDGMENT}

We acknowledge support of the US DOE for the coal-related portion of this work. 


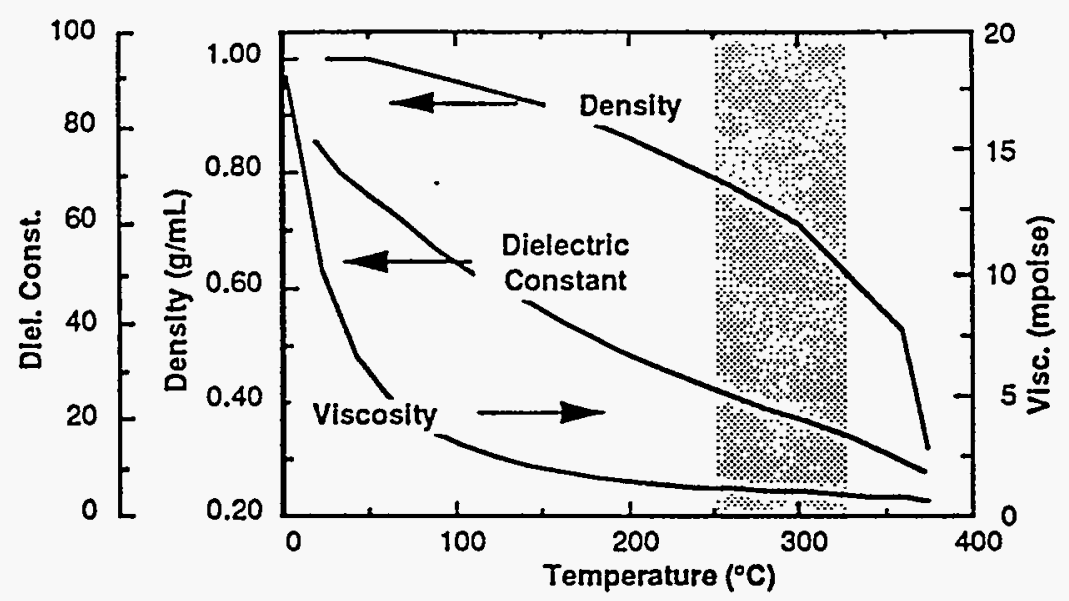

Figure 1. Some key properties of liquid water.

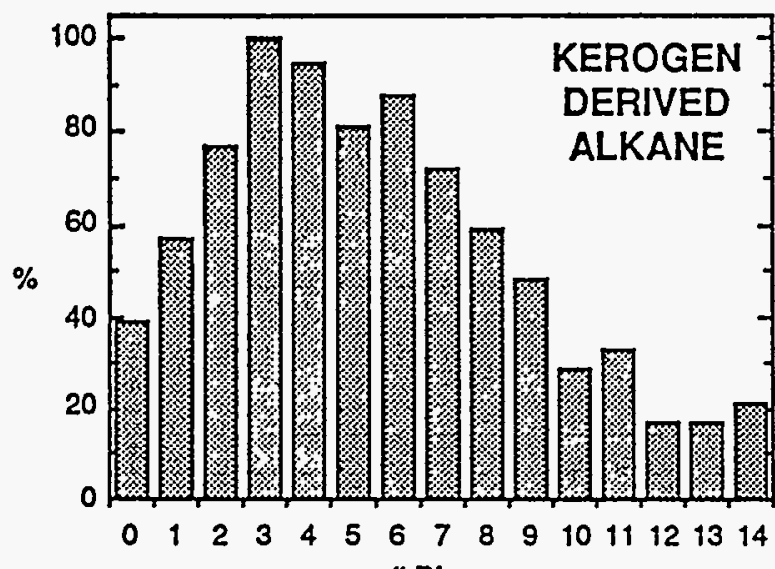

\# D's

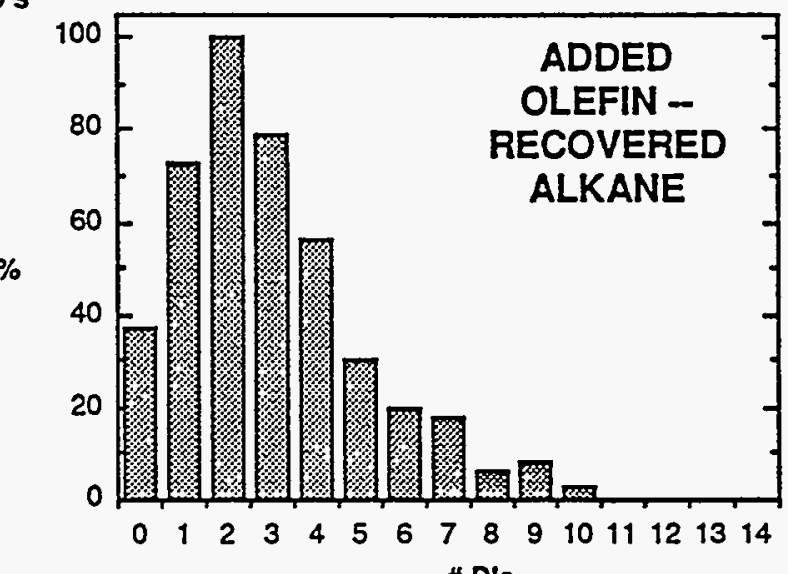

\# D's

100

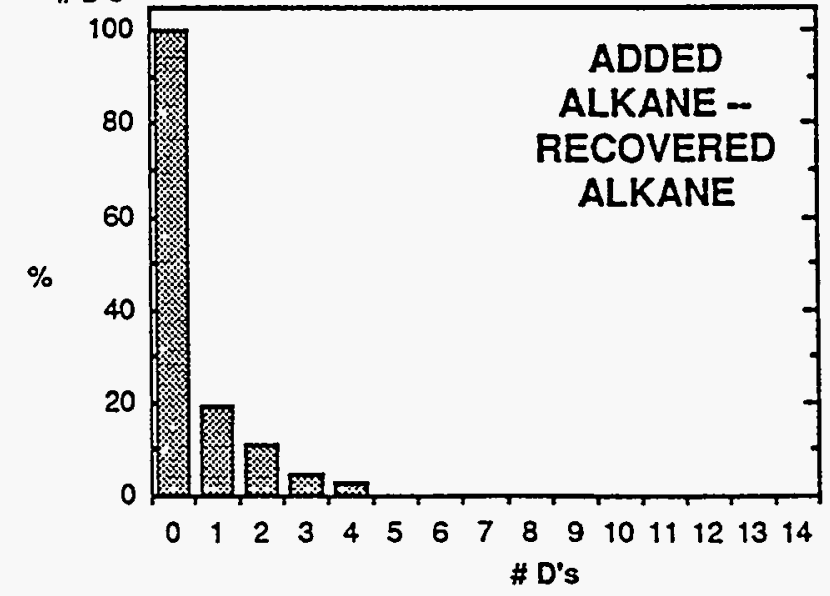

Figure 2. Hoering data on the hydrous pyrolysis of preextracted messel shale in liquid water at $330^{\circ} \mathrm{C} / 3$ days. 


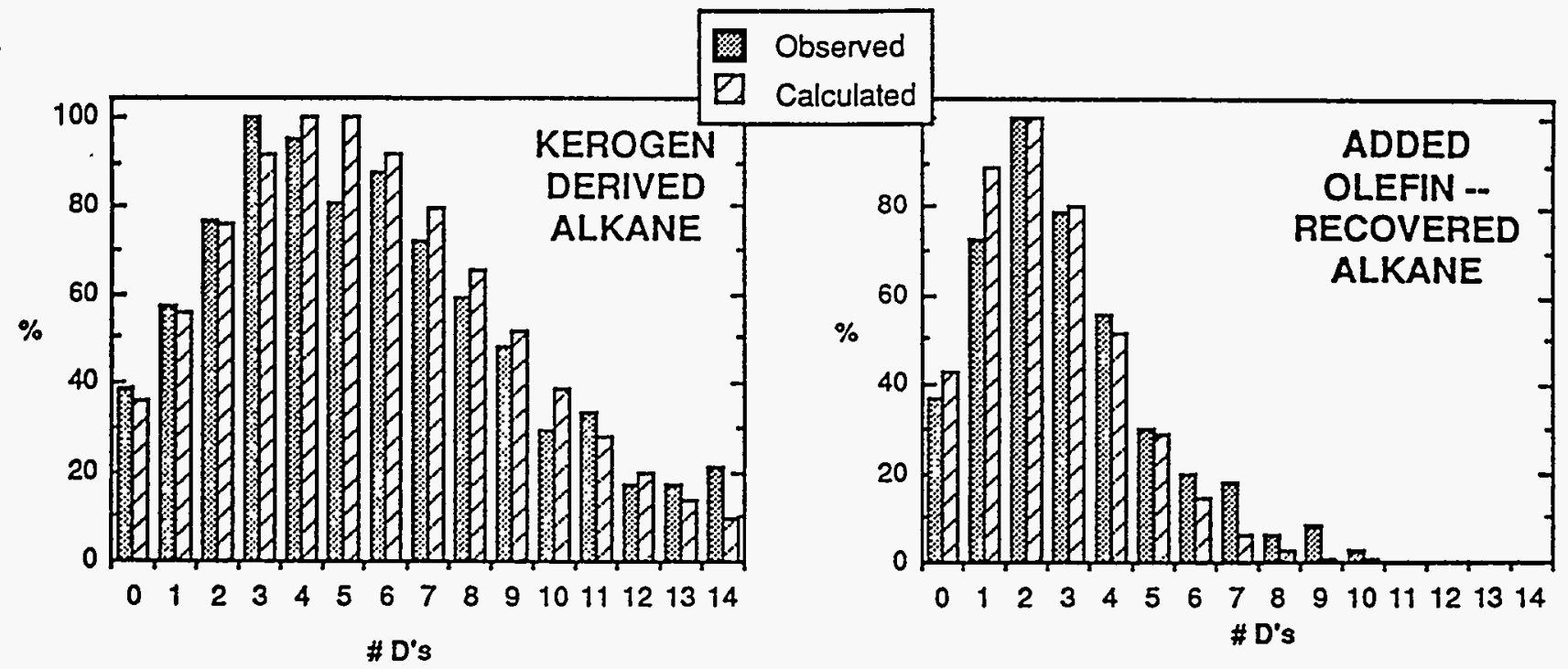

Figure 3. Hoering data and calculated profiles. The kinetic factors are reduction $\gg$ pyrolysis and exchange $\approx 2 \times$ pyrolysis.

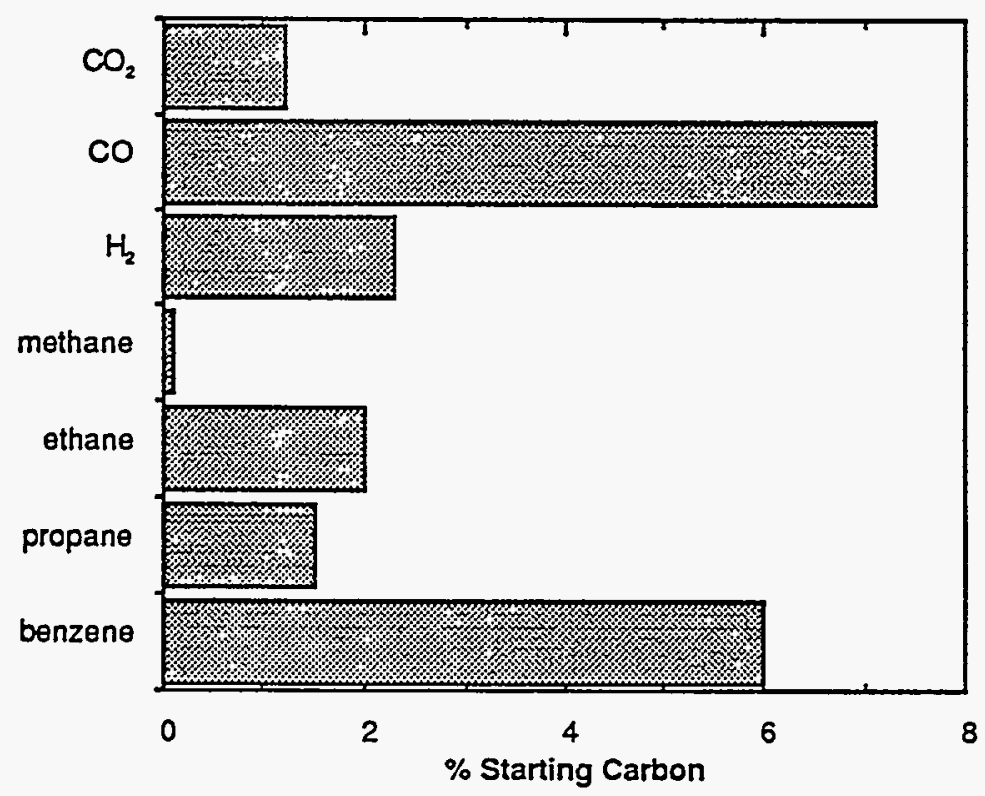

Figure 4. 1,1,2-trichloroethane conversion $428^{\circ} \mathrm{C} / \mathrm{\rho}=0.32 \mathrm{~mL} / 50 \mathrm{~min}$. 


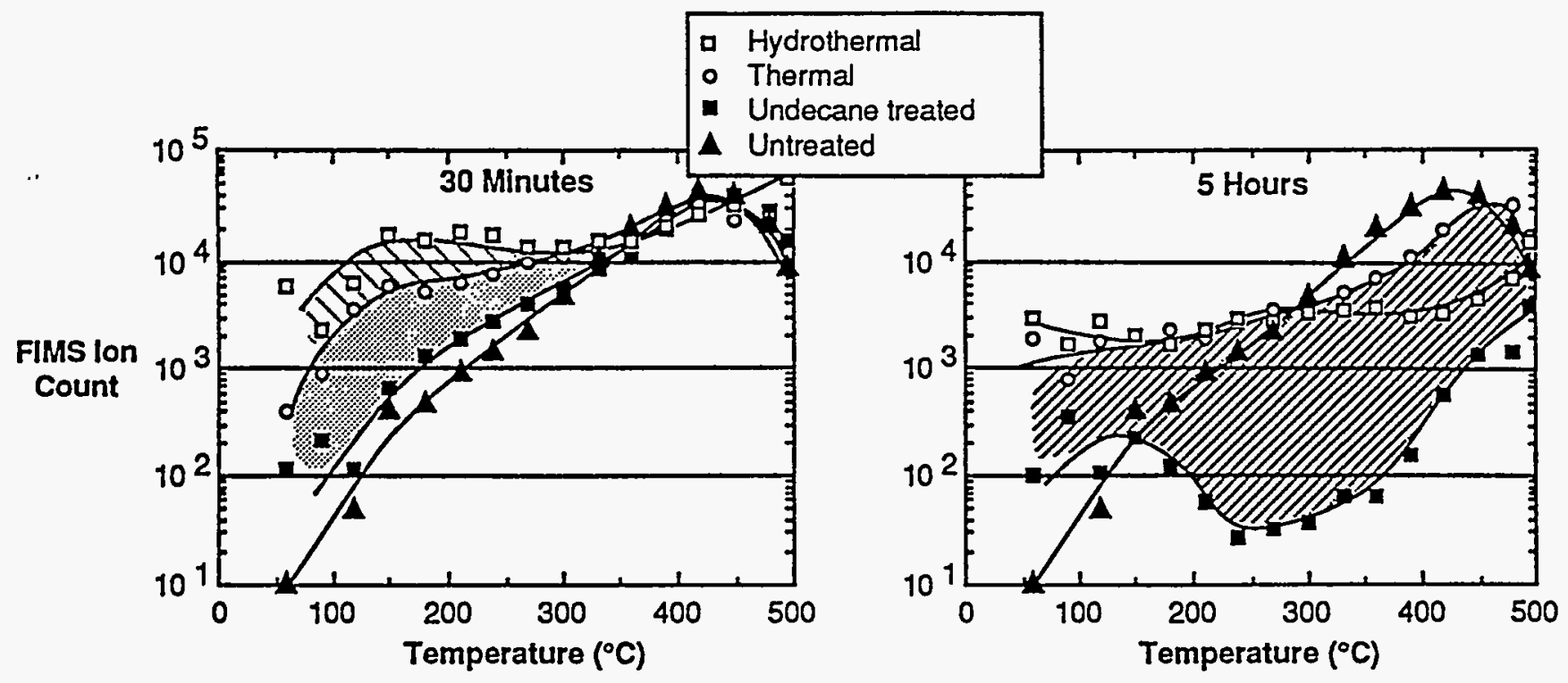

Figure 5. FIMS ion count values vs evaporation temperature for 30-min and 5-hr runs at $350^{\circ} \mathrm{C}$. 


\section{REFERENCES}

Alexander, R, Kagi, R. I., and Larcher, A. V. (1984). "Clay catalysis of alkyl hydrogen exchange reactions-reaction mechanisms." Organic Geochemistry, 6, 755-760.

Allen, R. M., and VanderSande, J. B. (1984). "Analysis of sub-micron mineral matter in coal via scanning transmission electron microscopy." Fuel, 63, 24-29.

Alwani, Z. and Schneider, G. M. (1969). "Phasengleichgewichte, kritische Erscheinungen und PVT-Daten in binären Mischungen von Wasser mit aromatischen Kohlenwasserstoffen bis $420^{\circ} \mathrm{C}$ und 2200 Bar." Ber. Bunsenges., 73, 294-301.

Amin, S. I. (1975). "Reforming and decomposition of organics in water." Thesis prepared for M. Modell, MIT.

Comet, P. A., McEvoy, J., Giger, W., and Douglas, A. G. (1986). "Hydrous and anhydrous pyrolysis of DSDP Leg 75 kerogens-a comparative study using a biological marker approach." Organic Geochemistry, 9, 171-182.

Commins, B. T. (1969). "Formation of polycyclic aromatic hydrocarbons during pyrolysis and combustion of hydrocarbons." Atm. Env. 3, 565-572.

Eglinton, T. I., Rowland, S. J., Curtis C. D., and Douglas, A. G. (1986). "Kerogen-mineral reactions at raised temperatures in the presence of water." Organic Geochemistry, 10, 1041-1052.

Hoering, T. C. (1984). "Thermal reactions of kerogen with added water, heavy water and pure organic substances." Org. Geochem. 5, 267-278.

Hoogwater, S. (1991). "High pressure hydrothermolysis of chlorinated hydrocarbons." Thesis prepared for J.M.L. Penninger, Eindhoven University of Technology.

Jockers, R. and Schneider, G. M. (1978). "Fluid mixtures at high pressures-fluid phase equilibria in the systems fluorobenzene + water, 1,4-difluorobenzene + water, and 1,2,3,4tetrahydronaphthalene + decahydronaphthalene (trans) + water up to $360 \mathrm{MPa}$." Ber. Bunsenges. Phys. Chem., 82, 576-582.

Lewan, M. D., Winters, J. C., and McDonald, J. H. (1979). "Generation of oil-like pyrolysates from organic-rich shales." Science, 203, 897-899.

Lewan, M. D., Winters, J. C., and Williams, J. A. (1981). "A laboratory study of petroleum generation by hydrous pyrolysis." Adv. in Organic Geochemistry 1979, M. Bjorøy et al., Eds. (John Wiley and Sons, Ltd., Chichester), p.p. 524-533

Lydersen, A. L. (1955). "Estimation of critical properties of organic compounds." College of Engineering, University of Wisconsin, Eng. Expt. Sta. Rept. 3, Madison, WI.

Magda, J. J., Fredrickson, G. H., Larson, R., and Helfand, E. (1988). "Dimensions of a polymer chain in a mixed solvent." Macromolecules, 21, 726-732. 
Monthioux, M., Laniais, P., and Monin, J-C. (1985). "Comparison between natural and artificial maturation series of humic coals from the Mahakam Delta, Indonesia." Organic Geochemistry, 8, 275-292.

Moore, J., and Pearson, R. (1981). Kinetics and Mechanism Third Edition (John Wiley and Sons, New York), p.p. 318-324.

Ross, D. S. (1992). "Autoradiographic and hydrothermal probes of interfacial chemistry in oil shale and coal." American Chemical Society Division of Fuel Chemistry Preprints 37, 375-384.

Ross, D. S., Hirschon, A. S., Tse, D. S., and Loo, B. H. (1990a). "The effects of hydrothermal treatment on Wyodak coal." American Chemical Society Division of Fuel Chemistry Preprints 35, 352-363.

Ross, D. S., Loo, B. H., Tse, D. S., and Hirschon, A. S. (1990b). "Hydrothermal treatment and the oxygen functionalities in Wyodak coal." Fuel 70, 289-295.

Simoneit, B.R.T. (1985). "Hydrothermal petroleum: Genesis, migration, and deposition in Guaymas Basin, Gulf of California." Can. J. Earth Sci. 22, 1919-1929.

Simoneit, B.R.T. (1988). "Petroleum generation in submarine hydrothermal systems: An update." Can. Mineralogist 26, 827-840.

Stein, S. E., Wang, F., and Senthilnathan, V. P. (1989). Proceedings of the 1989 International Conference of Coal Science, International Energy Agency, p.p. 165-168.

Tannenbaum, E. and Kaplan, I. R. (1985). "Low-M $\mathrm{M}_{\mathrm{r}}$ hydrocarbons generated during hydrous pyrolysis and dry pryolysis of kerogen." Nature, 317, 708-709. 


\title{
APPENDIX B
}

\section{PAPER PRESENTED AT THE 4TH INTERNATIONAL SYMPOSIUM ON HYDROTHERMAL REACTIONS*}

\author{
HYDROTHERMAL MEDIA, OIL SHALE, AND COAL
}

\author{
D. S. Ross, I. Jayaweera, and S. Hoogwater \\ SRI International \\ Menlo Park, CA 94025
}

\begin{abstract}
We propose a model for the generation of petroleum hydrocarbons during hydrous pyrolysis, which involves disproportion (internal oxidation and reduction) of kerogen at active sites in the mineral matrix. The model views naturally occurring mineral buffers of oxygen fugacity in hydrothermal systems as sites where the redox can occur and predicts that $\mathrm{CO}_{2}$ should accompany alkane generation. The process is very highly favored thermochemically and is supported by recent experimental results described in the literature.
\end{abstract}

\section{INTRODUCTION}

Hydrous pyrolysis is viewed by many as a useful tool for the study of accelerated petroleum hydrocarbon generation in source rocks (Lewan et al., 1981; Hoering, 1984), although there are several questions about the process. Some workers have questioned the claim that it mimics natural systems (Monthioux et al., 1985; Comet et al., 1986). Landais and coworkers (1992) suggested that the key factors are confinement and pressure, and that the need for water is as yet unclear.

The process employs liquid water as a medium at $290^{\circ}-360^{\circ} \mathrm{C}$ (critical temperature $=$ $374^{\circ} \mathrm{C}$ ), and its role remains an alluring puzzle. A particularly intriguing observation was recorded by Hoering (1984), who found in work with pre-extracted Messel shale that $60 \%$ of an alkene added to the water/rock mixture was recovered as the corresponding alkane. Thus the mixture provides a surprising reduction potential, the source of which is the focus of the discussion here.

\footnotetext{
* Held in Nancy, France, 31 August - 3 Sept., 1993.
} 


\section{DISCUSSION}

\section{A. The Medium and Radical Reactions.}

A number of workers have suggested that water acts to cap thermally generated organic free radicals (Monthioux et al., 1985; Hoering, 1984; Comet et al., 1986).

$$
\mathrm{H}_{2} \mathrm{O}+\mathrm{R} \cdot-->\mathrm{HO} \cdot+\mathrm{R}-\mathrm{H}
$$

This reaction is unlikely to be significant, however, as is reflected in Table 1, which assesses the probable route of reaction of organic free radicals in water at $330^{\circ} \mathrm{C}$. The rate constants have been estimated by the techniques of Benson (1968). The table shows that the least competitive process is scission of a C-H bond $\beta$ to the radical site. And while reaction with water is somewhat faster, it is still much too slow to compete with $\beta \mathrm{C}-\mathrm{C}$ scission to yield an olefin and another radical. The significance of even that process can be questioned, however, since it should be so rapid that at $330^{\circ} \mathrm{C}$ most of the alkyl content of the sample should "unzip" to ethylene and other simple olefins. Since that process is not observed, it would appear that routes involving alkyl radicals may not be significant to the generation of products during hydrous pyrolysis.

Table 1. Estimated Reaction Rates for a Secondary Carbon Radical at $330^{\circ} \mathrm{C}$

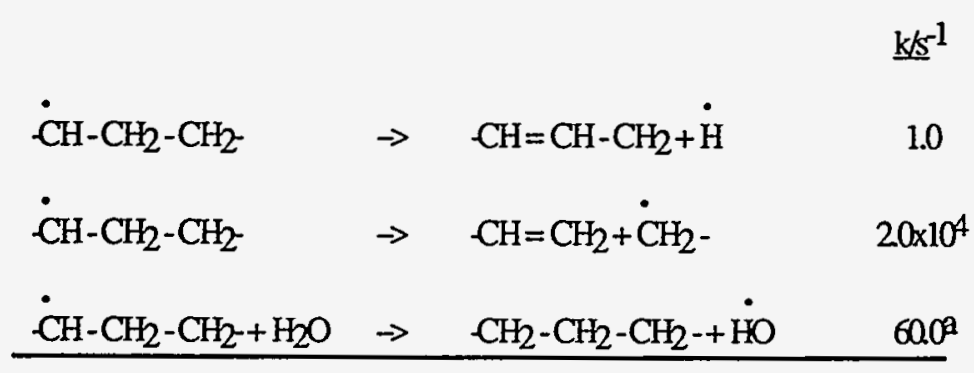

a. For water at $37 \mathrm{M}$.

\section{B. Alkane Generation via Disproportionation.}

Accordingly, we suggest a model for alkane generation that involves action at the mineral-organic interface in the source rock. The model employs disproportionation (internal oxidation-reduction) of the kerogen carbon, prompted at mineral sites that engage in mineral buffering of oxygen fugacity in hydrothermal systems. These sites are commonly iron-bearing silicate assemblages, although many other elements with multiple oxidation states including other transition metals and sulfur can serve the same function (Barnes, 1987). While reactions at buffer sites are usually seen as directly involving molecular $\mathrm{O}_{2}$, they are viewed here as regions facilitating electron transfer and bringing about oxidation and reduction of the organic phase. 
For the $\mathrm{Fe}_{2} \mathrm{SiO}_{4} / \mathrm{Fe}_{3} \mathrm{O}_{4} / \mathrm{SiO}_{2}(\mathrm{FMQ})$ system, for example, magnetite can in principle oxidize a portion of the kerogen to $\mathrm{CO}_{2}$, going to fayalite.

$$
3 \mathrm{Fe}_{3} \mathrm{O}_{4}+4.5 \mathrm{SiO}_{2}+-\mathrm{CH}_{2}--->4.5 \mathrm{Fe}_{2} \mathrm{SiO}_{4}+\mathrm{CO}_{2}+\mathrm{H}_{2} \mathrm{O}
$$

The fayalite in turn can act to reduce another portion of the kerogen, regenerating magnetite.

$$
1.5 \mathrm{Fe}_{2} \mathrm{SiO}_{4}+-\mathrm{CH}_{2}-\mathrm{CH}_{2}-+\mathrm{H}_{2} \mathrm{O}-->2-\mathrm{CH}_{3}+1.5 \mathrm{SiO}_{2}+\mathrm{Fe}_{3} \mathrm{O}_{4}
$$

The overall disproportionation of the carbon phase and concomitant oxidation state cycling of the metal ion can be represented as a chain process as in (4), consuming kerogen and ultimately yielding petroleum hydrocarbons and $\mathrm{CO}_{2}$.

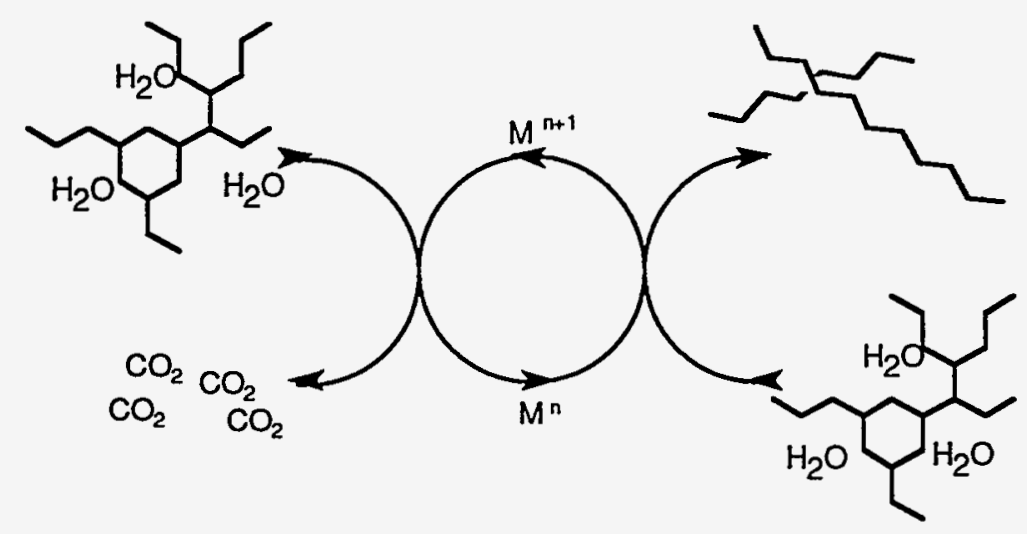

To assess the likelihood of such chemistry we have calculated the equilibrium constant from standard thermodynamic data (Stull et al., 1969) for the hydrothermolytic process in eq (5) over a range of temperatures. Propane is used as the feed for simplicity, although any hydrocarbon or hydrocarbon fragment could be used in the calculation. The net process is the hydrogenolysis of $\mathrm{C}-\mathrm{C}$ bonds in three of the starting propanes, while one of the carbons in the fourth is converted to $\mathrm{CO}_{2}$. For comparison we include pyrolytic routes of hydrocarbon degradation at anhydrous conditions in eqs 6 and 7. The formation of benzene in eq 7 simulates the production of graphitic char.

$$
\begin{aligned}
4 \mathrm{C}_{3} \mathrm{H}_{8}+2 \mathrm{H}_{2} \mathrm{O} & ->3 \mathrm{CH}_{4}+4 \mathrm{C}_{2} \mathrm{H}_{6}+\mathrm{CO}_{2} \\
\mathrm{C}_{3} \mathrm{H}_{8} & ->\mathrm{C}_{3} \mathrm{H}_{6}+\mathrm{H}_{2} \\
2 \mathrm{C}_{3} \mathrm{H}_{8} & ->\mathrm{C}_{6} \mathrm{H}_{6}+5 \mathrm{H}_{2}
\end{aligned}
$$


The results in Figure 1 show that while the dry processes are unfavored at temperatures below about $450^{\circ} \mathrm{C}$, hydrothermolysis is very heavily favored to temperatures well above those used in hydrous pyrolysis.

A thermochemical argument does not mean a route for reaction necessarily exists, of course, and it must be emphasized that eqs 2 and 3 are conjecture at this point. However, some recently reported experimental data provide support for the model. Lewan (1992) reports high yields of expelled oil combined with significant $\mathrm{CO}_{2}$ production for hydrous conditions in studies with Woodford Shale. In contrast, no expelled oil developed in parallel anhydrous experiments, and the $\mathrm{CO}_{2}$ levels for this case were only about $10 \%$ of the quantities seen in the hydrous runs. The author was careful to point out that since the mineral phase was virtually free of carbonates, the $\mathrm{CO}_{2}$ source must be oxidation of the kerogen carbon.

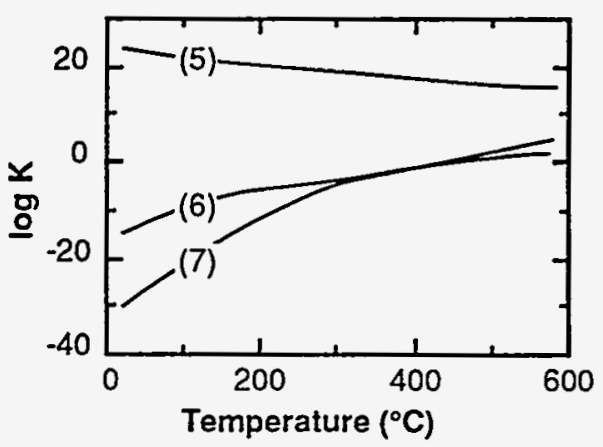

Figure 1. Equilibrium constants for eqs 3,4 , and 5 as a function of temperature.

Results from our work with Wyodak coal in hydrothermal media also support the model (Ross et al., 1990). We found that expelled tars were developed only in hydrous experiments; they were not observed in the absence of water nor when water was replaced by an inert fluid. The tars, moreover, underwent continued upgrading in extended experiments.

Finally, there is evidence that disproportionation for some carbonaceous materials may take place in hydrothermal media even in the absence of a bulk mineral phase. In water at low, gas-like densities glucose is converted to a char and some quantities of $\mathrm{CO}_{2}$, methane, and other light gases (Amin, 1975). However, when the water density is increased to liquid-like levels, the char for the most part is replaced by an oil, and the gas quantities are increased by a factor of 3 .

\section{ACKNOWLEDGMENT}

We acknowledge support of the US Department of Energy for a portion of the work reported here.

\section{REFERENCES}

Amin, S. I. (1975). "Reforming and Decomposition of Organics in Water," thesis prepared for M. Modell, MIT. 
Barnes, H. L. (1987). "Buffers for $\mathrm{pH}$ and Redox Control of Hydrothermal Systems." Hydrothermal_Experimental Techniques, G. C. Ulmer and H. L. Barnes, Eds. (John Wiley and Sons, Inc., New York).

Benson, S. W. (1968). Thermochemical Kinetics (John Wiley and Sons, Inc., New York).

Comet, P. A., McEvoy, J., Giger, W., and Douglas, A. G. (1986). "Hydrous and Anhydrous Pyrolysis of DSDP Leg 75 Kerogens - a Comparative Study Using a Biological Marker Approach". Organic Geochemistry, 9, 171-182.

Hoering, T. C. (1984). "Thermal reactions of kerogen with added water, heavy water and pure organic substances." Org. Geochem. 5, 267-278.

Landais, P., Michels, R., Elie, M, Gerard, L., and Mansuy, L., 1992. "Evaluation of factors influencing the thermal maturation of organic matter during confined pyrolysis experiments." American Chemical Society Division of Fuel Chemistry Preprints, 37 (4), 1588-1594.

Lewan, M. D., Winters, J. C., and Williams, J. A. (1981). "A Laboratory Study of Petroleum Generation by Hydrous Pyrolysis." Adv. in Organic Geochemistry 1979, M. Bjorøy et al., Eds. (John Wiley and Sons, Ltd., Chichester), p.p. 524-533

Lewan, M. D. (1992). "Water as a Source of Hydrogen and Oxygen in Petroleum Formation by Hydrous Pyrolysis." American Chemical Society Division of Fuel Chemistry Preprints, 37 (4), 1643-1649.

Monthioux, M., Lanais, P., and Monin, J-C. (1985). "Comparison between Natural and Artificial Maturation Series of Humic Coals from the Mahakam Delta, Indonesia." Organic

Geochemistry, 8, 275-292.

Ross, D. S., Loo, B. H., Tse, D. S., and Hirschon, A. S. (1990). "Hydrothermal treatment and the oxygen functionalities in Wyodak coal." Fuel 70, 289-295.

Stull, D. R., Westrum, Jr., D. F., and Sinke, G. C. (1969). The Chemical Thermodynamics of Organic Compounds (John Wiley and Sons, Inc., New York). 


\section{APPENDIX C}

\section{PREPARATION OF METAL CARBONYL-LOADED COALS}

Loading with iron was accomplished by treating a toluene slurry of the coal with $\mathrm{Fe}(\mathrm{CO})_{5}$ under reflux for 24 hours, then removing solvent under vacuum. The iron loading was only about 2\%; a thin mirror formed in the reaction flask and some unreacted $\mathrm{Fe}(\mathrm{CO})_{5}$ may have been lost during evacuation.

Loading with $2 \%$ molybdenum was similarly accomplished, using $\mathrm{Mo}(\mathrm{CO})_{6}$. 


\section{APPENDIX D}

PARTS, MATERIALS, AND SAFETY DATA FOR THE CELL ASSEMBLY 
Table D-1. Parts Used in the Continuous Flow Observation Cell System

\begin{tabular}{|c|c|c|}
\hline Item & Supplier & Part Number \\
\hline HPLC pump & Waters & 510 \\
\hline Autoclave & custom built & \\
\hline $\begin{array}{l}\text { Valves } \\
20,000 \text { psi } \\
5,000 \text { psi }\end{array}$ & $\begin{array}{l}\text { A.E. } \\
\text { Whitey }\end{array}$ & $\begin{array}{l}20 S C 4071 \\
\text { SS-0RS2 }\end{array}$ \\
\hline Relief valve & Nupro & SS4R3A \\
\hline Fittings & Swagelok & \\
\hline Pressure gauge & NoShok & 25.400 .6000 psi $1 / 4$-in. NPT \\
\hline $\begin{array}{l}\text { Optics system } \\
\text { Diamonds } \\
\text { Clamps } \\
\text { Video camera } \\
\text { Lenses }\end{array}$ & $\begin{array}{l}\text { Dubbeldee Harris } \\
\text { Custom built } \\
\text { Dage Miti } \\
\text { Edmund Scientific }\end{array}$ & $\begin{array}{l}2 \mathrm{~A} \text { modified brilliant, } 0.19 \mathrm{ct} \text {., girdle } \\
\text { dia. } 3.5 \mathrm{~mm}\end{array}$ \\
\hline $\begin{array}{l}\text { Heater } \\
\text { Copper tube } \\
\text { Heating wire } \\
\text { Insulation } \\
\text { Controller } \\
\text { Solid state relay } \\
\text { Heat sink } \\
\text { Fuse + holder } \\
\text { Limiting device } \\
\text { Setpot } \\
\text { Thermocouple } \\
\text { TC connector }\end{array}$ & $\begin{array}{l}\text { Custom built } \\
\text { ARi } \\
\text { Eurotherm } \\
\text { Omega } \\
\text { Omega } \\
\text { Omega } \\
\text { Watlow } \\
\text { Watlow } \\
\text { Omega } \\
\text { Omega }\end{array}$ & $\begin{array}{l}1 \text { in OD } \times 1 / 4 \text { in ID } \times 10 \text { in long } \\
\text { IHNO63B-1.6 ; } 22 \mathrm{ft} \\
\text { Mineral wool } \\
808 \text { L1 NO NO NO QS AKKC } 100 \\
\text { SSR240DC25 } \\
\text { FHS-1 } \\
\text { KAX-25/ FB-1 } \\
141 \text { A-2604-3000 } \\
\text { A006-0224-0000 } \\
\text { TJ36-CAIN-18N-12-CC-OST-M } \\
\text { RSJ-K-S }\end{array}$ \\
\hline $\begin{array}{l}\text { Tubing OD } \times \text { ID } \\
1 / 4 \times 1 / 16 \\
1 / 8 \times 1 / 16 \\
1 / 4 \times 1 / 8 \\
3 / 8 \times 5 / 16\end{array}$ & $\begin{array}{l}\text { A.E } \\
\text { Kilsby Roberts } \\
\text { Kilsby Roberts } \\
\text { Kilsby Roberts } \\
\text { Kilsby Roberts }\end{array}$ & $\begin{array}{l}\text { MS15-092 } \\
1 / 4 \times 083 \text { in. } \\
1 / 8 \times 028 \text { in. } \\
1 / 4 \times 049 \text { in. } \\
3 / 8 \times 028 \text { in. }\end{array}$ \\
\hline
\end{tabular}


Table D-2. Maximum Allowable Pressure for Flow System Components

\begin{tabular}{lc}
\hline \multicolumn{1}{c}{ Part } & $\begin{array}{c}\text { Maximum Pressure (psi) } \\
\text { at Room Temperature }\end{array}$ \\
\hline Whitey valve SS-ORS2 & 5,000 \\
Waters 510 HPLC pump & 6,000 \\
Autoclave & 6,000 \\
Tubing 1/4-in. OD 0.049 & 7,500 \\
Relief valve Nupro SS4-R3A & 8,000 \\
Tubing 1/8-in. OD 0.028 & 8,500 \\
Tubing 1/4-in. OD 0.083 & 20,000 \\
& $15,200^{\mathrm{a}}$ \\
AE valve 20SC4071 & 20,000 \\
Fittings & $>$ Tube specs \\
\hline
\end{tabular}

a. Maximum allowable pressure at $550^{\circ} \mathrm{C}$.

Table D-3. Maximum Allowable Temperature ( $\left.T_{\max }\right)$ for System Components at $\mathbf{5 0 0 0}$ psi

\begin{tabular}{lc}
\multicolumn{1}{c}{ Part } & $T_{\max }\left({ }^{\circ} \mathrm{C}\right)$ \\
\hline Relief valve Nupro & 120 \\
AE valve 20SC-4071 & 250 \\
Tubing 1/4" OD $¥ 0.049$ & 500 \\
Tubing 1/8" OD $¥ 0.028$ & 550 \\
Tubing 1/4" OD $¥ 0.083^{a}$ & 700 \\
Heating wire and copper bara & 1000 \\
Thermocouplea & 1100 \\
\hline
\end{tabular}

a Heated directly. 